University of San Diego

Digital USD

2005-08-01

\title{
Connecting the Dots: A Study of an Innovative Principal Preparation Program's Impact on the Mental Models and On-The- Job Behaviors of Aspiring School Leaders
}

Rich Newman EdD

University of San Diego

Follow this and additional works at: https://digital.sandiego.edu/dissertations

Part of the Leadership Studies Commons

\section{Digital USD Citation}

Newman, Rich EdD, "Connecting the Dots: A Study of an Innovative Principal Preparation Program's Impact on the Mental Models and On-The-Job Behaviors of Aspiring School Leaders" (2005).

Dissertations. 748.

https://digital.sandiego.edu/dissertations/748

This Dissertation: Open Access is brought to you for free and open access by the Theses and Dissertations at Digital USD. It has been accepted for inclusion in Dissertations by an authorized administrator of Digital USD. For more information, please contact digital@sandiego.edu. 


\title{
CONNECTING THE DOTS: \\ A STUDY OF AN INNOVATIVE PRINCIPAL PREPARATION PROGRAM'S IMPACT ON THE MENTAL MODELS AND ON-THE-JOB BEHAVIORS OF ASPIRING SCHOOL LEADERS
}

\author{
by \\ RICH NEWMAN \\ A dissertation submitted in partial fulfillment \\ of the requirements for the degree of \\ Doctor of Education \\ University of San Diego
}

August 2005

\author{
Dissertation Committee \\ Robert Donmoyer, Ph.D. \\ Lea Hubbard, Ph.D. \\ Margaret Basom, Ph.D.
}


(C) Copyright by Richard Newman, 2005 All Rights Reserved 


\begin{abstract}
Despite years of criticism aimed at university-based principal preparation programs, most of these programs continue to be judged less than successful in producing effective school leaders. Furthermore, there is also little rigorous and systemic research about principal preparation in general; there is even less work focused on understanding how preparation programs might assist emerging school leaders in developing the sorts of intellectual capacities needed to be successful in an era when principals are expected to be instructional leaders and work with teachers to improve student achievement. Consequently, little is known about how principal preparation programs can help individuals (a) incorporate theory on leadership and instruction into their own belief systems and (b) link these belief systems to their on-the-job behavior.

This study examined how one innovative program, resulting from a university/school district collaboration, impacted the belief systems of the aspiring principals who participated in the program. The study also examined how participants' espoused beliefs aligned with their on-the-job activity and which program components appeared to have the greatest impact on participants whose beliefs were altered in significant ways. Interviewing, participant observation and document analysis techniques were used to explore the above issues.
\end{abstract}

The findings suggest that: (a) principal preparation programs can impact participants' beliefs in rather dramatic ways; (b) participants' on-the-job behaviors frequently were consistent with the beliefs they espoused; (c) certain contextual factorsmost notably the role-related constraints experienced by those program participants who became vice principals rather than principals—-kept some participants from acting in 
ways that are consistent with both their espoused beliefs and the theory of action promoted by the program that prepared them to be school administrators; and (d) the problem-based learning strategy appeared to have the greatest impact on participants whose beliefs had changed in significant ways and whose on-the-job actions were consistent with their newly developed belief systems. 


\section{DEDICATION}

To Nicole

For your love, tenderness, insight, guidance, patience and support.

You are an amazing partner and an even more amazing Mom. I never could have completed this dissertation without you. I love you!

\section{To Dylan}

Thanks for always making sure I kept what was important in perspective.

Daddy has finally finished writing his book filled with letters and words.

Now I can read you as many bedtime stories as you like. 


\section{ACKNOWLEDGEMENTS}

The writing of a dissertation can be a lonely and isolating experience. It can also be difficult to see the light at the end of the tunnel and not mistake it for a train coming at you. Fortunately, I had the support of many friends, colleagues and family members who helped remind and assure me that the sun would appear the next day and that this dissertation would in fact "Get done."

This dissertation would never have been completed without the support, love and encouragement of my wife, Nicole. She read endless drafts, challenged my thinking and logic and ALWAYS reminded me that someday this dissertation would end and we would be "normal" again. Thank you Nicole for helping me tackle this degree, for picking up the slack at home while I spent countless hours writing and for teaching me the true meaning of LOVE. You are not only an amazing partner and an incredible mother but also my soul mate. I am lucky to have walked this walk with you. You no longer have to watch movies alone - I'm done!!!!!!!

My three year old son, Dylan, constantly reminded me that "words and letters are important" but so is playing. Thank you Dylan for making sure I always had perspective and for making sure that I did not lose sight of the forest for the trees. Thank you for making sure I stopped writing and looked at the bark on the tree and the moon in the sky. Daddy loves you and is finished "writing his words and letters in his book." I promise to not miss putting you to sleep on Tuesday nights anymore.

I also owe a debt of gratitude to my chair, Dr. Bob Donmoyer. It is fitting that he would be there to help guide me through the morass of finishing this degree as he was the one who recruited me to USD. Bob, I cannot thank you enough for challenging me to think in new and different ways. My time at USD would have been far less rewarding if it 
had not been for you. I am a better person in more ways than I can mention for having worked with you. Thank you for always being available to talk through the dissertation and, of course, life. Every doctoral student should be so lucky to have the experience with their chair as I did with you.

I am also eternally grateful to my other committee members, Dr. Lea Hubbard and Dr. Peggy Basom. Thank you Lea for your willingness to share your knowledge and expertise with me. I learned more about research and writing working on the DILNS evaluation with you than most of my doctoral classes combined. You were always willing to share words of support when the clouds seemed foreboding and I wondered whether I would finish. I look forward to sharing another eggplant parmesan sub with you in the very near future. You are an amazing woman and one of the strongest I have ever metthank you for also teaching me about how to find that inner strength especially in times of need.

Peggy, your research on cohorts had a great impact on my thinking and I continue to read your work as though it was the first time I discovered it. Thank you for being willing to serve on my committee.

I am also grateful to Dr. Terri Monroe who early on in my doctoral work introduced me to the world of Tavistock and group dynamics. My perspective on leadership and life has been drastically changed because of my work with you. Thank you.

My acknowledgements would not be complete without saying thank you to Dr. Paula Cordeiro, Dean of the School of Leadership and Educational Sciences at the University of San Diego. Thank you for taking an early interest in my work, for 
supporting my research, for always having an open door and for providing guidance when I most needed it. You are the Dean of Deans.

As I began my doctoral work, I was given a few pieces of advice from a talented professor, Dr. Fred Galloway. Thank you Fred for telling me early on that the doctorate was a terminal degree and for constantly reminding of it. This advice carried me through many a dark moment.

I also want to say thank you to my mother-in-law, Jane. You always had the correct answer to any grammatical question I threw your way. Thank you for fielding all my questions and for your constant support.

Thanks to my good friend, Christian. I always enjoyed our early morning crosscountry chats. Your friendship and support were immensely important. I looked forward each day to sharing "Dad" stories with you along with a few war stories. Thanks for your friendship. You're next in line to finish a degree - I'll be rooting for you all the way.

To my sister, Joy, thanks for your encouragement and support and for always checking in to see how the writing was going. I am sure that Mom is looking down proudly at this whole experience but especially at you for all you do!

I have also been changed in more ways than I can recall by my colleagues at the Wallace Foundation and especially Dr. Jody Spiro and Richard Laine. Jody, thanks for always assuring me that this degree would end, for your ability to break out in song on the spur of the moment and, most of all, for your friendship. Richard, thanks for always asking about the progress of my dissertation and for offering keen advice when I often needed it. I thank you both for always pushing me to think about impacting education leaders on a national scale in new and innovative ways. I am blessed to be working with both of you. 


\section{TABLE OF CONTENTS}

\section{CHAPTERS}

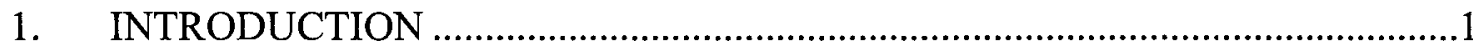

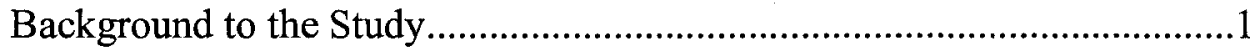

Problem Statement ...................................................................................

Purpose of the Study .................................................................

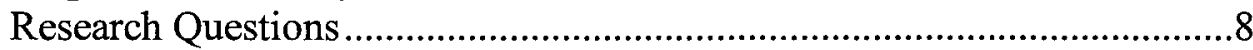

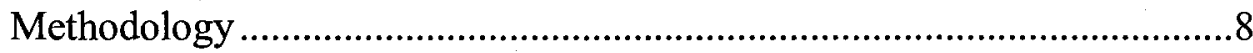

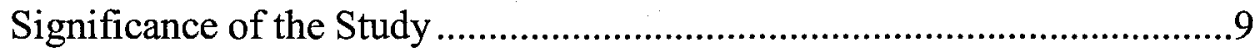

Limitations of the Study................................................................11

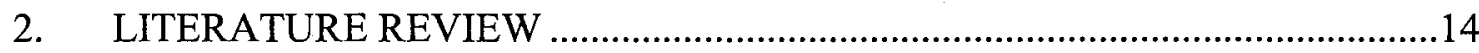

Instructional Leadership.................................................................14

The Effective Schools Literature ..............................................16

Mid 1980s and Onward: The Indirect Impact of Principals ..........21

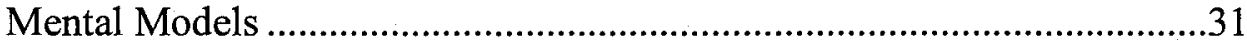

Promising Features of Principal Preparation Programs ...........................40

Purposeful Recruitment and Selection .....................................42

Use of Cohorts ....................................................................44

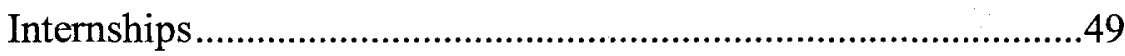

Problem-based Learning .......................................................51

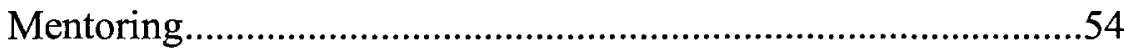

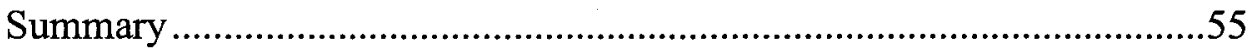

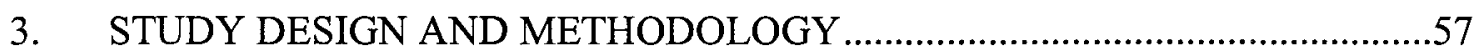

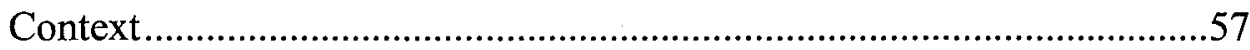

Site Selection .............................................................................60

Data Collection and Analysis ...........................................................63

Phase 1: Initial Interviews to Examine Participants'

Mental Models .......................................................................64

Phase 2: Reexamination of Participants' Mental Models

at the End of Year One.............................................................66

Phase 3: Observation of Participants' Practice in the Role of School Leader .............................................................68

Phase 4: Reexamination of Participants' Mental Models at the End of Year Two ...............................................................70

Phase 5: Document Collection and Analysis .............................. 71 


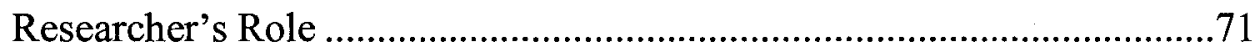

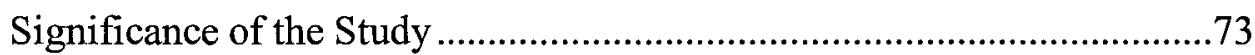

Limitations of the Study .......................................................................75

4. FINDINGS, PART I: SHIFTING BELIEFS …………………………….......79

Participants' Leadership Philosophies Upon Entering DILNS:

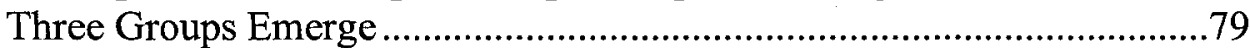

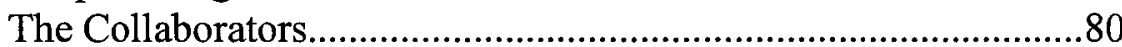

Developing a shared vision................................................82

Creating a professional learning community ......................84

Supporting and working with school staff..........................87

The Vision Setters.........................................................................90

Setting the vision for the school and charting

the course .......................................................................92

Using communication strategically to engage staff...........94

Modeling best practices for staff.......................................96

The Keeper.................................................................................99

Keeper of the status quo....................................................99

A link between the district and the school.........................100

Communicating and engaging with staff only

indirectly ..........................................................................101

An elitist view of public education ..................................102

Participants' Leadership Philosophies at the End of a Year

of Training ....................................................................................103

The Collaborators..........................................................................104

Developing a shared vision..............................................104

Developing a professional learning community ...............106

Supporting and working with school staff.........................109

The Vision Setters...................................................................112

Developing the vision for the school ................................113

Modeling instruction.......................................................116

The Keeper...........................................................................120

Summary

5. FINDINGS, PART II: COMPARING DILNS PARTICIPANTS' BELIEFS

WITH THEIR ACTIONS ……………………………................................123

Programmatic Context .........................................................................123

Collaborators Become School Leaders ..................................................125

Actions Consistent with Beliefs.................................................126

Actions Not Consistent with Beliefs..........................................131

Role Interference in Translating Beliefs to On-the-Job Actions .134

Vision Setters Become School Leaders ...................................................136

Reformed Vision Setters ............................................................136

Connecting beliefs to action..............................................136

Unchanged Vision Setters.........................................................142

Constrained by the role and unable to implement

administrative strategies. 
Summary

6. FINDINGS, PART III: PROGRAMMATIC INFLUENCES ..........................146

Program Features that Influenced the DILNS Members ........................147

Program Features that Influenced the Collaborators .................147

The impact of the intership experience on the

Collaborators

The impact of the cohort experience on the

Collaborators.

The impact of problem-based learning on the

Collaborators

Program Features that Influenced the Vision Setters.

The impact of the problem-based learning coursework

and simulations on the Vision Setters

The impact of the intership experience on the

Vision Setters

The impact of the cohort experience on the

Vision Setters

Program Features that Influenced the Keeper...........................163

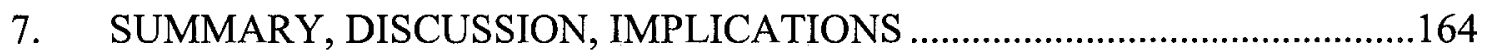

Brief Review of the Problem And Methods of Study ............................164

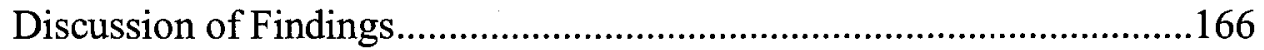

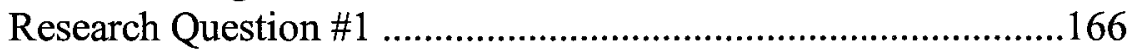

Research Question \#2 .......................................................169

The Collaborators.......................................................169

The Vision Setters......................................................170

The Keeper...............................................................171

Research Question \#3 .......................................................172

Research Question \#4 ..........................................................173

Reformed Vision Setters ..............................................174

Implications of the Findings for Practice............................................174

Impacting Beliefs is a Realistic Goal for Principal Preparation ..175

Experiment with the Problem-Based Learning (PBL) Strategy ...177

Reconsider Whether Cohorts and Internships are Unequivocal

Indicators of Best Practice .........................................................178

Implications for Further Research .................................................181

Summary .............................................................................. 184 


\section{APPENDICES}

A. DILNS Cohort 3 Protocol I: Initial interview .............................................201

B. DILNS Cohort 3 Protocol II: Second Interview .........................................204

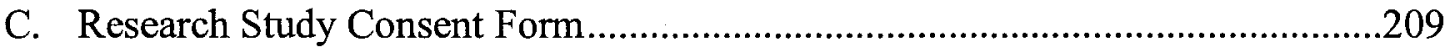




\section{LIST OF TABLES}

Table 3.1. DILNS Cohort III Demographics

Table 4.1. Leadership Dimensions of the Collaborators, Vision Setters and the Keeper

Table 4.2. Collaborators' Demographics p.81

Table 4.3. Collaborators' Beliefs on Developing a Shared Vision p.83

Table 4.4. Collaborators' Beliefs on Developing a Learning Community p.85

Table 4.5. Collaborators' Beliefs on Supporting and Working with School Staff

Table 4.6. Vision Setters' Demographics p.91

Table 4.7. Vision Setters' Beliefs on Setting the Vision for School p.92

Table 4.8. Vision Setters' Beliefs on Strategically Using Communication to Engage Staff

Table 4.9. Vision Setters' Beliefs on Modeling Best Practice for Staff p.97

Table 4.10. Collaborators' Beliefs on Developing a Shared Vision p.105

Table 4.11. Collaborators' Beliefs on Developing a Professional Learning Community

Table 4.12. Collaborators' Beliefs on Supporting and Working Alongside Staff

Table 4.13. Vision Setters' Beliefs on Developing the School's Vision p.114

Table 4.14. Vision Setters' Beliefs on Modeling Instruction p.117

Table 5.1. Placement of Participants after One Year of Training p.124

Table 5.2. Leadership Positions of Collaborators after the First Year p.125

Table 5.3. Leadership Positions of Vision Setters During the Second Year

Table 6.1. Program Features that Influenced the Collaborators p.148 
Table 6.2. The Impact of the Internship Experience on the Five Collaborators Who Indicated this Programmatic Feature as Influential

Table 6.3. The Impact of the Cohort Experience on the Three Collaborators Who Indicated this Programmatic Feature as Influential

Table 6.4. The Impact of the Problem-based Simulations on the Three Collaborators Who Indicated this Programmatic Feature as Influential

Table 6.5. Program Factors that Influenced the Vision Setters

Table 6.6. The Impact of the PBL Experience on the Four Vision Setters Who Indicated this Programmatic Feature as Influential

Table 6.7. The Impact of the Internship Experience on the Two Vision Setters Who Indicated this Programmatic Feature as Influential 


\section{CHAPTER I INTRODUCTION}

Background to the Study

Principals are increasingly viewed by both policy makers and the general public as critical linchpins for transforming schools and bringing about real reform within their school communities (Fullan, 2001; Fullan, 1992; Leithwood \& Jantzi, 1990). They are continually expected to think in new ways and tackle increasingly complex social and academic problems. This thinking is supported by research pinpointing the importance of the principal as the leading force in promoting academic achievement within a school (Bredeson, 1993; Griffith, 1999; Fullan, 1993; Hall \& Hord, 2001; Leithwood, SeashoreLouis, Anderson \& Wahlstrom, 2004; Lucas, 2001).

As the importance and complexity of the role of the principal has grown, renewed attention and debate has focused on how best to prepare individuals for the demanding role of the principalship. In recent years, principal preparation programs have often been criticized because of a perceived disconnect between what tends to be taught in such programs and what practitioners need to know and be able to do when they become principals (Cambron-McCabe, 1999; Tirozzi, 2001; Young, Peterson \& Short, 2001). Researchers have suggested that principal preparation programs need to be more pragmatic by teaching knowledge and skills needed to successfully tackle the role of the principal. Farkas, Johnson, Duffet, Foleno and Foley (2001), for example, indicate that principal preparation programs are "out of touch with the realities of what it takes to run today's school district," and thus must be radically revamped if they are to have a significant impact on the preparation and training of school leaders (p.31). A report released by the Institute for Educational Leadership (2000) makes a similar point: 
Traditional principal preparation programs offered by colleges and universities are disconnected from the daily routines and needs of schools. Principal training seldom is anchored in hands-on leadership experience in real schools, where principals-in-training might learn valuable lessons in shaping instructional practice, sharing and delegating authority, nurturing leadership ability among school faculty and staff, and exercising community and visionary leadership. (p.9).

Others such as Cambron-McCabe (1999) and Murphy (2001) also agree that principal preparation programs need to become less abstract in their teaching by relying less on the transmission of theoretical knowledge while focusing more attention on developing closer ties to the field and ensuring that aspiring principals are provided the necessary training to develop knowledge of the day-to-day dealings one might encounter as principal.

The movement to de-emphasize the predominant role of theory in the training of aspiring principals has led to a certain irony in the educational administration field at present. There is a growing recognition that the transmission of theory that is general in nature and thus often disconnected from practice needs to be replaced with theory that is grounded in practice (Stein \& Gewirtzman, 2003). Moreover, the traditional notion of the school leader as plant manager has been replaced by the notion of principal as instructional leader of the school. This change requires principals to acquire a different body of knowledge and skills - one that is grounded in practice to the role they will take on and the work they will encounter. Being an instructional leader, after all, encompasses a range of new skills and behaviors. It involves spending more time in 
classrooms, developing the leadership capacity of others, engaging staff in conversations around improving instruction, supervising, evaluating and coaching instruction, maintaining high visibility on campus, helping school personnel become a professional learning community to support teacher and student success, using data to inform decisions, and spending less time on administrative, logistical, and financial matters (Hallinger, 1984; Hallinger \& Murphy, 1985; Stein, Hubbard \& Mehan, 2002).

But we know from Hallinger and McCary (1992) that being an instructional leader is not just a set of discreet skills. In fact, the skills they must develop mean very little unless they can be connected to a new way of thinking -- a new theoretical conception of the role of the principal. Hence, at a time when people are talking about the de-emphasis of theory, there seems to be a necessity to focus on theory, albeit a different kind of theory. In general, this is a move away from a theory of operations management to a theory of leadership, adult learning and instruction. It is also a move towards a more personal form of theorizing in which the focus is on helping individuals develop their own theories of leadership.

In short, while the principal preparation field in general continues to place relatively less emphasis on the teaching of theory and greater importance on teaching the practical elements of the principalship, there appears the need to teach a different theory; one that is grounded in instruction and leadership and is also more personal and informal as opposed to formal and general. The very nature of the role of instructional leader places greater emphasis on understanding the theoretical processes involved in leading, learning and developing solid instructional practices, and thus requires participants to be engaged in developing a theoretical understanding of this knowledge base. 
All of the above suggests that in the future, principal preparation programs need to help individuals incorporate theory on leadership and instruction into their own belief structures and furthermore help individuals tie their behaviors to their beliefs about leadership. The increasingly complex role of a principal demands a more expanded notion of school leadership.

Developing this capacity is not easy. If principals are going to be successful in guiding, coaching and supporting others, they will need to develop theoretical conceptions of leadership and instruction that ties their behaviors together and makes the whole greater than the sum of the parts. In other words, the theories required to develop instructional leaders may be as much about developing participants' beliefs as well as developing their knowledge of leadership and instruction. The emphasis on the future therefore needs to be more about developing and making explicit people's personal theories regarding leadership, education and learning. As Murphy (2001) states, "In a rather dramatic shift from earlier times, school and district administrators will be asked to exercise intellectual leadership not as head teachers, but as head learners" (p.10). Principal training therefore will need to give participants an understanding of how their personal theories of leadership construct their practice.

\section{Problem Statement}

Unfortunately, we do not understand how to assist principals in developing the sort of intellectual capacity alluded to above. A collection of papers written for the Cognition and School Leadership Conference (Hallinger, Leithwood \& Murphy, 1993), for instance, detailed the importance of understanding the cognitive processes that help us understand how aspiring and current principals develop the capacity to think and act. As 
the editors of the papers from the conference explain, they sought to set out an agenda for research in this area because:

Cognitive approaches [such as mental models] seem to hold promise as a response to charges of irrelevance and moribundity aimed at the field of leadership and administration, charges of which most in the field are uncomfortably aware. However, few people in the field are actively using cognitive approaches in their research or their teaching. Many are only vaguely aware of this work and have not had an opportunity to seriously consider its contributions. (Hallinger et al, 1993, p.268).

Principals come to their current positions with a set of beliefs about their role, what it encompasses, about how practice ought to take place, and what instruction should look like. In fact, their beliefs and perspectives are shaped by the very experiences and roles they have assumed previously. We also know that belief systems are very resistant to change and act as a protective barrier permitting information to enter or to filter out, depending on whether the new knowledge is deemed to be a suitable or unsuitable match with current beliefs (Nespor, 1987; Pajares, 1992; Richardson, 1996).

The ability to acquire new knowledge, new ways of thinking and new beliefs regarding the role of instructional leader is essential to the success of current and future principals who will continually face new challenges. As was noted above, however, not a great deal is known about the complexities of how aspiring principals actually acquire new beliefs, knowledge and skills. Little systematic research has focused on studying and identifying the effects and influences that principal preparation programs, in particular, have on individuals' mental models 
This study used the concept of mental models (Senge, 1990) to help organize the research. The underlying assumption in this study was that mental models help instructional leaders make sense of their world in new ways and help guide their actions. We know from the work of Senge (1990) and others that mental models "exert powerful influences over human experience [and] act as perceptual 'filters' of new information" (Sanders, 2000, p.31). We also know that in general individuals make sense of situations and react to stimuli based on their beliefs, knowledge and their perception of reality which is shaped by previous experiences. In other words, individuals' actions are guided by their mental models which comprise each of our beliefs, values, knowledge and assumptions about the world in which we live (Fauske \& Johnson, 2003; Ruff, 2002). Mental models was chosen, in part, to function as one of the central concepts in this study because as Kim (1993) suggests, mental models "provide the context in which to view and interpret new material, and determine [whether] information is relevant to a given situation" (p.39). By examining individuals' mental models and understanding how and, in what ways, principal preparation programs actually impact individuals' mental models it was hypothesized that the study might shed new light on how best to prepare individuals to be instructional leaders. This study therefore attempted to determine whether a principal preparation program could, indeed, impact the mental models of participants and determine what program components, if any, had an impact.

Most studies that looked at the belief systems or mental models of principals focused on developing a greater understanding of how principals utilize their models in their leadership practice to conceptualize their role. Ruff (2002) for instance, studied acting principals and sought to develop an understanding of the "mental models that 
elementary school principals use to conceptualize their role as instructional leaders" (p.7). Fauske and Johnson (2000) sought to examine what events and activities capture a principal's attention and compare and contrast this information across principals in the hopes of moving "toward developing a collective mental model and theory of environmental selection by principals" (p.161). What is missing from these studies and the field in general is: (a) a focus on how aspiring principals develop their beliefs regarding the restructured role of the instructional leader; (b) how these beliefs affect their job as principal; and more specifically (c) how principal preparation programs impact those belief structures.

\section{Purpose of the Study}

The purpose of this study was to help fill the gap in the literature and begin to address the issues raised in the previous section, and in particular, the three specific points listed above. Specifically, this study investigated the impact that one principal preparation program, "Developing Instructional Leaders for New Schools (DILNS)," had on the belief systems of its aspiring principals, and, furthermore, how these beliefs compared and contrasted to their actual practice. This study first sought to understand how the aspiring principals' belief systems and mental models regarding school leadership changed, if at all, over the course of their training in the DILNS. This study also examined what participants, themselves, said about how their thinking was altered, if at all, by participation in the program. Finally, this study also investigated how the belief systems and mental models the participants held at the end of their first year of training (their espoused theories) compared and contrasted with their actions (i.e. their theories in 
use) as they subsequently began their first year as a school leader (Argyris, Putnam \& McLain Smith, 1985; Argyris \& Schön, 1974; 1978).

\section{Research Questions}

The purposes articulated in the previous section were translated into the following four research questions:

1) What are the aspiring principals' beliefs and conceptions regarding school leadership as they enter the Developing Instructional Leaders for New Schools (DILNS) program?

2) How did the aspiring principals' beliefs and conceptions regarding school leadership change, if at all, over the two year period of this study?

3) To what do the aspiring principals attribute changes in their beliefs to components of the DILNS program?

4) To what extent do participants' espoused theories of school leadership coincide with their theories in use once they assume administrative roles?

\section{Methodology}

The research for this dissertation involved a qualitative study of 13 aspiring principals who were participants in the principal preparation program, "Developing Instructional Leaders for New Schools" (DILNS). These participants were selected for study in this program in large part based on convenience considerations. The program also was a rich setting for study because of its innovative approach to training and the collaboration that existed between a university and school district. Individual interviews were conducted with the 13 participants in the program in order to explore how the mental models participants articulated at the beginning of the program compared and contrasted with the mental models they articulated at the end of their first year in the program. This study also aimed to understand what elements of the DILNS program, if 
any, the aspiring principals attributed to having an impact on their belief systems. Lastly, this study aimed to compare and contrast the espoused theories each participant held at the end of their first year of training in the program with their actions (theories in use) in their second year as they assumed the role of school leader (Argyris \& Schön, 1974; $1978 ; 1996)$.

Prior to the interviews, an interview protocol was developed to ensure that the same topics and issues were covered in each interview (Patton, 2002). In addition to interviews, participant observation strategies were utilized along with an analysis of key documents in order to triangulate the interview data. Participation in the study was voluntary and all participants signed a consent form. A more complete description of the methods is presented in Chapter III.

\section{Significance of the Study}

This study has potential implications for the field of principal preparation. As for the domain of research aimed at enhancing the training and preparation of aspiring principals, this study offers insight into how one program can effect a change in the belief systems of its participants, and more importantly, understand what program components participants believe had the greatest effect on their beliefs. For the practice of administrators, this study offers a chance to understand the complexities and difficulties that occur when an individual's beliefs are challenged by new ways of thinking. The knowledge gained through researching the interplay between beliefs and how one principal preparation program, the DILNS, impacts individuals' preconceived notions and beliefs regarding the role of the principal will also serve as a first step to aid and support the growth and future development of school leaders. 
While the results of this study are not directly generalizable in a traditional scientific sense, the data collected from this study will be available to those who design, evaluate and implement principal preparation programs. In many ways, this program is highly representative of the best ideas in the field and thus holds promise for what programs of the future may look like. As Pounder, Reitzug and Young (2002) suggest, the "core" elements essential to developing educational leaders with the knowledge, skills and dispositions necessary to drive school improvement must include training in which a close collaboration between the university and district exists, a focus on carefully selecting applicants who work in cohorts and serve as apprentices gaining hands-on field knowledge, and the coursework must also be integrated with these field experiences. They advocate that without these essential "core" elements principal preparation programs will continue to function as "silos" rather than move towards a more holistic preparation of school leaders.

The significance of this fact should not be underestimated, especially in light of the fact that the program under study, the DILNS, was designed specifically to connect the training of its students directly to a particular theory of instructional leadership that is linked openly to the goals and reform initiatives of a large urban school district in southern California. The ultimate goal of this training was to ensure that the participants can successfully act as change agents, and as instructional leaders in the district. The aspiring principals, in fact, were being asked to do something new. They were expected to develop a theory of leadership that coincided with a district model of leadership and were expected to take up the role of the principal in sharply contrasting ways to how the role has historically been conceived. That is, they were expected to be change agents in 
the district by developing a deep understanding and knowledge of instruction and most importantly, develop the understanding and skills needed to effectively lead and teach adults at their sites about instruction.

The knowledge generated by responding to the challenge of studying how aspiring principals develop the capacity to think and act, how they give meaning to situations, how they develop beliefs regarding the role of instructional leader and how these beliefs contrast with their actions will help us to begin to understand how school leaders can effectively be trained to adapt to the complex school contexts in which they will work.

\section{Limitations of the Study}

There are several limitations to the proposed study I wish to acknowledge. First, my involvement with the Developing Instructional Leaders for New Schools as both an outside data collector and evaluator of the program and as an instructor for a school management course in which participants of this study were students undoubtedly gives rise to certain concerns around confidentiality as well issues of objectivity. Because of the power differential that initially existed between me and the participants, respondents may not have been as forthcoming and open with their answers in the interview as they might have been had this relationship not previously existed. To some extent these concerns were offset by the fact that my role was initially distinguished and demarcated at the first meeting of the class in which I co-taught the members of Cohort III. I realize that the impact of the researcher on a study is never fully understood. I have, however, taken every step to ensure the trustworthiness of the data collected. 
Another limitation which I would like to acknowledge is the examination of participants' ability to affect practice in the various roles they take on as a school leader. As stated earlier, participants were expected to become school leaders upon completion of their first year in the program, most likely as a principal or vice principal. Because of the widely disparate functions inherent in these two roles, it was necessary to differentiate the expectations for impacting instruction in the classroom between the roles. Vice principals are often relegated to directing and managing the operational functions of the school and as a result are not always intimately involved in impacting instruction. So, while those taking up the role of vice principal may have previously stated their philosophy of leadership and a vision for a school they had hoped to lead, they did not all have the opportunity to realize that vision. Depending on how these individuals engaged in the role of vice principal, I differentiated the data analysis in a manner that articulated the participants' impediment to fully realizing their leadership philosophy and vision.

It is important to acknowledge three events that influenced both the pool of participants and the particular program components that were studied. First, one participant became so seriously ill that he not only took a medical leave at the end of the first year but also could not participate in the second interview that would have occurred at the year's end. Because of this unavailability, there was no opportunity to assess the impact the program had had on him by the time he had dropped out. Consequently, he was not included in the study.

A second person also left the district- - and, in fact, the education field-after the first year. A member of his family became gravely ill and he moved away to care for this family member. He was included in the study because two interviews were conducted 
with him before he exited and, consequently, there were data to address the question about programmatic impact on this person's thinking. Obviously, this person was not included in the implementation and practice components of the study.

Lastly, all participants were expected to complete two years of the program. During the first year, participants were engaged in a full-time internship and coursework co-developed and often co-taught by university faculty and district administrators. The second year was structured around more advanced coursework taught by either district personnel, university faculty or a university/district team of instructors. In addition, a mentor was provided to each individual to support their work as a new school administrator. Because flexibility was built into the second year of the program by providing participants the option of extending their coursework over a two year period, many participants (9 of the 13) chose to delay their second year of work and devote their attention to their new roles as a school administrator. As a result, this study's findings relate primarily, but not solely, to the impact of the first year of the program on participants. 


\section{CHAPTER II \\ REVIEW OF THE LITERATURE}

To restate, this study aimed to understand how aspiring principals' beliefs and conceptions regarding school leadership changed, if at all, during and as a result of their participation in a principal preparation program and how these beliefs transferred, if at all, into practice to help the participant become an effective instructional leader. As was noted in the problem statement section in Chapter 1, the field at present, has, at best, a limited understanding of both how aspiring principals actually acquire new beliefs, knowledge and skills and how principal preparation programs impact individuals' ways of thinking and their beliefs. Even less is known about how and whether principals transfer the new knowledge and skills they have acquired into practice. To situate this study within what is already known, this chapter reviews the literature on instructional leadership and then moves into a discussion of how principal preparation programs prepare individuals for the role of instructional leader. This chapter concludes with a discussion of the literature on mental models as part of a more general discussion of how beliefs change and how new ones are acquired.

\section{Instructional Leadership}

Leadership is considered a critical factor in a school's effort to increase student achievement. As Lunenberg and Ornstein (1996) note, "Every educational reform report in the past decade has concluded that schools are only as good as their administrators" (p.548). A recent study by Leithwood, Seashore-Louis, Anderson and Wahlstrom (2004) reinforced the importance of the principal; the report revealed that "of all the factors that contribute to what students learn at school, present evidence led us to the conclusion that leadership is second in strength only to classroom instruction" (p.42). Importantly, this 
study suggests that leadership accounts for roughly a quarter of the impact on student achievement.

As the importance of the principal role has been recognized, the expectations and demands of the job have increased. Principals are increasingly expected to bring about significant change by performing minor miracles that turn around low performing schools. In part because of this sort of expectation, over the past few decades, the role of the principal has been reconceptualized from that of a plant manger to an instructional leader. Plant managers were primarily concerned with managing the school plant. Leading instruction was rarely seen as a core responsibility. In contrast, instructional leaders have as their primary focus leading instruction, improving student achievement and ensuring the continued improvement of staff throughout the school.

In its broadest terms, instructional leadership includes all actions and functions that support the effective and successful improvement of the school which ultimately leads to student improvement. Over time, however, the concept of instructional leadership has changed. In the 1970 s and early 1980 s researchers focused primarily on trying to determine whether or not schools had an impact on student learning, and if so, what school characteristics were most important. Largely on the basis of the largely correlational findings of the so-called effective schools literature, the principal was characterized as the central figure that had a direct effect on improving student performance. Beginning in the late 1980 s, researchers began to shift their focus. Researchers concentrated more deliberately on identifying the indirect manner in which principals had an impact on student achievement. In particular, researchers began to focus on identifying the key strategies, pathways and functions that principals undertook to lead 
their respective schools. Researchers also focused on how the principal could engage the leadership of other key school agents to bring about change and improved student performance.

\section{The Effective Schools Literature}

The research into school effectiveness can be traced back to the landmark study released in 1966 by James Coleman and his associates (Coleman, Campbell, Mood, Weinfeld, Hobson, York \& McPartland, 1966). The Coleman Report, as it has come to be known, originally intended to look at the impact of the distribution of resources in schools which were attended by either a majority of white or black students, but its findings have had a much more far reaching effect. Coleman et al. (1966) studied over 600,000 children at 4,000 schools across the United States and found that funding disparities between schools attended by whites and blacks were smaller than had been predicted. School funding was also found not to be a significant factor in a student's achievement. In particular, the study found that while teacher salaries were relatively equal across schools and that the curriculum was also similar, minority children were not achieving at the same level as white students, and the achievement gap continued to widen as students progressed through high school. The dominant theme that ran throughout the report was that schools had little influence on a student's achievement; socioeconomic status and family background were the only really significant predictors of student achievement. In short, family status mattered more than schooling and education spending was considered relatively unrelated to a child's achievement.

This notion that schools had little impact on a student's achievement challenged the basic premise of schooling: that is, the idea that schools are providers of opportunity 
and serve to help students learn, improve themselves and attain equal footing with their peers. In response to the report, a flurry of research was undertaken with the aim of both countering the finding that schools do not make a difference and investigating what impact, if any, schools and school leaders had on student achievement.

One of the first major studies that countered the Coleman report was Weber's (1971) study of four inner city schools. Weber looked at the reading achievement of four successful inner city schools. He found that schools could, and in fact did, make a difference in the reading scores of students, especially those who were poor. Weber's work highlighted the fact that poor students could be successful and achieve high standards even when compared to national norms. Four characteristics were found to be common across each successful school site. First, each school had "strong leadership"; that is, the principal was prominent in both distributing school resources and making instructional decisions. In addition, the principal and teachers set high expectations for their students. Each school also focused on building reading skills and frequently assessed student performance. Lastly, each school also had an "orderly, relatively quiet and pleasant atmosphere." (cited in Edmonds, 1979, p.16).

A study by Brookover and Lezotte (1977) produced similar findings. Their study was conducted at the request of the Michigan Department of Education and looked at eight schools in the state. The eight schools, six of which were considered improving and two which were considered declining, were identified based on student scores on statewide standardized criterion referenced tests. Interviews and questionnaires were used at each of the eight school sites to identify the differences between the improving and declining schools and to determine which differences seemed to have the greatest impact 
on student performance. The findings demonstrated that the principals and teachers at the improving schools held higher levels of expectations for students than did the principals and teachers at declining schools. In addition, a stronger emphasis was placed on ensuring students' mastery of reading and math skills. The role of the principal was also quite different at improving schools. The principal was "more likely to be an instructional leader, more assertive in his/her instructional leadership role, more of a disciplinarian, and perhaps most of all assumes responsibilities for evaluation of the achievement of basic objectives" (cited in Edmonds, 1979, p.18).

Two other studies, one by Edmonds (1979) and the other by Rutter, Maughan, Mortimore, Ouston and Smith (1979), would also support the conclusion that schools could — and, in fact, had made a difference. Each study was conducted independently of the other, but each provided a picture of the impact of schools that was much different from what Coleman et al. (1966) reported. Both studies accepted the notion that socioeconomic status was a significant factor in understanding a child's ability to succeed academically. Yet, each study found that schools did make a difference in the achievement of students and both rejected the notion that schools were relatively powerless in helping students achieve and learn. As Edmonds (1979) declared: While recognizing the importance of family background in developing a child's character, personality, and intelligence, I cannot overemphasize my rejection of the notion that a school is relieved of its instructional obligations when teaching the children of the poor. I reject such a notion partly because I recognize the existence of schools that successfully teach basic school skills to all children. (p. 21). 
According to Edmonds (1979), six characteristics comprised the effective schools in his study: a) strong school leaders were at the helm of the school; b) high expectations were set for all children; c) an orderly but calm atmosphere permeated the school; d) priority was placed on the teaching of basic skills; e) school resources were focused in the area of greatest needs; and f) student progress was monitored frequently and continuously. Edmonds research demonstrated that "all children are eminently educable and that the behaviour of the schools is critical in determining the quality of that education" (p.20).

The other 1979 study alluded to above, the one by Rutter et al., looked at some of the most poverty ridden inner city schools in London and reached similar conclusions to those reached by Edmonds. Rutter and his associates found that a student's progress was associated with his or her attendance in school and that variation in student learning could not be accounted for solely by family characteristics. Successful schools in their study shared common characteristics such as setting high expectations for all students, emphasizing the teaching of key academic skills and actively engaging students. Rutter et al. (1979) concluded that "the results [from their study] carry the strong implication that schools can do much to foster good behaviour and attainments, and that, even in a disadvantaged area, schools can be a force for the good" (p.205).

The findings reported above, along with the findings of other researchers, turned out to be highly significant. Among other things, they provided evidence that schools do make a difference and that a child's destiny in life is not solely determined by his family's socioeconomic status. As Soder and Andrews (1985) state, "By identifying schools that were effective... regardless of family income or ethnic status, the effective 
schools research ... attributed differences in children's performance to the schools themselves" (p.8). The effective schools research was also significant because it helped to identify common characteristics that were seen as being of key importance in successful schools. Having a principal who was an effective instructional leader was one of these characteristics; other characteristics included: a) having high expectations for all students; b) providing adequate time on task for subject matter to be learned; c) creating and maintaining a safe and orderly school environment; e) continuously monitoring student work; and f) developing home and school connections.

Underpinning these studies and others (see also Andrews \& Soder, 1987; Murphy \& Hallinger, 1992) however, was an assumption that went well beyond the largely correlational data on which the assumption was based. That assumption was that at each effective school, the principal's direct impact was the guiding force in ensuring success. The leadership of the school principal, acting as a kind of lone ranger, was considered of vital importance to the development of the school culture, and the specific actions of the leader provided the basis for school improvement. As Lashway (2002) points out, during the 1970 s and much of the 1980 s, instructional leadership was viewed in the literature as "principal-centered, often accompanied by images of heroic leaders single-handedly keeping the school on track" (p.3).

In Weber's (1971) study, for instance, all four schools had principals that were described as strong. Each played a pivotal role in distributing resources, deciding on instructional strategies and setting high expectations for students and staff. Brooker and Lazotte (1979) also noted a marked difference between the principals at the improving schools versus those at the declining schools. The principal was more assertive and 
likely to be a disciplinarian at an improving school, and he or she placed a heavy emphasis on tracking student progress. Principals at declining schools "focused less on the evaluation of the school's effectiveness in providing a basic education for students" . (Brooker \& Lezotte, 1977, p.67). Edmonds (1979) found that "the most tangible and indispensable characteristic of [an] effective school [was]: (a) they have strong administrative leadership without which the disparate elements of good schooling can neither be brought together nor kept together" (p.8).

In sum, "the effective schools research suggests a model of schools which conforms closely to the classical model of bureaucratic organizations; i,e, goal oriented organizations with hierarchical authority structures, with central managers who monitor behavior and deliberately adjust organizational performance" (Cohen, Koehler, Datta \& Timpane, 1991, p.10). Camburn, Rowan, Taylor (2003) also point out that "a wellknown conclusion from this [effective schools] research was that strong principal leadership—and especially strong instructional leadership—is central to successful programmatic change and instructional improvement” (p.347).

\section{Mid-1980s and Onward: The Indirect Impact of Principals}

The effective schools research soundly supported the belief that schools did indeed have the ability to impact student achievement. It also pointed out the important role the principal played in ensuring the success of a school. The principal was considered the gatekeeper for what occurs in the school, and his or her leadership was essential to determining the mission of the school and the direction of the instructional program. This view of what effective principals did was more imposed than emergent from the data that had been gathered. The data used in effective schools research, in fact, 
revealed little about how leaders actually operated and achieved results. Consequently, in the mid-1980s the central questions for researchers shifted away from understanding whether or not schools did indeed have the ability to help students learn and whether or not principals did in fact make a difference in schools towards understanding what types of leadership or models of leadership an instructional leader must undertake to maximize the performance of staff and improve student performance.

While earlier attempts to define an effective school assumed that the principal single-handedly changed the school, from the mid 1980s onward, the research on instructional leadership shifted to focusing on how the principal's leadership influenced a school and made it successful. While these earlier studies credited the principal directly for the success or lack of a success a school had, researchers in the 1980 s began to try to unpack how and in what ways the leadership of the principal influenced instruction. A multitude of instructional leadership models were developed and then tested empirically to identify and explain the strategies an effective instructional leader undertakes.

Sergiovanni (1984), whose instructional leadership model was one of the first to be developed, included five leadership forces: technical; human; educational; symbolic; and cultural. The technical leader brings structure and organization to the school by planning, scheduling and coordinating events and being a "management engineer". The human leader acts as a "human engineer" and builds relationships and provides support and opportunities for staff to grow and develop. The educational leader serves as "clinical practitioner" and uses the strong instructional knowledge he or she has to supervise, support and evaluate staff. The symbolic leader assumes the role of "chief" and is highly visible on campus modeling key behaviors and articulating the goals of school. Lastly, 
the cultural leader takes on the role of "high priest" and seeks to shape the culture of the school by transmitting the goals and values that "defines the school as a distinct entity within an identifiable culture" (p.9).

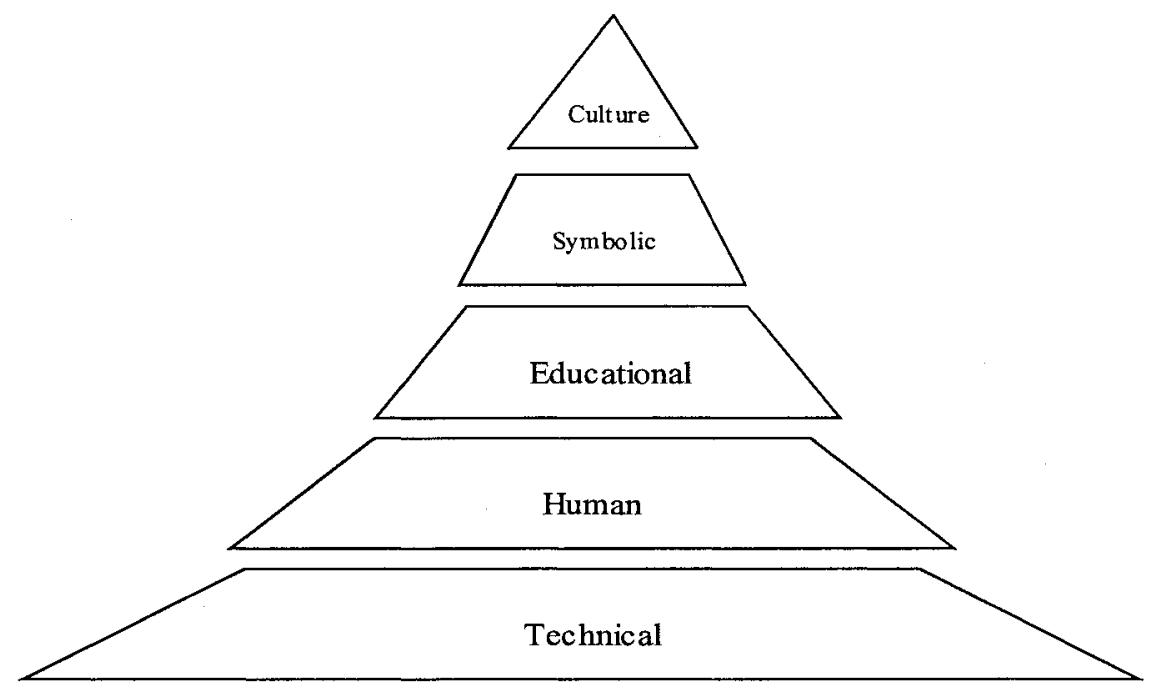

Sergiovanni, T. (1984). Leadership and Excellence in Schools.

Perhaps the most fully tested approach to instructional leadership is the one developed by Hallinger and Murphy (1985). Their model was developed by examining both the literature on school effectiveness and the leadership behaviors of elementary school principals. Their model extends the view of the principal as an all important force in improving student achievement which was central in the effective schools literature. Hallinger and Murphy's model, in fact, offers 20 specific functions within three dimensions of leadership: a) defining the school mission; b) managing the instructional program; and c) promoting school climate. There are 11 policy, practices and behaviors associated with these three categories. 


\begin{tabular}{|l|l|l|}
\hline Defines the mission & Manages Instructional Program & Promotes School Climate \\
\hline $\begin{array}{l}\text { Framing school goals } \\
\text { Communicating school } \\
\text { Goals }\end{array}$ & $\begin{array}{l}\text { Supervising and evaluating } \\
\text { Instruction } \\
\text { Coordinating curriculum } \\
\text { Monitoring student progress }\end{array}$ & $\begin{array}{l}\text { Protecting instructional time } \\
\text { Promoting professional } \\
\text { development } \\
\text { Maintaining high visibility } \\
\text { Providing incentives for teachers } \\
\text { Enforcing academic standards } \\
\text { Providing incentives for students }\end{array}$ \\
\hline
\end{tabular}

Dimensions of Instructional Management (Hallinger \& Murphy, 1985)

The first dimension, defining the school mission, is concerned with the principal's role in working with staff to develop the school's mission and to ensure that the goals of the school are focused on student achievement. This dimension has been the focus of many researchers (Leithwood \& Stager, 1989) and continues to be thought of as a critical aspect of the principal's job. The emphasis is on the principal defining a relatively small number of goals that focus on student achievement. Both formal and informal communication lines can be used to communicate the goals.

The second dimension, managing the instructional program, points to the important role principals play in monitoring instruction and student performance. It "involves working with teachers in areas specifically related to curriculum and instruction" (Hallinger \& Murphy, 1985, p.222). Three specific functions serve to help the principal achieve this dimension: supervising and evaluating instruction, coordinating curriculum and monitoring student progress. Principals provide close supervision and help teachers by providing instructional support. They help ensure that curriculum is aligned across grades and that assessment results are utilized to assess the curriculum and assess progress on goals.

The third dimension, promoting a positive school learning climate, involves the strategies the principal employs to develop a school culture that is focused on student achievement. Effective instructional leaders focus on protecting classroom time and 
developing policies that limit interruptions. Opportunities are provided for teachers to continue to develop their skills. The principal is also highly visible on campus and uses his/her visibility to articulate the goals of the school and to connect with students on a more personal level. While setting high standards is also an important strategy, providing rewards to both teachers and students helps to develop a positive learning climate.

Others such as Smith and Andrews (1989) defined instructional leadership in terms of four key qualities: resource provider; instructional resource; communicator; and visible presence. As the resource provider, the principal effectively manages the use of human and financial resources and marshals these resources to support the improvement of instructional staff and to achieve the mission of the school. As an instructional resource, the principal "is actively engaged in the improvement of classroom circumstances that enhance learning" (p.12). As communicator, "the principal articulates a vision of the school that heads everyone in the same direction" (p.15) and models the values of the school to staff and parents while maintaining a highly visible presence on campus.

In review of the models described above, a few key similarities arise. First, the models outline key functions of effective leadership which, in general, were to be the responsibility of the principal. The principal's role was essential in developing a mission and vision for the school, monitoring teacher performance and student achievement, being highly visible on campus and bringing coherence to the work of the school. These models provided greater understanding to the roles and behaviors that principals must undertake to be successful instructional leaders. 
The concept of instructional leadership, however, continued to evolve in the late 1980s and 1990s. "The conceptual models guiding research on school leadership came to focus on what Rowan (1990) called 'network' patterns of control where leadership activities are distributed across multiple roles and responsibilities" (in Camburn, Rowan \& Taylor, 2003, p.348). In fact, what emerged as a result of - or, at least in part, as a reaction to-the effective schools literature and subsequent research was a vision of leadership where multiple levels of staff in the school were viewed as being able to exercise leadership. Leadership was viewed as taking shape in the engagement with and interaction between many individuals - not just within the formal authority that resides in the principal.

As Camburn et al. (2003) suggest, "from the mid 1980s onward, the focus of school leadership research changed" (p.347). No longer was there a heroic leader who made all decisions and was seen as the sole source of authority and power. In fact, what "emerged [was] a new vision of effective leadership, one in which multiple school members are seen as exercising powerful instructional leadership, sometimes in redundant fashion, in order to effect programmatic change and instructional improvement" (p.248). Murphy (1988) suggested that continuing to view the principal as the epicenter of the school and as the sole source of leadership and change "ignores the invisible leadership of lower-level staff members" (p.655).

Researchers (Martin \& Willower, 1981) during the 1980s and 1990s had shown that, while principals believed they should spend their time in classrooms focusing on instruction and student achievement, most of their day was being taken up by the constant need to handle managerial tasks. Principals simply could not be successful in leading a 
school by themselves. They would need to count on the work and contributions from many other members of the school community if they were going to be successful in ensuring that all students were succeeding in school.

The concept of developing and relying on the contributions of others to achieve the school's goals has been characterized in the literature in a variety of ways: as distributed leadership (Spillane, Halverson \& Diamond, 1999; 2001; Gronn, 2000; 2002; Elmore, 2000); as shared leadership (Fullan, 2001; Gastil, 1997); and as participatory or democratic leadership (Dew, 1995). All of these terms reference a conception of leadership that does not view leadership as residing in one individual, and in fact, according to more recent thinking about the principal's leadership, the responsibility of an effective instructional leader is to ensure that the staff is utilized to share and take on responsibility and leadership for increasing student performance (Elmore, 2000; Sergiovanni, 1984; Spillane, Diamond \& Jita, 2000). As Bennett, Wise, Woods and Harvey, (2003) note, 'Distributed leadership is not something 'done' by an individual 'to others,' rather it is ... an emergent property of a group or network of individuals in which group members pool their expertise" (p.3).

Hallinger and Heck's (1996) review of the instructional leadership literature also supported the need to view leadership in a manner that didn't focus solely on the principal. They identified both "“blank spots' (shortcomings in the research) and "blind spots" (areas that have been overlooked because of theoretical and epistemological biases)" within the educational leadership field (Spillane, Halverson, \& Diamond, 1999, p.5). With respect to blind spots, they pointed out that much of the literature on instructional leadership tended to focus on the formal authority and leadership role of the 
principal and, therefore, other sources of leadership, such as teacher leaders, were ignored. They suggested that the "black box" of leadership needed to be opened up and a different view of leadership needed to be examined.

Elmore (2000) argued that one way to view leadership is to see it as being distributed across people in an organization. In any organization there are people who have specialized skills, competencies and interests. To be successful in any effort, Elmore contends, an organization would best be served by identifying the key people and skills which are needed to be successful in an endeavor. Once identified, the job of the leader is to find a way to balance, complement and where possible, share the skills each member has with the larger group to achieve the organization's goal. In short, the goal of distributed leadership, according to Elmore, is to make the whole greater than the sum of the parts. Each member of the team holds the other accountable for their contribution to the organization's goal.

Distributed leadership does not mean that no one is responsible for the overall performance of the organization. It means rather that the job of administrative leaders is primarily about enhancing the skills and knowledge of people in the organization, creating a common culture of expectations around the use of those skills and knowledge and holding the various pieces of the organization together in a productive relationship with each other, and holding individuals accountable for their contributions to the collective result. (Elmore, 2000, p.15) Spillane and Sherer (2004) have developed a model of distributed leadership that is somewhat different from Elmore's approach. Looking beyond those with formal power as holding leadership, Spillane and Sherer see leadership as being "stretched over" a 
variety of players and situations. The unit of analysis in their model is the school rather than the individual (i.e. the principal) or group of individuals. This is in contrast to previous notions of leadership which saw leadership as emanating from the individual and different from Elmore who viewed the group of actors as the unit of analysis. Spillane and Sherer argued that "leadership practice is constituted - defined or construed - in the interaction of leader's, followers and their situations" (2004, p.7). The boundaries for who is considered a leader are, however, not limited nor well defined. Leadership is not the sole dominion of principals, teacher leaders and other readily identifiable groups and individuals. Spillane and Sherer believe looking at leadership from the perspective of who does what is limiting. This view, or as they call it, the "leadership plus perspective," is little more than mapping who does what and fails to take into account how leadership is "potentially stretched over the practice of two or more leaders, followers and their situation. It also involves understanding how leadership practice is stretched over the work of various school leaders and exploring how the practice is generated in the interactions of these people" (p.6).

While there are different views of how leadership is shared, the idea that leadership is an activity that many in schools must take on if students are to achieve success academically is growing in acceptance. As Lashway (2002) pointed out, "A growing number of researchers say that instructional leadership is distributed across the school community, with principals, superintendents, teachers, and policy makers having complementary responsibilities." Hallinger and McCrary (1992), for instance, suggested that to be effective, "instructional leaders must think strategically and engage others rather than focus on enacting prescribed behaviors" (p.13). Others such as Hallinger and 
Heck (1996) suggested that research on instructional leadership needed to focus on "understanding the routes by which principals can improve school outcomes through working with others" (p.39). In a subsequent article, Hallinger and Heck (1998) conducted an extensive review of over a decade of instructional leadership research and explored the relationship between principal leadership and student achievement. Their review pointed to the fact that principals usually achieve their goals through "indirect paths" that engage a variety of stakeholders.

Leadership practices contribute to the outcomes desired by schools but the contribution is always mediated by other people, events and organizational factors such as teacher commitment, instructional practices or school culture. This conceptualization is consistent with the proposition that leaders achieve their results primarily through other people. (p.167).

They also concluded that "principals exercise a measurable, though indirect effect on school effectiveness and student achievement. While this indirect effect is relatively small, it is statistically significant and ... meaningful" (Hallinger \& Heck, 1998, p.186). Their review included 40 published works, dissertations and conference papers and “captured most empirical studies of principal impact on school effectiveness disseminated internationally between 1980 and 1995" (p.161).

In their review, they sought to "understand what has been learned about the substance of claims that principals' leadership practices make a difference in school effectiveness" (Hallinger \& Heck, 1998, p.159). Each work reviewed was classified into one of three categories: a) direct effects of the principal's action that influence school outcomes; b) mediated effects whereby the principal's action indirectly affects school 
outcomes; and c) reciprocal effects whereby the influence factor between the principal and teachers is shared. Their review reinforced the indirect impact principals have on student achievement and the importance that others play in bringing about change in schools.

\section{Mental Models}

We know from the literature review above that leadership is a necessary and critical ingredient in successful schools, and we also know that there are several features of leadership training programs that hold promise in helping aspiring school leaders develop the necessary knowledge and skills to be successful instructional leaders. However, we continue to know little about how-or even whether-principals transfer the new knowledge and skills they acquire in their training programs into practice. It has often been said that much of what is learned in the classroom rarely finds its way into practice in the real world. Principals, teachers and students can, in fact, learn new skills and knowledge yet not change their practice.

Part of the answer to understanding how to help principals transfer new beliefs, knowledge and skills they have gained into practice may lie in understanding the branch of research that is interested in the mind of the leader and deals with how leaders make decisions, change their beliefs and solve problems. This branch is often referred to as cognitive dimensions of leadership. Spillane, Halverson and Diamond (1999) write, "Scholars working from a cognitive perspective investigate how leaders use mental representations to understand and order their repertoire of responses to experiences" (p.10). At the heart of this work is the concept of mental models, which I believe is an 
area that is understudied and offers great promise in helping leaders develop the beliefs, knowledge and ability to be successful.

The concept of mental models can be traced back to Kenneth Craik (1943) who suggested that we construct "small scale models" in our minds to make sense of the world in which we live. According to Craik, humans construct internal representations of the world, or mental models, based on their interactions with events and these models are in turn then used to guide future actions. Put another way, mental models "are an integrated set of ideas and practices that shape the ways people view and interact with the world" (Senge, 1999, p.2). Mental models play a critical role in prompting a leader to attend to a situation and to certain features of a situation.

We know from the work of Rokeach $(1968 ; 1973)$ that individuals possess a highly structured system of beliefs that guide behavior. These beliefs are established, often deeply entrenched, and are exceedingly resistant to the efforts of others to change them. These beliefs help us make sense of the world in which we live. Senge, CambronMcCabe, Lucas, Smith, Dutton and Kleiner (2000) also point out that most people are drawn to take in and remember only the information that reinforces their existing mental models (see also Senge, 1990; Kim, 1993). King (2001) also reminds us that "we are confined greatly by what we know and believe and what we have experienced" (p.6). Particularly in complex situations, leaders often resort to the familiar and draw on experiences that have worked previously but may not be a match for the current situation.

King's (2001) study, which sought to explore the relationships between school leader's previous experiences and their current actions, revealed that previous learning experiences often become entrenched and "deeply rooted and [are] closely associated 
with how [individuals] perceived themselves, how they perceived others, how they perceived the world, and their strategic situation" (p.153). The importance of how difficult it is to change the way people think about things should not be underestimated. As Senge (1990) points out, "new insights [often] fail to get put into practice because they conflict with deeply held internal images [mental images] of how the world works, images that limit us to familiar ways of thinking and acting" (p.174). Yet, the importance of understanding how principal preparation programs go about transmitting a new set of beliefs and knowledge to aspiring principals and how these participants go about internalizing the information and eventually go about putting it into practice is of great significance. This is especially relevant given the fact that principals are being asked to become instructional leaders.

Undoubtedly, educators who enter principal training programs are profoundly shaped by their previous experiences in schools and carry deeply held images of the role of the principal (Finkelstein \& Hambrick, 1996; Hitt \& Tyler, 1991). Yet, programs are increasingly expecting participants to develop the beliefs, knowledge, and capacity to be an effective instructional leader. Accomplishing this task will require many individuals to rethink their understanding of the role of the principal as well as many of their own theories and beliefs regarding school leadership. In essence, many will be required to adopt a set of new beliefs consistent with the role of the principal as instructional leader.

Developing new beliefs and then transferring these new beliefs into action is a difficult process. Ruff (2002) reminds us that an individual's belief system often serves as a filter preventing the internalization of new information. In fact, these belief systems, or mental models (Senge, 1990) or mindscapes (Sergiovanni, 1996), "exert powerful 
influences over human experience, acting as perceptual 'filters' of new information" (Sanders, 2000, p.31). So, while participants in many principal preparation programs are expected to develop new perspectives on leadership and the role of the principal and thus alter their existing mental models, "little systemic effort has been devoted to exploring the thinking that underlies the behavior of educational administrators" (Dana \& Pitts, 1993, p.323).

Darling-Hammond and McLaughlin (1995) contend that the success of becoming an instructional leader ultimately rests on the individual's ability "in accomplishing the serious and difficult tasks of learning the skills and perspectives assumed by new visions of practice and unlearning the practices and beliefs about students [schools and the role of the principal] that have dominated their [i.e. future principals] professional lives to date" (p.597).

Arygis and Schön $(1974 ; 1978)$ also point out that there are often differences between what people do and what they say they believe. In other words, people's espoused theories (what they say they believe) and their theories in use (what they actually do) are often in conflict. Put another way, individuals can learn new information and espouse the belief that they employ a new strategy in practice, and actually believe it is the case, but their actions may differ significantly from what they espouse. The disconnect that often exists between beliefs and actions has serious implications for the development of new school leaders. First, it is not enough to assume that because participants in training programs develop new beliefs and skills that they will actually put them into practice. In fact, Argyris's work points out that even if individuals believe that they act in a certain way, they may not. If school leaders are being asked to change their 
beliefs or develop new conceptions regarding the role of the principal, preparation programs will have to learn to help participants make known what their beliefs are regarding the principal's role or student learning, for example. Second, programs will then need to learn to help aspiring school leaders make known the incongruence that may exist between their espoused theories and their theories in use and help them align them. Bringing coherence to what people say and do is not an easy task.

Argyris (1985) reminds us that one reason for insisting that what people do is consistent with what they say "is to emphasize that what people do is not accidental. They do not 'just happen' to act in a particular way. Rather their action is designed; and, as agents, they are responsible for the design" (p.82). However, people are not always consciously aware of the "design" or that there is a discrepancy between their espoused theories and their theories in use. Argyris (1980) argues that individuals' theories in action can be made explicit by reflecting on action. He also suggests that leadership effectiveness requires congruence between one's espoused theories and theories in use. He believes that double-loop learning, which involves learning to change underling values, beliefs and assumptions, can help individuals align what they say with what they actually do (Argyris, 1976). In double-loop learning "a person engages in critically reflective practice by looking inward and considering his or her own behaviors and assumptions and tries to understand how thought and action impact the situation" (Bierema, 2003, p. S29). The contention of double-loop learning is that only by understanding our beliefs, assumptions and values can we change our behaviors and ensure that what we believe is translated into how we act. When people recognize that 
that their actions are not aligned with their beliefs, there is an opportunity to help them identify the incongruence that exists and make changes in behavior.

Double-loop learning, Argyris (1982) argues, is essential to helping individuals make informed and effective decisions in rapidly changing, complex an uncertain situations. Yet, double-loop learning is hard to achieve and, consequently, changing one's beliefs and actions is very difficult.

The underlying theory, supported by years of empirical research, is that the reasoning processes employed by individuals in organizations inhibit the exchange of relevant information in ways that make double-loop learning difficult -and all but impossible - in situations in which much is at stake. This creates dilemma as these are the very organizational situations in which double-loop leaning is most needed. (Edmondson \& Moingeon, 1999, p.160).

Argyris has developed two models which describe how double-loop learning is either enhanced or inhibited: Model I and Model II. Model I inhibits double-loop learning and Model II enhances it. In a Model I framework, when we face difficult, challenging and potentially embarrassing situations, we tend to strive to be in control and protect ourselves by withholding thoughts and feelings. "As a result, error escalates and effectiveness in problem solving and in execution of action tends to decrease" (p.89). This leads to defensive routines made up of "action and policies intended to protect individuals from experiencing embarrassment or threat, while at the same time preventing them as well as the organization as a whole from identifying the causes of the embarrassment or threat in order to correct them" (Argyris, 2000, p.68). New behaviors and beliefs, therefore, never get put into place because they are undermined by defensive 
routines. To produce lasting behavioral change we must engage in a new theory of action, which is Model II. "In a Model II environment, the action theory in use helps - indeed, requires- mistaken assumptions to be reformulated, incongruities reconciled, incompatibilities resolved, vagueness specified, unstable notions made stable, scattered information brought together into meaningful patterns and previously withheld information shared" (Argyris, 2000, p. 72).

While Argyris offers a theoretical model for understanding why individuals' theories in use often differ from their espoused theories and how double-loop learning can help reconcile the incongruence that exists between the two, Ruff (2002) points out that there is little research to guide our understanding of how principal training programs impact individuals' beliefs and how aspiring leaders transfer new knowledge and skills into practice. He reminds us that "there has been a paucity of studies that have investigated the mental model, tacit knowledge or assumptions in the area of educational administration" (Ruff, 2002, p.6). He goes on to point out that "by looking at precisely these concepts, it is expected that a greater understanding will be gained about the structures within education that determine what is maintained and what is changed within an education system" (Ruff, 2002, p.6). Consequently, we turn to the research on teacher beliefs to guide our understanding of how beliefs change and transfer into practice.

Research that has been conducted on the relationship between teacher development and teacher beliefs has shown that when teachers are introduced to new strategies and ways of thinking, they often remained attached to their established ways of thinking (Kagan, 1992; Richardson, 1996). In fact, Block and Hazelip (1995) noted in their research "teacher beliefs and belief systems are grounded in their personal 
experiences, and, hence, are highly resistant to change" (p.27). Weick (1983) also points out that a "leader's cognitive structure is a highly personalized interpretation of reality, not necessarily aligning with objective conditions.... One's cognitive structure can become self-fulfilling and self-reinforcing and in some cases elements of a leader's cognitive structures are so well established and unshakable that contrary data are overlooked or, if noticed, severely discounted (in King, 2002, p.153).

While beliefs are resistant to change, the literature on teacher beliefs does offer insight and optimism into the process of shifting beliefs. Dwyer, Ringstaff and Sandholz (1991), for example, studied teacher beliefs in high-access-to-technology classrooms. They found that "teachers' beliefs may be best modified while they are in the thick of change, taking risks and facing uncertainty" (p. 52). They also found that teacher beliefs were subject to being influenced and did in fact change.

[The] teachers have become more disposed to view learning as an active, creative, and socially interactive process than when they entered the program. Knowledge tends to be viewed more as something children must construct and less like something that can be transferred. The nature of teachers' classrooms, the permissions they have granted their students, and their own instructional behaviours demonstrate that shift in action [from previously held beliefs]. (Dwyer et al., 1992, p.8)

Pajares (1993) also shows us that while strong and central beliefs are resistant to change, they can be altered. Pajares writes, "The process of accommodating new information and developing beliefs is thus gradual, one of taking initial steps, accepting and rejecting certain ideas, modifying existing belief systems, and finally accepting new 
ideas" (p.46). Understanding the impact of teacher beliefs on actions provides a framework to allow us to begin to look at the impact of beliefs on actions in the development of principals. As Pajares (1992) notes, "little will have been accomplished if research into educational beliefs fails to provide insights into the relationship between beliefs ... and teacher practices, teacher knowledge and students outcomes" (p.327). Principal preparation programs are designed to help foster self-exploration and a reconceptionalization of beliefs regarding school leadership. In fact, many of the promising leadership training processes described in the previous section are designed to challenge individual's beliefs and ideologies in covert and overt ways and, thus, the consequences that result from these challenges have implications for the success of the participants. As Buffie (1989) states, "the knowledge and skill possessed by leaders can only be used within a context of a set of beliefs and values" (p.6). Spillane, Halverson and Diamond (1999) however, caution us that context is important. They believe that if cognitive research focuses solely on "administrators intentions, values, and beliefs, cognitive approaches run the risk of ignoring organizational, cultural, and political factors that also influence what school leaders do" (p.10)

This researcher agrees that "practice cannot be understood solely as a function of the mental capacity of the individual because practice is enabled (and constrained) by the situation in which it takes place" (Spillane \& Sherer, 2004, p.4) and that to fully understand an individual's leadership practice "leaders thinking and behavior as well as their situation need to be considered together in an integrated framework, for a thoroughgoing consideration of leadership practice" (Spillane et al., 1999, p.11). 
While context is critical and will always play an essential factor in how individuals act and behave in situations, Fullan (1992) reminds us that change must first begin with individuals. "The starting point for improvement is not system change, not change in others around us, but change in ourselves" (Fullan, 1992, p.87). "If principals are to heed the call from educational reformers to become instructional leaders, it is obvious that they must take on a dramatically different role" (Stronge, 1988, p.33). This new role will require new ways of thinking, new habits, beliefs and skills and most importantly the ability to conceptualize, internalize and transfer these new attributes in the role of instructional leader. In particular, the concept of mental models is important in the context of developing instructional leaders capable of leading schools for improved change.

\section{Promising Features of Principal Preparation Programs}

The review of the instructional leadership literature above indicates that principals do matter when it comes to promoting overall school effectiveness and student achievement. We also know that if aspiring school leaders are to be successful, they must be trained and prepared to be effective instructional leaders. As was noted in Chapter 1, there are still many unanswered questions regarding how principal preparation programs can help prepare individuals for the difficult job of being an instructional leader and ensure participants acquire the skills, beliefs and competencies needed to be successful on the job. Even so, there is general agreement in the literature about certain features of leadership training programs that hold promise in effectively training individuals to be successful instructional leaders. These features include the careful selection and 
recruitment of participants, the use of internships, cohorts, problem-based learning and experiential learning.

Unfortunately, while there appears to be consensus on many of the essential program features, there is little systematically gathered empirical evidence to support assumptions about the impact that these features have on participants' abilities to be effective on the job. In fact, the recent literature review of principal preparation and development programs by Davis, Darling-Hammond, Lapointe and Meyerson (2005) points out that "much of the empirical support for the most popular program components consists of self-reported candidate perceptions and experiences and there is virtually no evidence for how graduates of different kinds of programs perform on the job" (p.4). This section of the literature review highlights those features of principal preparation programs that are often seen as significant in the development of an effective instructional leader.

At present, most individuals aspiring to be a school leader are trained in university-based graduate programs. Over the past few decades there have been questions raised about the viability of this system of training and the less than stellar principal candidates the university-based system has produced in the past. While many have called for an overhaul of the educational leadership preparation system (Hess \& Kelly, 2005; Levine, 2005; Murphy, 1992; Restine, 1997; Wendel, 1992), change to university based programs has been rather slow. Even so, there are a number of innovative program components and learning approaches being used by both traditional and non-traditional programs to identify and develop aspiring principals with the appropriate knowledge, skills, beliefs and dispositions necessary to be an effective instructional leader. These 
program components are: purposeful recruitment and selection of potential school leaders, use of cohorts, internships, problem-based learning and mentors.

\section{Purposeful Recruitment and Selection}

The importance of recruitment and selection of principals has been widely written about for years (Browne-Ferrigno \& Shoho, 2002; Browne-Ferrigno \& Shoho, 2003; Coleman \& Achilles, 1987; Creighton \& Jones, 2001; Creighton \& Shipman, 2002; Milstein \& Krueger, 1997; Murphy, 1999; Playko \& Daresh, 1992; Smith \& Piele, 1997; Young, Petersen \& Short, 2002). Many writers have indicated that the operative selection process in most university programs is inadequate and lacks rigor. For example, Coleman and Achilles (1987) have criticized preparation programs because of the "self select, open admissions system which absorbs anyone who can persevere" (p.121; see also Hale \& Moorman, 2003). Others (NASBE, 1999) have criticized the self selection process for failing to attract minority candidates to the principalship, and yet others have criticized them for being "cash cows" and selecting students because they serve as a constant source of funding for the university, funding that normally is spent on other, higher priority university programs (Levine, 2005; Tucker, 2003).

Some systematic research has been done that supports the above claims.

Creighton and Jones (2001), for example, looked at the admissions practices of 350 principal preparation programs and found that there was little rigor to the process of selecting candidates. They reviewed each university's website to identify the selection criteria being used to admit aspiring principal candidates. They also selected a purposeful sample of 45 universities and communicated with university personnel including deans and program chairs to verify the data collected. The most commonly used criteria for 
admissions to training programs consisted of reviewing letters of recommendation, GRE scores and students' prior GPAs. In fact, only $26(7 \%)$ of the programs reviewed required an interview as part of the selection process.

To shift the nature of how potential school leaders are admitted to programs, many researchers, including Milstein and Krueger (1997), have suggested that programs need to move away from "a laissez-faire approach" and be more purposeful in ensuring that candidates with the greatest potential for success are admitted (p.103). They suggest the need to more purposefully seek out minority candidates, mentor promising candidates early on while they are still teachers and also engage in a targeted and focused communication strategy to reach potential candidates.

In a review of five successful leadership preparation programs funded by the Danforth Foundation, Milstein (1993) found that a critical characteristic of each program was that each "made major efforts to change the ground rules regarding who participates in preparation programs" (p.184). School district officials were actively engaged in partnership with university faculty in the selection and screening of candidates. This strategy is based on the idea that leaders need to be chosen based on leadership potential, not solely on academic potential, as traditional programs have often done. As Milstein (1992) suggested, "The ability to absorb and recall knowledge is important, but the more important intent of preparation is to produce leaders, not scholars" (p.188).

Others such as Jones and Creighton (2002) believe that having real life scenarios as part of the screening process will provide a more accurate measurement of how a candidate will react in a real life situation than that of an interview. Jones and Creighton (2002) stated: 
Acceptance into school administration preparation programs should indicate more than perseverance and one's willingness to complete the course. It should indicate that some of our best, most well-prepared and most creative people have entered the field. The time has come to take a more rigorous approach to the selection and training of school administrators. (p.18).

In fact, Jones and Creighton (2002) suggested the "need to view leadership as a performing art" (p.7) and use auditions as part of the admissions process. They argued that interviews provide a quick and often inaccurate picture of how one may actually deal with potentially difficult situations, and, therefore, believe that auditioning candidates using a realistic school situation provides a more accurate assessment of a candidate's ability to be spontaneous, creative and attentive to the variety of stakeholders in a school. Use of Cohorts

Using cohorts in principal preparation programs is not a new phenomenon. The use of this strategy in leadership training programs, however, has grown tremendously in recent years (Anstrom, 1999; Basom, Yerkes, Norris \& Barnett, 1996; Milstein, 1993). A 1995 study by the Center for the Study of Preparation Programs found that "half of UCEA units used cohorts at the master's level and $80 \%$ used them at the doctoral level" (McCarthy, 1999, p.128). Each of the 22 universities offering Danforth programs also utilized cohorts as part of their structure for developing school leaders (Krauss, 1996). Proponents of cohort groupings (Barnett, Basom, Yerkes \& Norris, 2000; Basom, Yerkes, Norris \& Barnett, 1996; Jackson \& Kelley, 2002; Krueger \& Milstein, 1995; Scribner \& Donaldson, 2001) maintain that they are an effective means for: a) developing a strong system of support and collegiality for participants while in a preparation 
program; b) building professional networks that last long after the completion of a program; c) increasing contact and interaction between participants and faculty; d) ensuring coursework is appropriately and effectively scaffolded and sequenced; e) achieving higher participant completion rates; and f) promoting individual and group development.

There is some empirical research, however, that suggests that cohort programs do not provide an advantage over non-cohort training programs. An example is Anstrom's (1999) dissertation study. Anstrom used qualitative and quantitative data to "explore the effectiveness of a cohort model in principal preparation programs and in leadership practices" (1999, p.35). A sample of graduates from cohort based and non-cohort based programs were surveyed and interviewed. Colleagues and teachers working with the graduates who went on to serve in school leadership positions were also surveyed. Anstrom found no significant difference when the skills and leadership practices of those trained in cohort groups were compared to the skills and practices of those who had not been part of a cohort. More importantly, her findings suggest that there may actually be a downside to training individuals in cohort groups, at least when cohorts members come from a single district. Anstrom wrote:

Non cohort groups were describes [sic] as having diversity in cultures, disciplines, school districts and problem solving strategies. In contrast, the cohort groups consisted of peers from the same school district and training was provided by instructors from the same school district in which the cohorts were employed. (1999, p.101). 
In other words, training cohorts of students, at least if they come from a single school district as apparently was the case in the Anstrom study, may actually lead to conformity of thinking on what an effective leader should do on the job. This sort of conformity could have both positive and negative consequences. On the one hand, a program that trains a select group of students from a single district can impact a distinct theory of action to guide the aspiring leaders' work and ensure that it is continually reinforced throughout the program. On the other hand, participants may not be exposed to a diversity of viewpoints and experiences and therefore lack a larger perspective of how to be an effective school leader.

Thus, Anstrom's study raises questions as to whether or not cohort models (or at least certain versions of cohort models that are currently very much in vogue) are more effective than non-cohort programs in preparing individuals to be principals. Her study, however, also suggested that cohort programs provide participants with the advantages of networking and support mechanisms that non-cohort programs do not offer. Kraus's (1996) qualitative study of graduates from five New England principal preparation programs - both Danforth Foundation supported and non Danforth programs - also documented the networking opportunities that the cohort structure provided participants. In her study, Kraus sought "to explore the factors that impact job preparedness and learning of aspiring school administrators" (p.69). A purposeful sample of 25 graduates from the programs was selected to be interviewed and surveyed. All were serving in administrative positions at the time of the study.

One of the central findings from her study was the value participants placed on being involved in a cohort. Many identified the cohort as the most significant part of their 
training program. Kraus's findings suggest several advantages of cohorts. First, involvement in a cohort helped individuals develop a sense of family and belonging. The structure of the group also impacted the participants' learning in a positive manner and they were able to form a networking system that served as a form of job counseling.

While there is limited direct empirical support to establish the utility of the cohort experience, one can find additional support for the cohort strategy within the adult development literature. In fact, the research on adult learning suggests that individuals learn best when they build relationships with their peers, are reflective, focus on problems that are directly related to practice, and have the ability to influence the decision making process (Merriam \& Caffarella, 1991). The building of trust is also seen in the adult development literature as a critical ingredient in the formation of an effective learning environment. Knowles (1980), for example, described the importance of "mutual trust and respect" (p.57) and Brookfield (1986) pointed to the significance of "respect among participants for each other's self worth" (p.10) as key to building an effective learning community. As trust and respect develop, individuals are more able to promote a free exchange of ideas without the fear of retribution. As a result, individuals are better able to develop and grow.

Basom et al. (1995) also provide support for the cohort approach by reminding us of the societal context in which our schools operate: schools are "characterized by shared leadership, communities of learners and visionary leadership" (p.1-2). Cohorts provide an important socialization factor by immersing participants in a group, mirroring the work of schools and helping members develop the capacity and ability to work in a collaborative 
team structure that shares leadership in a variety of ways while forming a learning community.

Crow and Glascock (1995) also identified the important socialization function cohorts serve. Their study of 16 aspiring principals in a non-traditional principal preparation program used both qualitative and quantitative measures to examine "the socialization process of developing a conception of the [principal's] role" (Crow \& Glascock, 1995, p.22). They also found "the strongest response [from program participants] regarding sources of role conception focused on the cohort" (Crow \& Glascock, 1995, p.34). Interacting in the cohort gave participants a sense of identity and an opportunity to develop leadership skills. Their findings provide evidence to suggest that "a cohort approach is an excellent way to encourage the development of innovative, rather than custodial norms and facilitate commitment to change after candidates move into the principalship" (Crow \& Glascock, 1995, p.40).

Norris (1992) pointed out that the experience in a cohort can help guide participants "to increased awareness of their unique strengths and become cognizant of areas that might need development" (p.122). Basom et al. (1995) also discussed how cohorts can serve to impact individuals' beliefs and ways of thinking. As she stated, "Students use time within the cohort to discover and utilize their colleagues [as well as their own] unique talents and skills and to appreciate individual differences" (p.10). This is a skill that is readily needed on the job, as principals will have to be able to assess the talents of their staff and use the information to strategically engage them. 


\section{Internships}

An internship experience is also cited by many acknowledged experts in the field as a critical feature of programs that develop effective school leaders. A number of experts (Crow \& Matthews, 1998; Jean \& Evans, 1995; Milstein, Bobroff \& Restine, 1991; Suk Yee Hung, 2001), in fact, have articulated a sort of face validity case for internships. They have argued that internships provide aspiring principals with the opportunity to have real world experiences and place the theoretical knowledge they gain in the classroom into practice while experiencing an administrative role (or at least aspects of that role) first hand. Kraus (1996), for example, has stated, "The administrative internship can be viewed as a transforming praxis (i.e. a way to practice an art, skill, or science) which when designed, developed and delivered, generates an understanding of the challenges of school leadership" (1996, p.36; see also Daresh, 1988; Laplant, 1988).

Unfortunately, there is little systematic research to support what amounts to a face validity argument about the usefulness of internships. As Cordeiro and Sloan (1996) stated, "Despite the steady increase in the number of internship programs in educational administration, there is little empirical evidence with which to determine how internships impact both the novice or intern's learning as well as the mentor administrator or expert" (p.7).

Cordeiro and Sloan's (1996) study of internship participants in the University of Connecticut's Administration Preparation Program research did, however, identify five critical components of internships: authenticity, relevancy, independence, working closely with another person, and theory to practice tie. According to Cordeiro and Sloan (1996), participants believed that the experiences they engaged in through their internship 
were extremely relevant to their development because they were provided the opportunity "of 'living though' real experiences" rather than just shadowing a principal (p.11). As a result, participants felt they had authentic and relevant experiences that were applicable to their future role and, thus, they felt well prepared to be a school leader. In addition, participants found that because they were being held accountable for the activities and duties they were taking on as part of their internship, they were forced to think about the consequences of their actions from a variety of points of view. As Cordeiro and Sloan stated, "Being pushed to work independently, the intern's awareness increased and it allowed the intern to develop a sense of accountability for his or her actions" (1995, p.12). Working with others also provided opportunities for members to bond and reflect together and make connections between theory and practice.

Cordeiro and Sloan's (1996) study helped emphasize the importance of the internship in acquiring skills and knowledge though real world settings. A more recent dissertation study by Suk Yee Hung (2001) had similar findings. Suk Yee Hung's study examined and evaluated the internship component of the Future Schools Administrator Academy. She found that those participants who had engaged in an internship believed that they were extremely well prepared to pursue an administrative role and were confident of their skills given the opportunities the internship provided. Of course, both the Suk Yee Hung and the Cordeiro and Sloan studies employ research designs that rely "heavily on self-reports, individual perceptions, and personal testimonies" that scholars such as Davis, Darling-Hammond, Lapointe and Meyerson (2005, p. 16) argue are insufficient to make a well supported case for the effectiveness of a practice or program component. 
While internships have the potential to be powerful learning opportunities and there is much support for using internships in the training of aspiring principals, some scholars have emphasized that the details associated with the internship experience are crucial. All internships are not created equal, in other words. Some scholars, for instance, criticize internship experiences because they often involve little more than having the intern "shadow" and observe the supervising principal. The implicit argument, here, is that interns must be actively engaged in activities that help develop the participants' capacity to lead (see for example SREB, 2005). Unfortunately, McKerrow (1998) found that most participants in internships spend their time observing meetings, taking on menial tasks, or helping the principal deal with discipline issues rather than engaging in the "real" work of being a principal.

Finally, even some experts who endorse the use of internships often indicate that even a well-designed internship experience is, at best, a necessary but not a sufficient condition for producing effective principals. Playko and Daresh (1992) make this point when they write:

Leadership development must involve strong field experiences such as internships and other forms of practica. However, these learning experiences are not sufficient to improve the formation of leaders. They must be accompanied by strong academic preparation so that aspiring administrators and other leaders learn the 'grammar' and 'vocabulary' of leadership. (p.23).

Problem-based Learning

Problem-based learning (PBL) is yet another strategy-in this case, a pedagogical strategy - that has been associated with the notion of best practices in administrative 
preparation (Bridges \& Hallinger, 1992; 1995). In PBL, real life scenarios are used to help students actively construct knowledge and information. Whereas the professor has traditionally served as the primary disseminator of knowledge, in PBL the instructor acts more as a facilitator of learning and encourages students to construct meaning through the interaction of the problem and working with others. As Smith (2003) stated, "Problem based instruction aims to focus the learning process, not the content. In this manner, problem-based instruction transfers control of the learning process from teacher to student" (p.46). Bridges and Hallinger (1997) also pointed out that in PBL activities, "the instructor creates or selects the problems that are the focal point for learning but does not take an active role in presenting the content" (p.133).

PBL was originally developed for use in training medical students and has been used extensively in the medical field for some time. The PBL approach was first used in the 1960s at McMaster Medical School where faculty sought to find a method more stimulating than lecture to deliver information and engage students in a motivating, thought provoking learning environment. Students were placed into small groups of five or so students, given clinical problems to address and "solve," and provided a tutor to guide students and help them reflect on what they were learning. The entire curriculum at McMaster was eventually delivered through problem-based learning and was eventually used in other medical schools including Harvard, University of New Mexico and Wake Forest University.

The popularity of PBL has continued to grow outside the medical field in part because students consistently report high levels of satisfaction with a teaching method that offers a hands-on experiential approach to learning that links research, theory and 
practice (Albanese \& Mitchell, 1993; Vernon \& Blake, 1993). Krivel-Zacks' (2001) qualitative study of participants in a PBL based teacher education program at the University of British Columbia showed that students participating in a PBL based program felt a significant increase in their ability to affect student learning. In addition, $73 \%$ of the students in the PBL program indicated that their attitude and beliefs had changed about teaching and learning as a result of participating in PBL activities compared to $55 \%$ of a comparison group of students who did not participate in a PBL program (p.79). In fact, her data suggest that "PBL can assist student teachers in: a) modifying their existing beliefs and cognitions about learning and teaching, and b) incorporating the theory learned in university to the practice of teaching" (p.4). Once again, of course, these studies utilize the sort of self-report design strategies that Davis, Darling-Hammond, Lapointe and Meyerson (2005) have criticized.

Others such as Coles (1985) and Newble and Clark (1986) suggest that students in PBL training programs experience a range of benefits. They possessed higher problem solving skills and were more likely to take a "deep" approach to learning than students who were enrolled in traditional courses. The tenets of PBL also align well with adult learning theory which posits that adults learn best when they can direct their own learning, when the problems they focus on are relevant to their work and can be immediately applied and when there is time to reflect and assess one's own leaning.

However, according to Major and Palmer's (2001) review of PBL literature,most studies of problem based learning have shown "no significant difference between the knowledge that PBL students and non-PBL students acquire about sciences" (p.4; see also Albanese \& Mitchell, 1993). This is not unexpected given that PBL focuses 
primarily on helping students learn how to learn and engage in problem solving strategies rather than solely on the mastery of specific knowledge as traditional didactic teaching does. Even so, several researchers have documented that students who participate in PBL are more highly engaged in their learning, have better attitudes about the information they are learning and have high rates of retention of the material (Bridges \& Hallinger, 1997; de Vries, Schmidt \& de Graaff, 1989; Lieux, 1996; Schmidt, Dauphinee \& Patel, 1987).

\section{Mentoring}

Mentoring is viewed by many researchers as another essential component in principal preparation programs (Peterson, 2001). As the retention of quality administrators has become a major problem for the field, mentoring has come to be viewed by many as a "magic potion" to support school leaders (Playko, 1995, p.90). In fact, mentoring is seen by many as providing a valuable link between theory and practice that is often missing from administrator preparation programs (Hegarty \& Simco, 1995). Mentors are expected to provide aspiring and current administrators with support, practical knowledge, time to reflect and insight the mentor has gleaned from a wealth of experience.

Mentors can serve as a force to socialize principals into the role and help new administrators cope with the myriad of responsibilities and tasks they are expected to take on and complete daily (Playko, 1995; Daloz, 1999). Mentors are frequently called upon to make explicit to the aspiring or new principal what has been rather automatic over the years for the mentor. For example, scheduling, district procedures and management responsibilities are often one area where the mentor provides immediate assistance. To 
be successful, mentors also need to be provided with regular, systemic support throughout the period of time the formal relationship exists.

While many articulate the virtues of mentoring, there are also several criticisms of mentoring programs. The first is that the training of mentors is often neglected when, in fact, the individuals who are selected to be mentors need specialized training to support the individuals they work with (Creasap, 2003). Barnett (1995) suggests that training mentors is essential to ensuring their success: "To expect mentors to be able to grasp and excel in their roles as cognitive coaches without periodic debriefing, feedback and monitoring of their process, is to underestimate the complexity of this new mentoring role" (p.56). Daresh and Playko (1990) also argues that not everyone is capable of being a mentor and thus careful attention must be focused on selecting individuals to be mentors (p.77; see also Crow and Matthews, 1998). The pairings of mentors with mentees is also a critical aspect to ensuring their success especially because personalities often play a critical role in how individuals relate to one another.

\section{Summary}

To situate this study within what is known about effective instructional leadership, how aspiring principals acquire new beliefs, knowledge and skills and how principal preparation programs impact individuals' ways of thinking and beliefs this chapter reviewed the literature on instructional leadership, mental models and principal preparation program features.

The review of literature on instructional leadership suggests that instructional leaders play a significant role in improving student achievement. The effective schools literature viewed the principal as the central figure of the school who was single handedly 
responsible for improving the academic performance of students and turning around a low performing school. Recent studies, however, suggest that principals have a far more indirect impact on student achievement and must develop and rely on the contributions of others to achieve the school's goals.

To be effective in their roles, principals must also conceptualize the role of the principal as an instructional leader rather than a plant manager. This will require many individuals to develop a set of beliefs about the role of the principal that are quite different from how the role has traditionally been perceived (i.e. plant manager). The literature on mental models nonetheless revealed that changing beliefs is not easy. They, in fact, are hard to change because our belief systems are deeply embedded in our psyche.

Principal preparation programs are however designed to help individuals think in new and different ways. So, while there appears to be growing agreement in the literature about the program features that should be included in administrative preparation programs (purposeful selection of candidates, internship opportunities, working in a cohort, problem based learning and mentoring) there is little empirical evidence-beyond a limited number of studies that almost always employ self-report designs-to help us understand how these program features actually influence the ability of principals to be successful on the job. 


\section{CHAPTER III \\ STUDY DESIGN AND METHODOLOGY}

To restate what was stated in considerable detail in Chapter 1, the goal of this study is to understand how and in what ways the Developing Instructional Leaders for New Schools (DILNS) program appeared to influence the participants' belief systems and mental models. To do this, the mental models participants articulated at the beginning of the program were compared and contrasted with the mental models participants articulated at the end of their first year in the program. This study also aimed to understand what elements of the DILNS program, if any, the aspiring principals attributed to having an impact on their belief systems. Lastly, this study intended to compare and contrast the espoused theories each participant held at the end of their first year of training in the program with their actions (theories in use) in their second year as they assumed the role of school leader.

\section{Context}

This dissertation was part of a much larger study being undertaken to evaluate the effectiveness of the DILNS program in a large urban school district in southern California. The purpose of the larger study was to examine DILNS' practice and measure its success in preparing individuals to be effective principals, provided with the necessary leadership skills to drive instructional improvement at the site level. The following questions guided the larger evaluation study of the DILNS:

- What is the theory of action behind the Developing Instructional Leaders for New Schools program?

- Does the theory of action lead to the development of principals with the leadership skills demanded of the reform being undertaken in the school district?

- Who are the participants of the DILNS and how are they recruited?

- What are the program factors that facilitate or constrain success for the participants involved? 
- How, if at all, have DILNS graduates improved their skills as a result of completing this program?

- How does the growth of the DILNS individuals compare to the non-DILNS cohort?

- What are recommendations for adjustments and improvement to the program?

The larger study employed both qualitative and quantitative data. Qualitative data for the larger study were collected by conducting interviews with each member of the four cohorts that, at the time of this study, were participating in the program. The first cohort began in 2000 with a new cohort beginning each year thereafter. Interviews were conducted with the supervising and mentor principals who provided guidance to the participants, and with other key individuals including the Executive Director of the Program, the Program Coordinator and the Dean of the School of Education. In addition to interviewing and conducting observations of principals, course materials such as classroom videotapes, student platform statements and course evaluations were analyzed to gain multiple perspectives of the program. Quantitative data, such as school and student achievement data were also collected, analyzed and compared over time.

The data for the present study drew in part on the qualitative research conducted from the larger study. This particular study, however, focused only on the 13 participants of Cohort III who began their work with the DILNS in August of 2002. At the time of their entry into the program, ten of the DILNS participants were working at the elementary level, two at the middle school level and one in the literacy department of the district office. Twelve of the members were white and one was Hispanic. They ranged in age from 30 to 56 years old and had a range of teaching experience from four to 32 years. Ten of the members were female and three were male. Cohort III was selected for this study because it was the first cohort for which baseline data on the participants' views and 
beliefs regarding school leadership were collected as they began their participation in the program. At the time of their initial interviews, these students had just begun to work on their Tier I preliminary credential, which, at the time of data collection, was a required first step toward full credentialing as an administrator in the state of California. In addition, participants were serving as full time administrative interns with an experienced mentor principal.

Table 3.1 DILNS Cohort III Demographics

\begin{tabular}{|c|c|c|}
\hline 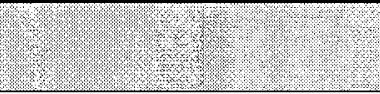 & \multicolumn{2}{|c|}{$\begin{array}{c}\text { Cohort III } \\
(\mathrm{N}=13)\end{array}$} \\
\hline Categories & $\#$ & $\%$ \\
\hline Gender & & 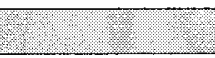 \\
\hline Male & 3 & $23 \%$ \\
\hline Female & 10 & $77 \%$ \\
\hline Age & 25 & \\
\hline $30-39$ & 4 & $31 \%$ \\
\hline $40-49$ & 5 & $38 \%$ \\
\hline $50-59$ & 4 & $31 \%$ \\
\hline Ethnicity & 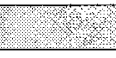 & 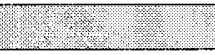 \\
\hline Latino & 1 & $8 \%$ \\
\hline White & 12 & $92 \%$ \\
\hline Grade Level & & \\
\hline Elementary & 10 & $77 \%$ \\
\hline Middle & 2 & $15 \%$ \\
\hline District office & 1 & $8 \%$ \\
\hline $\begin{array}{l}\text { Years of Teaching } \\
\text { Experience }\end{array}$ & & 8 \\
\hline $1-5$ & 1 & $8 \%$ \\
\hline $6-10$ & 5 & $38 \%$ \\
\hline $11-15$ & 2 & $15 \%$ \\
\hline $16-20$ & 1 & $8 \%$ \\
\hline $21-25$ & 2 & $15 \%$ \\
\hline $26-30$ & 1 & $8 \%$ \\
\hline $31-35$ & 1 & $8 \%$ \\
\hline
\end{tabular}

There were several other differences between the larger study and this particular study that were worth noting. First, the larger study had a much broader focus than this study. Four cohorts were included in the larger study while this study examined and 
studied only one cohort. In addition, the larger study sought, where possible, to make a casual connection between the training provided participants in the DILNS and improving or declining student achievement data for the sites where the participants served as principals or vice principals. This study sought to make no connection between the training provided in the DILNS and improving or declining student achievement data at the sites where participants worked as principals or vice principals. It was my belief that there were too many confounding variables, and participants had too short of a period of time on the job (one year) to expect to ferret out a direct link between any improved student achievement data and the training provided in the DILNS.

Another difference between this study and the larger study was that this study included numerous observations of the participants in Cohort III. Each participant in the study was observed on the job in a variety of settings including when participants conducted walkthroughs of classrooms, led school professional development sessions, staff meetings and engaged with parents and staff during various meetings. The larger study did not utilize direct observations, but rather, videotapes from training sessions and courses in which the individuals participated. Lastly, this study was largely qualitative in nature with some descriptive statistics provided to elaborate on the demographic characteristics of the participants. The larger study while primarily qualitative in nature also collected and analyzed some quantitative data.

\section{Site Selection}

In large part, DILNS was selected for study based on convenience considerations. Nevertheless, the program exhibits what the literature suggests should be characteristics of exemplary programs in the future. The program for instance: 
- paid careful attention to recruiting and selecting participants (as recommended, for example by Browne-Ferrigno \& Shoho, 2002; Creighton \& Jones, 2001);

- used a cohort based model (as recommended, for example by Barnett, Basom, Yerkes \& Norris, 2000; Hart \& Pounder, 1999; Pounder, Reitzug \& Young, 2002; Somers-Hill, 1995; Teitel, 1997);

- provided participants with a full time apprenticeship (as recommended, for example by Peel, Peel \& Baker, 2002; Pounder, Reitzug \& Young, 2002);

- utilized problem-based learning as a central focus for coursework and training (as recommended, for example by Bridges \& Hallinger, 1992; 1995; Cunningham \& Cordeiro, 2000);

- offered ongoing mentoring and support for the participants (as recommended, for example by NSDC, 2000; Peterson, 2001); and

- ensured close collaboration between a university and school district (as recommended, for example by Grogan \& Roberson, 2002; McCarthy, 1999; Pounder, Reitzug \& Young, 2002).

The DILNS program was specifically designed to meet the needs of a large urban school district in southern California. The program was intended to be grounded in a close collaboration between a local university and the neighboring school district. School district staff and university faculty collaborated on the teaching of some courses. While not completely uncommon, this characteristic is still considered rather unique and is cited as central to the development of school leaders (Grogan \& Roberson, 2002; McCarthy, 1999; Pounder, Reitzug \& Young, 2002). 
Over the last few years programs such as the DILNS have come to be known as "grow your own" principal programs (Peterson, 2001). They have gained increasing popularity and appear to offer great promise in training future school leaders with the specific skills, knowledge and leadership framework to be leaders for their respective school districts. These "grow your own" programs have developed as school districts have sought to gain more control over how their potential school leaders were being trained and to build district wide leadership capacity and develop their own leaders inhouse.

Such programs were designed to take advantage of the leadership talent that exists within respective school districts by designing, training and providing coursework and opportunities that equip individuals with the necessary leadership skills to drive instructional improvement at the site level. Because programs such as the DILNS are specialized and hand-pick their candidates, it was expected that the candidates chosen would have a philosophy of leadership and education that was in alignment with that of the school district. This, in fact, was not the case. The preliminary evaluation data of DILNS showed just the opposite (Hubbard \& Newman, 2002; Newman \& Hubbard, 2003). That is, many of the candidates entered the program with a theory of leadership that was quite different to that of the district. This increased the desirability of selecting the site and cohort for study.

The individuals chosen to participate in this program were hand picked and selected by District officials. All participants were district employees and were singled out because of their leadership potential and strong instructional knowledge. During their first year in the program participants were given a year out of the classroom at full pay to 
become administrative interns. During this time they worked closely with an experienced principal who served as a mentor and coach. In their second year in the program, each participant began his or her new role as an instructional leader (i.e. the principal or vice principal). During this time, participants continued to receive support and mentoring by an experienced principal from the district.

In short, the program that was studied was somewhat unique even when compared to other cutting edge programs that meet the sort of criteria listed above. Participants were immersed in training that was specifically designed to meet the needs of the district and was aligned with the reform agenda in the district (Hubbard, 2004). The training they were engaged in mirrored closely the work that was expected to be done in the district and thus served as a strong socializing factor to the role of principal. In addition, because all members of the cohort were also employees of the district and were expected to assume principalships or vice principalships upon completion of the program, the social networks participants created throughout the program could easily be carried over into the job and serve as an important support structure. The uniqueness of cases (including, presumably, a case like the DILNS program) can be "an asset rather than a liability" (Donmoyer, 1990, p.194).

Data Collection and Analysis

This study utilized three methods of data collection: in depth interviews, observations, and document analysis. The data collection and analysis took place over five phases: Phase 1 was built around a set of initial interviews designed to examine participants' mental models; Phase 2 included interviews intended to reexamine participants' mental models at the end of year one; Phase 3 involved conducting 
observations of participants' practice in the role of school leader; Phase 4 incorporated a third and last round of interviews for the purposes of reexamining participants' mental models at the end of year two; and Phase 5 involved a careful analysis of program documents.

\section{Phase 1: Initial Interviews to Examine Participants' Mental Models}

Each member of the fourteen members of Cohort III had already been interviewed as part of the larger study. These interviews which took place in August of 2002 were conducted at the earliest possible moment upon the interns entering the DILNS in order to gather preliminary data about the candidate's thinking prior to involvement with the program. The data collected from these interviews were utilized in the present study. An interview protocol (Appendix A) was utilized in these interviews to ensure that the same topics and issues were covered in each interview (Patton, 2002). Participants were asked to describe their backgrounds, their level of experiences in education, as well as the various leadership roles they have engaged in both in and outside of education. Participants were also asked to discuss their philosophies of education and leadership as well as what they hoped to learn during their time in the program. In addition, they were asked to identify the characteristics they attribute to being an effective school leader. The interviews served to help establish each participant's baseline mental model and to determine how the DILNS participants' conceptual framework of the principal changed, if at all, as a result of participating in the program. The interviews also served to help understand how the participants' beliefs about leadership and education were formed. Where possible, the data were also utilized to glean what aspects of the program, if any, the interns believed were helpful in 
developing their beliefs regarding school leadership. Each interview lasted about an hour and a half, and was taped and transcribed verbatim.

Data analysis began with an initial coding of these transcripts. The qualitative data analysis process was aided by the use of ATLAS.ti software, a grounded theory program. ATLAS.ti was used to assist in maximizing the efficiency and complexity of coding and analyzing each transcription. Coding of the transcriptions initially began by presorting the data collected in the interviews using the main lines of inquiry designed in the protocol. The coding was not purely inductive and began with more or less defined questions that were grounded in theories of education leadership, principal preparation and educational reform. However, after the initial coding, an inductive coding strategy was employed allowing for the possibility that codes, categories and patterns to emerge organically from the data analysis. The ATLAS.ti software provided an opportunity to further deconstruct and reconstruct data, and offered a powerful and intuitive mechanism to create, merge, rename, reorder and/or remove codes.

The first analysis of the data resulted in the identification of three groups of leadership philosophy for the participants. Upon review by the chair of my committee, I was asked to develop a matrix with the corresponding quotes to illustrate how the models of leadership philosophy were derived. The next stage of analysis thus involved experimenting with translating the initial interview transcripts into a role-ordered matrix as described by Miles and Huberman (1994). This approach was utilized because it provided a different method for analyzing the data. A role ordered-matrix provides a visual strategy to easily compare and contrast the available data. Because this technique begins with a general precoding of the data, the intention was to make the coding process 
and fleshing out of themes more manageable and salient themes more readily comparable. This coding strategy involved listing the participants down one axis and the corresponding coded categories being explored across the top axis. The relevant interview data and quotations that fit into each category were placed under the appropriate category. While role-ordered matrices are most often utilized for group data analysis, I employed this method with each individual as it provided a structured way for summarizing and displaying the desired data. The Atlas.ti program was also used to help define and assist in the development of the role-ordered matrix.

The following coding categories were initially used in the matrix: individual's leadership philosophy; skills and attributes of effective school leaders; participants' educational philosophy; participants' expected change in knowledge base; participants' expected change in skills; participants' rationale for participating in the DILNS, previous leadership experience; and career path. The matrix based analysis helped identify the fact that the categories that were initially created did not accurately fit what emerged from the data. In fact, the matrix helped flesh out the actual philosophies that each participant actually held and provided a much more accurate representation of the data rather than the categories I had seemingly "forced" the data to fit into. Following this matrix based analysis, I created a written profile depicting the participants' initial mental model in narrative form.

Phase 2: Reexamination of Participants' Mental Models at the End of Year One

At the completion of their first year, each participant was once again interviewed to understand the mental model they held regarding school leadership. The interview was audiotaped and transcribed verbatim. This interview was then compared to their initial 
interview to see if there had been a shift in their mental model. The participants were also asked to identify what elements of the program, if any, had an impact on their beliefs. These interviews took place as the participants began their new role as a school leader, as a principal or vice principal. An interview protocol was used once again in a flexible way so that I could investigate issues and topics as they emerged that may not have been accounted for in the protocol design. Special attention was also paid to understanding how the participants currently saw themselves as being effective in their role as school leader as well as how each participant planned to make adjustments in their leadership strategy in order to ensure the academic success of the students at their school site. Questions covered areas that were stressed in the DILNS program and focused on topics such as how they assessed the needs of their school community, how they planned on articulating a vision for their school, how they prioritized their role and their respective responsibilities, how they went about understanding the culture of the school, what expectations they set for the staff, student body and themselves, what challenges they currently faced in their role, how they anticipated meeting these challenges and how they believed they were impacting instruction and student achievement in the classroom. All of these questions were designed to unpack what the participants were taught in the DILNS and how they were actually putting into practice what they have been taught.

I analyzed these transcripts for evidence of: a) what were the participants' current beliefs regarding school leadership; b) whether there was any change from their initial beliefs; c) and if there was a change in beliefs, what components, if any, of the program did they attribute directly or indirectly to this change; d) how participants set out to tackle the job of leading a school; e) how they prioritized their responsibilities; f) how 
participants set out to develop, enhance or impact the culture of the school; g) how participants assessed the success of their interventions and; h) what impact participants believed their leadership had on the school community as a whole.

To categorize and code the substance of their learning, change in beliefs and their work as a school leader I again coded using the Atlas.ti program. At the same time, an inductive coding strategy was utilized allowing for other themes, categories and patterns to emerge. A conceptual framework was once again developed depicting each participant's mental model based on the Phase 2 interview transcript. A role-ordered matrix was once again utilized to help display the results of the coding strategies and to look for patterns that emerged across the various participants. I began the process of linking the patterns and learnings across the interviews and situations to determine whether the categories derived held for member to member. Throughout, I wrote conceptual memos in order to examine ideas, raise questions and record my thinking. Here again, the focus was on attempting to analyze the themes by tying them back into the original research questions while also remaining open to "disconfirming evidence when it appears" (Miles \& Huberman, 1994, p. 216).

Phase 3: Observation of Participants' Practice in the Role of School Leader

At the completion of their first year, it was expected that each participant would be placed in a leadership position within the school district. Each member of Cohort III was observed in their new position. The purpose of these observations was to ground the previous interviews and discussions by comparing and contrasting the manner in which participants took up their respective leadership roles and to determine how their leadership strategies fit or matched with their espoused theory of leadership. Time was 
spent shadowing each individual in order to better understand how they interacted with their staffs, what they articulated to their school community, what actions they prioritized, how they took on the role of school leader, and whether their actions were in congruence with the mental models they previously articulated. Immediately following the observation the participant was once again interviewed. Additional observations were also conducted with the participants so as to not rely on only one interview and one observation for this phase of the data analysis.

As a participant observer, I had the advantage of employing "multiple and overlapping data collection strategies: being fully engaged in experiencing the setting (participation) while at the same time observing and talking with ... [the] participant about whatever is happening" (Patton, 2002, p.265). Direct observation was included because it was the best method to develop an understanding of the events and experiences a school leader engaged in and the words and meanings they ascribed to the situation (Patton 2002). More specifically, the observation was used for consistency purposes to compare participants' espoused theories with their theories in use (Argyris \& Schön, $1974 ; 1978 ; 1996)$.

I conducted each observation and, where possible, audiotaped the discussions I had with the participants as well as took field notes. In keeping with the ethnographic tradition, I kept, whenever possible, a verbatim account of what the participants said and recorded what they actually did. I expanded these notes as soon as possible after the interview by filling in details (Spradley, 1979). The field notes and discussions obtained from the observations were coded for triangulation purposes using a coding schema that focused on determining whether the behaviors observed could be tied back to their 
beliefs. The coding categories were based on the protocol questions and were grounded in the education leadership, principal preparation and educational reform literature. They focused on the extent to which the principal impacted instruction (Instructional impact), the strategies and actions that participants utilized to build relationships at the school site (Relationship building), the extent to which the participant cultivated new leaders on campus (Capacity building), the style of leadership that participants used with their teachers and staff (Leadership style), the strategies the participant employed to challenge him or herself to continually develop as a leader (Professional study), the priorities participants set for her/his role, and the extent to which the principal was aware of undercurrents present in the school and used this information to address current and potential problems (Situational awareness).

\section{Phase 4: Reexamination of Participants' Mental Models at the End of Year Two}

The final phase of interviewing took place at the end of the participants' second year in the program which was also the end of their first year as a school leader. Again, a protocol was used to guide the questioning but greater latitude was built into this interview to explore topics and themes that emerged through the previous interviews and observations. Participants were asked to respond to specific questions and comments that arose from my observations. The goal was to press the participants to connect what they articulated in previous interviews with what I observed in practice and gleaned from analyzing participant and program documents. This line of questioning and the interview itself were used to triangulate what I experienced in the observations with the participants' espoused theories of action. The interviews were audiotaped and transcribed verbatim. Atlas.ti was once again used to categorize and code the responses. 
Phase 5: Document Collection and Analysis

Critical documents were also collected whenever they were available. Specifically, each participant's application, letter of intent, culminating portfolio and platform statement, which each participant developed during their time in the program to describe their beliefs about the principalship, were analyzed as another means of triangulation. The application as well as the letter of intent offered insight into the beliefs participants espoused about their leadership and education philosophy and the role of the principalship prior to their entering the program. The platform statement served as a means to compare their original beliefs regarding school leadership to what they espoused in each interview. Documents that detailed the program's coursework and expected outcomes were also collected for analysis. All documents that were collected were coded, analyzed and used for triangulation purposes. The use of documents helped link themes that were exposed from the interviews and observations. Documents were also used to cross check the interview and observational data.

Researcher's Role

I initially took on the role of full participant observer. This strategy, "simultaneously combines document analysis, interviewing of respondents and informants, direct participation and observation" (Denzin, 1978, p.183; see also Patton, 2002). As the co-instructor of the first course participants took in the DILNS program, I was continuously engaged with the individuals selected for this study. As a result, I was able to gain first hand knowledge and observe the individuals' ways of thinking and their work habits. The nature of my role for the remainder of the study, and the larger study 
changed to that of interviewer. I interviewed each participant in order to derive a contextual view of his/her encounters and interactions across the period of this study.

While my role in relation to the participants changed over the course of the study from participant observer to interviewer, I recognized that my initial role as co-instructor added complexity to the relationship, as well as possible bias on my part. I openly acknowledge this concern. Yet, my initial role as instructor/participant observer had both strengths and weaknesses. It was a strength in that I was able to gain first hand intimate knowledge of the participants' beliefs and their goals for the program, and a weakness in that "personal involvement introduces selective perception" (Patton, 2002, p.329). Thus "the nature of the data collected will, to some extent, be dependent on the role and perspective of the observer. And just as the presence of the observer can affect people observed, so too the observer can be affected" (Patton, 2002, p .329).

To minimize bias, I took several steps in the course to limit my role with these participants. Because the course was comprised of two groups, DILNS participants and math and literacy administrators, I took responsibility for reading and grading only the math and literacy administrators while the other instructor took responsibility for the DILNS students. This differentiation, as well as my role as one of the evaluators of the program, was made clear at the first class meeting. While every attempt was made to minimize bias, as Brody (1992) states:

Since the naturalistic investigator is him- or herself the research "instrument," naturalistic inquiry cannot avoid observer bias by using the instrument to insulate the experiment from the preconceptions of the investigator. Instead, open disclosure of preconceptions and assumptions that may have influenced data 
gathering and processing becomes an inherent part of the conduct of the inquiry. (p. 179).

My role as an observer began following the participants' successful completion of the Tier I administrative credential when they were placed either in the position of vice principal, principal or in one case a literacy administrator. Upon each participant's placement, I observed each individual in their new role. As stated earlier, the use of interviews, observations and document collection and analysis helped attend to any potential problems of validity. That is, hypotheses derived from the interviews were checked against data collected through observations and cross checked with a careful analysis of documents. To ensure that the codes, analysis and subsequent findings were credible, peer debriefing was utilized (Guba \& Lincoln, 1989). In addition to having the Principal Investigator from the larger study read transcripts and discuss whether the codes chosen were reasonable, an 'outsider' who is not intimately involved with the study was also asked to read three transcripts and determine whether the codes being utilized were reasonable. As Lincoln and Guba (1985) state, peer debriefing is "a process of exposing oneself to a disinterested peer in a manner paralleling an analytic session and for the purpose of exploring aspects of the inquiry that might otherwise remain only implicit within the inquirers mind" (p.308). These repeated and extended discussions around the codes employed and the emerging analysis served as means of ensuring internal validity.

Significance of the Study

This study has potential implications for the field of principal preparation. As for the domain of research aimed at enhancing the training and preparation of aspiring principals, this study offers insight into how one program can effect a change in the belief 
systems of its participants, and more importantly, understand whether a program can effectively teach a specific theory of leadership to its participants. For the practice of administrators, this study offers a chance to understand the complexities and difficulties that occur when an individual's beliefs are challenged by new ways of thinking. The knowledge gained through researching the interplay between beliefs and how one principal preparation program, the DILNS, impacted individual's preconceived notions and beliefs regarding the role of the principal will also serve as a first step to aid and support the growth and future development of school leaders.

While the results of this study are not directly generalizable, in a traditional scientific sense, the data collected from this study will be available to those who design, evaluate and implement principal preparation programs. In many ways, this program is highly representative of the best ideas in the field and thus holds promise for what programs of the future may look like. As Pounder, Reitzug \& Young (2002) suggest, the “core" elements essential to developing educational leaders with the knowledge, skills and dispositions necessary to drive school improvement must include training in which a close collaboration between the university and district exists, a focus on carefully selecting applicants who work in cohorts and serve as apprentices gaining hands-on field knowledge, and the coursework must also be integrated with these field experiences.

Without these essential "core" elements Pounder et al. (2002) argue that principal preparation programs will continue to function as "silos" rather than move towards a more holistic preparation of school leaders. In other words, programs need to be more intentional about ensuring that the training they provide actually meets the needs of the students and prepares them with the necessary skills to be a successful school leader. The 
significance of this fact should not be underestimated, especially in light of the fact that the program under study, the DILNS, was designed specifically to connect the training of its students directly to a particular theory of instructional leadership that is linked openly to the goals and reform initiatives of a large urban school district in southern California. The ultimate goal of this training was to ensure that the participants would become successful change agents as instructional leaders in the district.

The aspiring principals, in fact, were being asked to do something new. They were expected to develop a theory of leadership that coincided with a district model of leadership and were expected to take up the role of the principal in sharply contrasting ways to how the role has historically been conceived. That is, they were expected to be change agents in the district by developing a deep understanding and knowledge of instruction and, most importantly, developing the understanding and skills needed to effectively lead and teach adults at their sites about instruction. The knowledge generated by responding to the challenge of studying how aspiring principals develop the capacity to think and act, how they give meaning to situations, how they develop beliefs regarding the role of instructional leader and how these beliefs contrast with their actions helps us to further understand how school leaders can effectively be trained to adapt to the complex school contexts in which they will work.

\section{Limitations of the Study}

There are several limitations to the study I wish to acknowledge. First, my involvement with the Developing Instructional Leaders for New Schools as both an outside data collector and evaluator of the program and as an instructor for a school management course in which participants of this study were students undoubtedly gives 
rise to certain concerns around confidentiality as well as issues of objectivity. Because of the power differential that initially existed between the participants and me, respondents may not have been as forthcoming and open with their answers in the interview as they might have been had this relationship not previously existed. To some extent these concerns were offset by the fact that my role was initially distinguished and demarcated at the first meeting of the class in which I co-taught the members of Cohort III. I realize that the impact of the researcher on a study is never fully understood. I did, however, take every step to ensure the trustworthiness of the data collected and to ensure answers would be kept confidential.

Another limitation which I would like to acknowledge is the examination of participants' ability to affect practice in the various roles they took on as school leaders. As stated earlier, participants were expected to become school leaders upon completion of their first year in the program, most likely as a principal or vice principal. Because of the widely disparate functions inherent in these two roles, it was necessary to differentiate the expectations for impacting instruction in the classroom between the roles. Vice principals are often relegated to directing and managing the operational functions of the school and as a result are not always intimately involved in impacting instruction. So, while those taking up the role of vice principal may have previously stated their philosophy of leadership and a vision for a school they had hoped to lead, they did not all have the ability to realize that vision. Depending on how these individuals engaged in the role of vice principal, I differentiated the data analysis in a manner that articulated the participants impediment to fully realizing their leadership philosophy and vision. 
Lastly, it is important to acknowledge three events that influenced both the participant pool and the particular program components that were studied. First, one participant became so seriously ill that he not only took a medical leave at the end of the first year but also could not participate in the second interview that would have occurred at the year's end. Because of this participant's unavailability, there was no opportunity to assess the impact the program had on him by the time he was forced to drop out.

Consequently, he was not included in the study.

A second person also left the district - and, in fact, the education field-after the first year. A member of his family became gravely ill and he moved away to care for this family member. He was included in the study because two interviews were conducted with him before he exited and, consequently, there were data to address the question about programmatic impact on this person's thinking. Obviously, this person was not included in the implementation and practice components of the study.

Lastly, all participants were expected to complete two years of the program. During the first year, participants were engaged in a full-time internship and coursework that was co-developed and often co-taught by university faculty and district administrators. The second year was structured around more advanced coursework taught by either district personnel, university faculty, or a university/district team of instructors. In addition, a mentor was provided to each individual to support his or her work as a new school administrator. Because flexibility was built into the second year of the program by providing participants the option of extending their coursework over a two year period, many participants ( 9 of the 13) chose to delay their second year of work and devote their 
attention to their new roles as school administrators. As a result, this study's findings relate primarily, but not solely, to the impact of the first year of the program on participants. 


\section{CHAPTER IV \\ FINDINGS, PART I: SHIFTING BELIEFS}

The overarching purpose of this chapter is to assess what impact, if any, the Developing Instructional Leaders for New Schools (DILNS) program had on the thirteen individuals who participated in the program. To do so, this chapter begins with an analysis of the beliefs regarding leadership that cohort members held at the start of the program. Then, the chapter presents an analysis of cohort members' beliefs at the end of their first year of training and compares and contrasts them to the beliefs participants espoused upon entering the program.

Participants' Leadership Philosophies Upon Entering DILNS: Three Groups Emerge The leadership philosophies of the DILNS participants at the outset of the program fell into three groups: 1) the Collaborators - those who felt the role of the principal was to share decision making, build a collaborative community of learners and to work with and provide support to school staff; 2) the Vision Setters-those who believed that it was the principal's responsibility to set the direction and tone for the school by developing the school's vision and strategically engaging staff to carry out the mission; and, lastly, 3) the Keeper-the person who believed that the principal was not a change agent, but rather a keeper of the status quo whose goal was to be a link between the district (and district mandates) and the school by engaging with staff primarily in small group settings. 
Table 4.1: Leadership Dimensions of the Collaborators, Vision Setters and the Keeper

Group

Collaborators

Vision Setters

Keeper
Leadership Dimension

Developing a shared vision for the school Creating a professional learning community Supporting and working with school staff

Setting the vision and direction for the school Using communication strategically to engage staff Modeling and setting the example

Maintaining the status quo - not a change agent Linking the mandates of the district to the school site

Engaging staff individually or in small group meetings

\section{The Collaborators}

Six of the 13 DILNS members were classified as Collaborators. Five of them were female and one was male. They ranged in age from 34 to 55 years old. The average age was 49 years and the median was 50 years. In addition, the six Collaborators had a range of classroom teaching experience from a low of seven to a high of 26 years. The average time spent in the classroom as a teacher was 17 years and the median was 17.5 years.

The Collaborators tended to be the older members of DILNS. On average, they were approximately five years older than other members of the cohort. They also had approximately two and a half years more teaching experience than the average cohort member. 
Table 4.2: Collaborators' Demographics

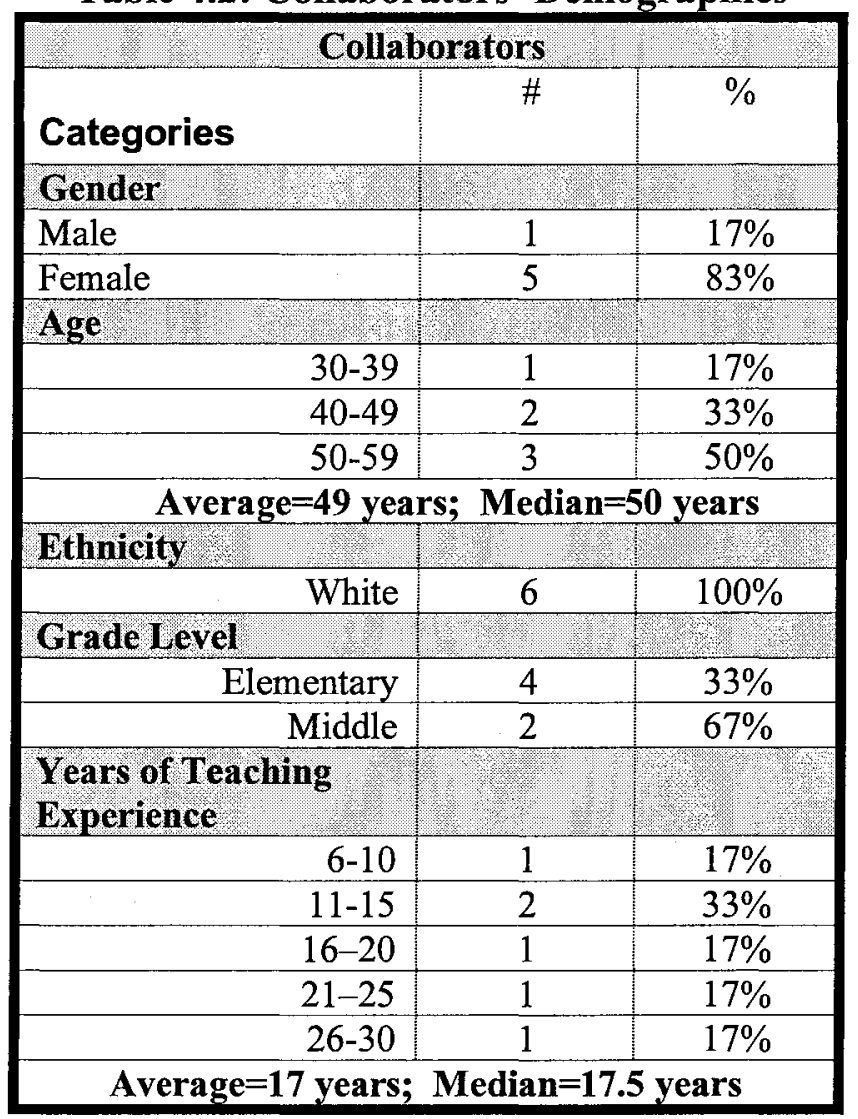

As their name implies, the sentiments of this group are best captured by the concept that leadership is about collaboration. They believed that school leaders must collaboratively engage school staff in the decision making and planning process if they are to be successful in turning around a school and improving student achievement. The Collaborators' strong belief in collaboration is illustrated by the following quote from Kate, one of the six cohort members that make up the collaborator group:

It is important to share control of the school and decision making. If people buy into something, you go a lot further. That's what's so important at the school site, that it's a collaborative community effort because you get all the teachers to buy 
into a certain type of learning, a certain format or learning or certain discipline plan or vision and a school will move a lot faster. Just like in the classroom, you have the students develop classroom rules and you get all the kids to buy into the rules. The kids are feeling like they are developing and improving the class and are part of the class, then they are going to buy in.

At the core of the Collaborators' beliefs regarding collaborative leadership were three major functions that were believed to be indispensable for being an effective instructional leader: developing a shared vision for the school; creating a professional learning community; and supporting and working along side staff to improve practice.

Developing a shared vision. One of the key dimensions articulated by those participants who are considered Collaborators was the fundamental belief that the principal should work in partnership with staff to craft the school's vision. Collaborators believed that working with staff to develop the school's vision will create a greater sense of ownership over the work that will be undertaken and more motivation, direction, and focus among staff members. Danna, for example, emphasized that "a successful vision inherently requires that all stakeholders promote it or it will not be achieved" and Mia emphasized that such buy-in means that "a vision should not just belong to the principal." This sort of thinking was characteristic of all six Collaborators as Table 4.3 illustrates. 
Table 4.3: Collaborators' Beliefs on Developing a Shared Vision

\begin{tabular}{|l|l|}
\hline Kate & $\begin{array}{l}\text { It is important to share control of the school and decision making. If people buy into } \\
\text { something, you go a lot further. That's what's so important at the school site, that it's a } \\
\text { collaborative community effort because if you get all the teachers to buy into a ... vision a } \\
\text { school will move a lot faster. }\end{array}$ \\
\hline Nidia & $\begin{array}{l}\text { To be effective, the principal needs to be able to bring the school community together to } \\
\text { share the responsibility for decisions, to work together to develop the school's vision and } \\
\text { goals. }\end{array}$ \\
\hline Danna & $\begin{array}{l}\text { A successful vision inherently requires that all stakeholders promote it or it will not be } \\
\text { achieved. These stakeholders will not cultivate the vision unless they help construct it. }\end{array}$ \\
\hline Mia & A vision should not just belong to the principal. \\
\hline Robert & $\begin{array}{l}\text { The fact is that you [as a principal] are there truly with a vision of how kids learn and that } \\
\text { you are able to get people around the table to help create the vision and have them become } \\
\text { invested and part of deciding the vision. }\end{array}$ \\
\hline & $\begin{array}{l}\text { The principal needs to be able to work with staff and collaborate with them on developing the } \\
\text { school's vision. }\end{array}$ \\
\hline
\end{tabular}

While all six cohort members who have been classified as Collaborators expressed a commitment to having the principal creating a school's vision collaboratively with staff members, Robert, a Collaborator with 20 years of teaching experience, did seem to have a somewhat more layered approach to involving staff members in creating a school's vision than the other five Collaborators had. In fact, he was the only Collaborator to emphasize the importance of the principal first developing his or her own vision and general direction for the school before working collaboratively with staff members on "the vision thing." At one point, for example, Robert said the following: The fact is that you [as a principal] are there truly with a vision of how kids learn, and that you are able to get people around the table to help create the vision and have them become invested and part of deciding the vision.

This and similar statements are somewhat difficult to interpret. It is possible that Robert believed in a form of collaboration that was little more than procedural display, i.e. collaboration that was no more than the staff becoming committed to his predetermined vision. It is also conceivable that Robert simply believed the principal 
needed to provide a direction for the school until a somewhat different shared vision was developed. Since he also identified the importance of the principal eventually serving as a facilitator of conversations that lead up to the development of a vision, presumably the second interpretation is more accurate. Indeed, he stated at another point:

The fact is that I don't want to be the one saying, "I think we need to do this." I can lead that conversation [around the vision] so that somebody in that group will say, "You know, I think it's possible for us to do that," and then supporting that.

So I think that it's not just sort of here I am, I'm changing everything, but, rather, let's look at this as a group.

Creating a professional learning community. A second key dimension articulated by each of the Collaborators was the belief that principals, teachers and school staff must collaboratively and continuously work together to promote learning and improve instructional skills and knowledge. Four of the six Collaborators specifically used either the term learning community or community of learners to describe the informal and formal structures created at the school site that engage staff in sharing skills and knowledge. While the other two members of the collaborators did not specifically use either of the terms, as Table 4.4 illustrates, they did describe the concept of a learning community or community of learners in similar terms as the others. Robert, who used the term learning community frequently, defined the concept the following way: "A learning community is a group of people getting together with a goal in mind and supporting each other. That it's not going to be one that just sort of is didactic, but the fact is that dynamic conversation takes place." 
Table 4.4: Collaborators' Beliefs on Developing a Learning Community

\begin{tabular}{|l|l|}
\hline Kate & $\begin{array}{l}\text { A school needs to function like a family so that all teachers are supporting } \\
\text { each other [and] that all teachers are there for the children [and] that a } \\
\text { teacher doesn't belong just in the front row of that classroom and that their } \\
\text { only concerns are those kids in that class. They have to expand their } \\
\text { concerns about the whole school, about their grade level, from their } \\
\text { classroom to grade level to the whole site. }\end{array}$ \\
\hline Nidia & $\begin{array}{l}\text { Effective administrators must foster a supportive environment so that } \\
\text { teachers are willing to take risks to improve their practice. Building a } \\
\text { community of learners is the responsibility of the principal, the leader of the } \\
\text { school. }\end{array}$ \\
\hline Manna & $\begin{array}{l}\text { Collaboration needs to occur so that teachers are encouraged to work } \\
\text { together at and across grade levels to identify strengths and weaknesses in } \\
\text { instruction. }\end{array}$ \\
\hline Robert & $\begin{array}{l}\text { In order to develop a true community of learners, teachers must have } \\
\text { opportunities to plan together, reflect together, read professional materials, } \\
\text { discuss them and then apply their learning. This constitutes a very powerful } \\
\text { way to not only respect teacher differences, but build leaders within a site to } \\
\text { support student achievement. As a leader I hope to make sure that teachers } \\
\text { have the time to help one another develop professionally and to be part of } \\
\text { that development. }\end{array}$ \\
$\begin{array}{l}\text { Well to me a learning community is a group of people getting together with } \\
\text { the goal in mind of supporting each other. That it's not going to be one that } \\
\text { just sort of is didactic, but the fact is that dynamic conversation takes place. }\end{array}$ \\
$\begin{array}{l}\text { It is your job as an effective school leader to create a dynamic learning } \\
\text { community where staff have many opportunities to learn together ... and to } \\
\text { create an atmosphere where risk taking is encouraged and teachers feel } \\
\text { supported. }\end{array}$ \\
$\begin{array}{l}\text { I think a leader needs to create a community of learners where teachers can } \\
\text { share their thoughts and strategies in a safe way and as a result others can } \\
\text { benefit. It is not just me determining what to learn. }\end{array}$ \\
\hline Cathy
\end{tabular}

While Robert's definition of a learning community could have been expressed by any of the other cohort members, there were some subtle differences between the roles the participants believed the principal should play in developing the learning community. Mia and Danna, for example, believed that the principal served a rather informal role in the learning community by primarily creating the time and space for staff to meet and "encouraging" them to work together; they did not envision the principal being intimately 
involved in helping determine what staff studied or which skills they should work on improving. Thus, Danna stated that a learning community develops when "teachers are encouraged to work together at and across grade levels to identify strengths and weaknesses in instruction," and Mia also put the emphasis on the teacher:

In order to develop a true community of learners, teachers must have opportunities to plan together, reflect together, read professional materials, discuss them and then apply their learning. This constitutes a very powerful way to not only respect teacher differences, but build leaders within a site to support student achievement. As a leader, I hope to make sure that teachers have the time to help one another develop professionally and to be part of that development. Other participants, such as Nidia and Robert, believed that the principal needed to take a more activist and engaged approach in developing and shaping the learning community. They, in fact, believed it was the principal's "responsibility" to develop and "create" the learning community. Nidia specifically stated that "building a community of learners is the responsibility of the principal, the leader of the school" and Robert expressed a similar belief when he said the following: "It is your [i.e., the principal's] job as an effective school leader to create a dynamic learning community where staff have many opportunities to learn together."

Of course, Robert's and Nidia's comments could be interpreted to mean that the principal simply had the responsibility to create a learning community by carving time out of the day for staff to work together as Mia and Danna suggested. Robert's and Nidia's other statements, however, clearly indicate that they viewed the principal's role differently than Mia and Danna did. Robert, for instance, specifically mentioned the need 
for the principal to provide guidance and help teachers "focus on what is important to know and learn in addition to what they feel they need," while also keeping in mind that the goal is " to create an atmosphere where risk taking is encouraged and teachers feel supported." Nidia also discussed working with teachers to help them develop "goals" to work on and ensuring that whatever they work on "brings about change and is implemented in the classroom."

Supporting and working with school staff. Another aspect of the model of leadership espoused by the Collaborators at the start of the program was the belief that principals must support teachers and collaboratively work with them in the classroom to help them improve their practice. Inherent in the idea of providing support to school staff is the belief that the principal can be a source of support by modeling effective instruction in the classroom and serving as a coach for staff. As Nidia stated, "An excellent leader needs to be willing to model ongoing professional development so they're [principals] not just on the outside organizing the school, but they know what's going on in the classroom because that's what this is all about."

Table 4.5: Collaborators' Beliefs on Supporting and Working with School Staff

\begin{tabular}{|l|l|}
\hline Kate & $\begin{array}{l}\text { A great leader is one that will never ask their workers to do something that they wouldn't } \\
\text { do or don't do. The principal's value and mission is student achievement-that means } \\
\text { that person has to be in the classroom and it's also a person that is assisting and } \\
\text { encouraging new approaches to education because you want to make everyone feel like } \\
\text { they've got something to offer and learn no matter how long they've been in the field. } \\
\text { Value the teachers, promote their growth, honor those old approaches while encouraging } \\
\text { new approaches and promote collaboration. }\end{array}$ \\
\hline Nidia & $\begin{array}{l}\text { Learning is lifelong. Without ongoing learning, principals would be on automatic pilot. } \\
\text { School leaders and teachers alike need to be learners. An excellent leader needs to be } \\
\text { willing to model ongoing professional development. }\end{array}$ \\
\hline Danna & $\begin{array}{l}\text { I lead by example and I think I lead by if I ask teachers to do something then I need to } \\
\text { also show them that I'm willing to take it on. If there is an area someone needs to work } \\
\text { on, I would be happy to work on it with them so that they know that I will learn } \\
\text { alongside them. You can have all the knowledge in the world but if you can't give it to } \\
\text { other people, what good is it. }\end{array}$ \\
\hline
\end{tabular}


Table 4.5 Continued

\begin{tabular}{|c|c|}
\hline Mia & $\begin{array}{l}\text { An effective school leader must know that good teachers want good leaders. They } \\
\text { [teachers] want to know that the person responsible for their school understands what } \\
\text { they do on a day to day basis. They want to rely upon that person to support them in } \\
\text { their efforts to educate and challenge students. They want to know that they will be } \\
\text { recognized for their knowledge, their willingness to continue learning and their } \\
\text { determination to work for the common good of their school communities. } \\
\text { I believe all people learn by example. It seems only logical to extend and express what I } \\
\text { value about teaching and learning, by showing and doing as well as expressing so that } \\
\text { others in the school community may begin to understand it and work with me to help the } \\
\text { school. If I provide a consistent model, the teachers will be encouraged to provide the } \\
\text { same for their students. }\end{array}$ \\
\hline Robert & $\begin{array}{l}\text { I don't want to go and ask them [teachers] to do something without giving them really a } \\
\text { lot of support. I don't want them to go in [the classroom] and feel I'm going to make a } \\
\text { fool of myself so I'll make sure that I go in there and spend a couple of hours a day } \\
\text { supporting teachers. }\end{array}$ \\
\hline Cathy & $\begin{array}{l}\text { As a principal you have an opportunity to help teacher's grow, nudging them, giving } \\
\text { them more of a push because it is all about kids. The principal can try to make changes, } \\
\text { maybe one on one, whatever the teacher needs. An excellent leader needs to be willing } \\
\text { to model ongoing professional development so they're [principals] not just on the } \\
\text { outside organizing the school but they know what's going on in the classroom because } \\
\text { that's what this is all about and I think in the past, principals from the past managed the } \\
\text { schools from the outside. }\end{array}$ \\
\hline
\end{tabular}

As Table 4.5 demonstrates, the other five cohort members also emphasized the importance of working with teachers in their classrooms to improve instruction. Kate, for instance, mentioned the importance of the principal being "in the classroom ... assisting and encouraging new approaches to education" and Robert discussed going into classrooms and spending "a couple of hours a day supporting teachers."

While all six of the Collaborators believed that the principal needed to support teachers and help them improve their instructional practice, only three of the Collaborators specifically emphasized the importance of valuing the knowledge and skills of staff and recognizing their strengths as well as their weaknesses. Kate, for instance, overtly discussed the need for principals to "value" and acknowledge all staff for the 
skills they possess while also seeking to help each teacher improve. According to Kate, it is important for the principal to "value the teachers, promote their growth, honor those old approaches while encouraging new approaches and promote collaboration." Mia also discussed the importance of teachers being "recognized for their knowledge, their willingness to continue learning and their determination to work for the common good of their school communities." Finally, Robert also was explicit in acknowledging that the principal needed to take into consideration the skill level a teacher had, what they were capable of learning and their ability to handle new challenges. He believed that the principal needed to provide adequate scaffolding and support for teachers as they learn new skills and knowledge so they don't "go in [their classrooms] and feel... [they're] going to make a fool of [themselves]."

While only three Collaborators explicitly mentioned the importance of valuing or acknowledging the strengths and weaknesses of staff, it was reasonable to assume that the other Collaborators were at least sympathetic with this sort of thinking given their discussions of the need to "walk the talk" and implement teaching strategies themselves (in demonstration lessons) that teachers were being asked to implement. For instance, Nidia stated the belief that "if I ask teachers to do something, then I need to also show them that I'm willing to take it on."

The emphasis in Nidia's comments, and throughout all Collaborator's discussions of the need for the principal to support and work with staff in their classrooms, is on the principal and teachers being partners in learning how to improve instruction and increase student learning. The other subgroup of cohort members which will be described below also believed in the principal working in the classroom. The difference, however, is that 
the Collaborators, true to their name, believed in working alongside teachers to solve classroom problems; they were not afraid to display vulnerability or the fact that they did not have all the answers and had not already mastered all instructional techniques. Indeed, as Nidia explicitly pointed out, from the Collaborator's perspective, principals needed to model ongoing learning so that teachers will be more likely to take risks and try new strategies, as well. As Nidia stated, "An excellent leader needs to be willing to model ongoing professional development ... and foster a supportive environment so that teachers are willing to take risks to improve their practice."

\section{The Vision Setters}

The Vision Setters, like the Collaborators, were comprised of six members at the start of the cohort experience in the program. There were five females and one male. They ranged in age from 30 to 56 years old, with the average and median age both being 41.5 years. The Vision Setters, however, had a larger variation in the range of their members' teaching experience than did the Collaborators. The range of teaching experience for the Vision Setters was 28 years, with one member having only four years of teaching experience and another member having 32 years of classroom experience. In contrast, the Collaborators had a range of 19 years with the least experienced member having seven years of experience and the most experienced member having 26 years. 
Table 4.6: Vision Setters' Demographics

\begin{tabular}{|l|c|c|}
\hline \multicolumn{2}{|c|}{ Vision Setters } \\
\hline Categories & $\#$ & $\%$ \\
\hline Gender & & \\
\hline Male & 1 & $17 \%$ \\
\hline Female & 5 & $83 \%$ \\
\hline Age & 3 & $17 \%$ \\
\hline $30-39$ & 2 & $33 \%$ \\
\hline $40-49$ & 1 & $50 \%$ \\
\hline $50-59$ & & \\
\hline \multicolumn{1}{|c|}{ Average=41 .5 years; Median=41.5 years } \\
\hline Ethnicity & 5 & $83 \%$ \\
\hline White & 1 & $17 \%$ \\
\hline Latino & & \\
\hline Grade Level & 5 & $33 \%$ \\
\hline Elementary & 1 & $67 \%$ \\
\hline Middle & \\
\hline Years of Teaching Experience & \\
\hline $6-10$ & 4 & $67 \%$ \\
\hline $11-15$ & 0 & $0 \%$ \\
\hline $16-20$ & 0 & $0 \%$ \\
\hline $21-25$ & 0 & $0 \%$ \\
\hline $26-30$ & 2 & $33 \%$ \\
\hline \multicolumn{2}{|c|}{ Average=14 years; Median=8.5 years } \\
\hline \multicolumn{2}{|c|}{} \\
\hline
\end{tabular}

In contrast to the Collaborators, Vision Setters had a more hierarchical and bureaucratic conception of the role of the principal. As the name suggests, the Vision Setters believed that developing the vision and setting the course for the school was the sole responsibility of the principal. Teachers and school staff were considered important for carrying out the vision of the school, but the big picture mapping, according to the Vision Setters, was the responsibility of the principal. At the core of the Vision Setters beliefs regarding leadership were three major functions the principal needed to engage in to be successful: setting the vision and direction for the school; strategically using 
communications to convince the school staff to embrace the school vision; and setting the example by modeling best practices for staff.

Setting the vision for the school and charting the course. Like the Collaborators, the Vision Setters emphasized the importance of creating a school vision. They, however, envisioned developing the vision in a very different manner than the Collaborators. Rather than collaborating with teachers and school staff to develop the vision, as the Collaborators suggested, Vision Setters believed that the principal needed to independently develop the vision for the school. Emma, for example, emphasized that, "ultimately, it comes down to you [as the principal] making the tough decision and deciding the direction of the school. You must possess a vision and mission about what you want to accomplish." Sierra believed that "the leader clearly sets the tone for the school. He or she must look toward the horizon and create a vision of where the school is going," Similarly, Joy discussed the need for the principal to "set the tone at the school site" and to use the vision as "the foundation for all decisions." Comments by the other Vision Setters about the principal's role in vision setting are included in Table 4.7.

Table 4.7: Vision Setters' Beliefs on Setting the Vision for School

\begin{tabular}{|l|l|}
\hline Liam & $\begin{array}{l}\text { What you are really trying to do is put your vision out or the vision you } \\
\text { have for the school for improving student achievement, putting your } \\
\text { vision out and you stand as the benchmark and get everyone to buy into } \\
\text { what you see as the direction for the school. } \\
\text { The teachers need to carry it [the vision] out and it is my job to get them } \\
\text { to do it. }\end{array}$ \\
\hline Sierra & $\begin{array}{l}\text { The leader clearly sets the tone for the school. He or she must look toward } \\
\text { the horizon and create a vision of where the school is going. }\end{array}$ \\
\hline Emma & $\begin{array}{l}\text { Ultimately, it comes down to you [as the principal] making the tough } \\
\text { decision and deciding the direction of the school. You must possess a } \\
\text { vision and mission about what you want to accomplish. It is through your } \\
\text { vision and mission statement that a leader is able to attract others to help } \\
\text { attain the ideas and goals found in the mission. }\end{array}$ \\
\hline
\end{tabular}


Table 4.7 Continued

\begin{tabular}{|l|l|}
\hline Elena & $\begin{array}{l}\text { An effective leader must be a change agent and have the knowledge, } \\
\text { vision and courage to get a commitment from others who may not like } \\
\text { one's ideas. I think you have to have a good vision and that vision is based } \\
\text { on what you see the kids need to learn. It's looking at your teachers. It's } \\
\text { being able to look at all of those things and know where you need to go ... } \\
\text { So you need to have a strong vision for the school. }\end{array}$ \\
\hline Joy & $\begin{array}{l}\text { The school vision serves as the foundation for all decisions. I do believe } \\
\text { that one of the main responsibilities [of the principal] is ... to set the tone } \\
\text { at the school site. }\end{array}$ \\
\hline Louise & $\begin{array}{l}\text { They [teachers] are what make what I [as a principal] see and believe } \\
\text { work so I need them to buy into things. They may not always see the way } \\
\text { it's going to be but at least they need to really understand my vision and } \\
\text { then they can carry it out. }\end{array}$ \\
\hline
\end{tabular}

While the Vision Setters didn't believe staff should be part of the process to develop the school's vision, several of the Vision Setters discussed the importance of getting staff to "buy into" the vision. Liam, for example, who had less than five years of teaching experience when he entered the DILNS program, emphasized the importance of getting "everyone to buy into what you [the principal] see as the direction for the school." Louise also discussed the importance of getting staff to "buy into" the vision, while Elena discussed getting "a commitment from others" to carry out the vision. The difference between the Vision Setters and the Collaborators on the buy-in issue is that Vision Setters did not share the Collaborators' assumption that staff participation in the vision construction process was a prerequisite for staff buy-in. Liam, for example, emphasized that the principal must be willing to "stand firm in his or her belief regarding the vision even if the vision being articulated to the staff is not popular." He also stated that "teachers need to carry it [the vision] out and it is my job [as the principal] to get them to do it." In like manner, Elena discussed the importance of the principal having the "courage to get a commitment from others who may not like one's ideas" to carry out the vision. 
Emma, however, had a somewhat more tempered view of the relationship between the principal's vision and the school staff. She believed that a vision could serve as a bridge between staff and the principal and attract people to the mission embedded in the principal's vision. To use her words: "It is through your [i.e., the principal's] vision and mission statement that a leader is able to attract others to help attain the ideas and goals found in the mission." Like all of the other Vision Setters, however, Emma emphasized what all the other Vision Setters emphasized: "You [i.e. the principal] must possess a vision and mission about what you want to accomplish."

Using communication strategically to engage staff. The second key dimension of the model of leadership espoused by the Vision Setters at the start of the program was the belief that a principal needs to strategically use communications as a lever for building staff support for the school's vision. Communication was seen by the Vision Setters as an especially important strategy for getting the school community, especially teachers, to "buy into" the vision since no one other than the principal was engaged in creating the school's vision. As Joy stated, "The goal of empowering and respecting teachers requires particular sensitivity and communication in a community where teachers feel they were not part of the vision making process that mandated how and what they should teach." Vision Setters' beliefs about the importance of communication are expressed in Table 4.8.

Table 4.8: Vision Setters' Beliefs on Strategically Using Communication to Engage Staff \begin{tabular}{|l|l|}
\hline Liam & $\begin{array}{l}\text { The community involves not only the school employees, the office } \\
\text { staff, the teachers, [but others] throughout the larger community and } \\
\text { I'd say your communication with all these groups--you are } \\
\text { balancing, you know, you're balancing people just like any } \\
\text { business, you know, different needs, wants, prior knowledge. [You } \\
\text { are always] Balancing them and trying to engage them and get them } \\
\text { to buy into the work of the school. }\end{array}$ \\
\hline
\end{tabular} 
Table 4.8 Continued

\begin{tabular}{|l|l|}
\hline Sierra & $\begin{array}{l}\text { A large part of a leader's responsibility lies in communicating to the } \\
\text { learning community with a passionate and motivated voice during } \\
\text { staff development and individual conferences. Communication must } \\
\text { be honest and direct in regard to both strong and weak instructional } \\
\text { practice. Communication is absolutely essential for the principal to } \\
\text { keep people focused on the vision and get buy in a little at a time. }\end{array}$ \\
\hline Emma & $\begin{array}{l}\text { A school leader has to be able to communicate [the vision] really } \\
\text { well and that's not just with the teachers but with the parents and } \\
\text { with your community. }\end{array}$ \\
\hline Elena & $\begin{array}{l}\text { An effective leader must communicate effectively and include all } \\
\text { stakeholders - students, parents, teachers and others - so that } \\
\text { everyone will be reminded of what the school's vision and mission } \\
\text { for achievement are. Teachers especially need to be reminded and } \\
\text { the more they hear the message the more they might buy in. }\end{array}$ \\
\hline Joy & $\begin{array}{l}\text { The goal of empowering and respecting teachers requires particular } \\
\text { sensitivity and communication in a community where teachers feel } \\
\text { they were not part of the vision making process that mandated how } \\
\text { and what they should teach. }\end{array}$ \\
\hline $\begin{array}{l}\text { An effective leader must also be able to efficiently communicate } \\
\text { with their colleagues on many levels and in a variety of situations. }\end{array}$ \\
$\begin{array}{l}\text { You can move mountains in just the way you ask people to do } \\
\text { things or people to think about things. I want them to see my } \\
\text { passion for education and internalize it and say, "Wow, she really } \\
\text { feels strong about his, maybe I should give it a whirl." I want to } \\
\text { create the desire in them. }\end{array}$ \\
\hline
\end{tabular}

Three of the Vision Setters, in particular, mentioned using communications as a means to get staff to "buy into" the principal's vision. Elena, for example, believed that "an effective leader must communicate effectively" to ensure "that everyone [teachers and the school community] will be reminded of what the school's vision and mission for achievement are." Elena went on to point out that a communication strategy was essential for a principal because "teachers especially need to be reminded [of the vision] and the more they hear the message the more they might buy in." Sierra also emphasized that "communication [was] absolutely essential for the principal to keep people focused on 
the vision and get buy in a little at a time" and Liam discussed using communication in an effort "to engage them [teachers] and get them to buy into the work of the school."

While Elena, Sierra and Liam discussed using communication as a means to get staff to "buy into" the vision, Louise, who comes from a family of educators and had been teaching for only four years upon entering the DILNS program, believed that powerful communication could also get staff to change their beliefs and outlook on teaching. As she stated, "You can move mountains in just the way you ask people to do things or people to think about things." Therefore, a principal, to be effective, needs to be "able to efficiently communicate with their colleagues on many levels and in a variety of situations."

Modeling best practices for staff. The third key dimension articulated by each of the Vision Setters was the belief that the principal sets the direction for effective instructional practice by being in the classroom, modeling instruction for teachers and setting the example that teachers presumably will emulate. The Collaborators also viewed themselves as within-classroom role models, of course, but what the Collaborators envisioned principals modeling in the classroom was quite different from what the Vision Setters believed should be modeled. While the Collaborators viewed themselves as working in partnership with staff to figure out how to improve instruction and increase student learning - and even envisioned principals not always succeeding so that teachers would become more comfortable with risk taking--the Vision Setters focused on the principal demonstrating best practices for staff. Vision Setters' emphasis on the principal as the person with all (or at least most of the answers) is at least partially captured in the imagery embedded in many of the quotes included in Table 4.9. The emphasis here is not 
on the importance of collaborating with staff; rather, the emphasis is clearly on the need for the principal to "push" staff into improving their instructional practice and on the need to "model" how instructional practice should look. Liam, for example, stated quite clearly that the principal "needs to push the envelope and model what are good teaching strategies for staff" and Elena also mentioned that the principal needed to "motivate and push students and staff forward." Louise may have provided the most vivid imagery for contrasting Collaborators' beliefs with the beliefs of Vision Setters on the modeling issue, however: Louise stated that "the school is a machine... and the principal is at the top of the machine."

Table 4.9: Vision Setters' Beliefs on Modeling Best Practice for Staff

\begin{tabular}{|c|c|}
\hline Liam & $\begin{array}{l}\text { My theory of leadership I would say is that you are the leader that can support your } \\
\text { staff to articulate your vision. You are sort of like on an island. I mean you have to } \\
\text { be the modeler and change agent. You can also provide the resources and the } \\
\text { materials and technology and funds, all of those things that focus on improving } \\
\text { instruction but you are the one that needs to push the envelope and model what are } \\
\text { good teaching strategies for staff. }\end{array}$ \\
\hline Sierra & $\begin{array}{l}\text { You know, you're it [as principal]. You've got to model and you've got to get out } \\
\text { there in the classrooms and make sure it's happening and not just sit in your office } \\
\text { and worry about the budget because it is the principal that brings about change. }\end{array}$ \\
\hline Emma & $\begin{array}{l}\text { There are two different streams of thought going into the school- } \\
\text { There are the teachers and then there is the administration. And there seems to be like } \\
\text { this river ruming between them and we don't have the same idea... The principal has } \\
\text { to shape the instruction in the classroom and make sure the teachers are teaching } \\
\text { effectively and the principal is the expert and needs to be in the classroom modeling } \\
\text { for staff. }\end{array}$ \\
\hline Elena & $\begin{array}{l}\text { I think the principal needs to be a role model for his or her staff. In order to motivate } \\
\text { and push students and staff forward, an effective leader needs to lead staff } \\
\text { development and model his or her learning. A leader must show others, through his or } \\
\text { her own actions, how to be reflective and insightful about instruction because } \\
\text { teachers, at least many that I have been around, will not change otherwise. }\end{array}$ \\
\hline Joy & $\begin{array}{l}\text { Leadership is best given by example. The principal is the epicenter. An effective } \\
\text { administrator will show what she values through example and action. } \\
\text { Principals must get out and model what they want their teachers to do otherwise it is } \\
\text { not going to happen and teachers will continue to stay at their level. Sometimes a } \\
\text { principal has to mandate things. }\end{array}$ \\
\hline Louis & $\begin{array}{l}\text { The school is a machine with no one part succeeding without the other. The machine } \\
\text { will work when there is understanding and professionalism ... no one piece is } \\
\text { untouchable and the principal is at the top of the machine. }\end{array}$ \\
\hline
\end{tabular}


The sense of separation between teachers and principals - and also the sense of a hierarchical relationship — that is implicit in Louise's machine imagery was also echoed in the comments of other Vision Setters. While the Collaborators consistently emphasized the importance of working in partnership with teachers and staff to improve practice and empower staff to take on more decision making responsibility, Vision Setters focused on the separation of and division in roles and responsibilities that existed between administrators and staff. Liam, for example, expressed the belief that the principal was "sort of like on an island," and Emma discussed the dichotomy that existed between staff and administrators:

There are two different streams of thought going into the school-there are the teachers and then there is the administration. And there seems to be like this river running between them and we don't have the same idea.... The principal has to shape the instruction in the classroom and make sure the teachers are teaching effectively. The principal is the expert and needs to be in the classroom modeling for staff.

Joy, Sierra and Elena also articulated beliefs similar to Emma's and Liam's regarding the separation of roles and the hierarchy built into this separation. Joy, for example, believed the principal was "the epicenter" of the school. In other words, "principals must get out and model what they want their teachers to do otherwise it is not going to happen and teachers will continue to stay at their level." Sierra, labeled the principal as being "it," meaning that the principal was single-handedly the change agent and needed to be in the classroom making sure change was occurring. Elena believed that principals needed to "get out and model what they want their teachers to do otherwise it 
[improved instructional practice] is not going to happen and teachers will continue to stay at their level." In short, unlike Collaborators who viewed the principal as being out and about in classrooms working alongside teachers to solve instructional problems, Vision Setters saw principals as the people with the answers and more-or-less ready-made solutions who were out and about in classrooms modeling what teachers should be doing and monitoring whether the correct strategies were getting implemented.

\section{The Keeper}

One member of the Cohort, Gabriel, a white male in his early 40s with less than 10 years of teaching experience, was an outlier and has been labeled the Keeper. At the core of Gabriel's beliefs regarding leadership were four convictions. The first was that the principal serves not as an agent of change but, rather, as a keeper of the status quo. The second was that the principal serves as a link between the district and its mandates and the school and the school staff's practices. The third was that the principal communicates and engages with staff only indirectly. The fourth involved an elitist view of public education.

Keeper of the status quo. Both the Collaborators and Vision Setters viewed themselves as change agents. That is, they believed that it was the principal's responsibility to foster improvement in the staff's instructional practices and ensure students are achieving academically, albeit through different strategies. By contrast, Gabriel believed that being a principal was "almost keeping the status quo." Gabriel explained the rationale behind this statement as follows:

I don't think anybody can go into a site and suddenly the first month or the first year even go initiating major change. I think an administrator must be at a school 
for several years before they can really start making and seeing changes....The principal should not come in and be rocking the boat.

It is important to note that Gabriel's views were in conflict with the expectations the district had for the DILNS participants as well as to the theory of action undergirding the reform efforts that were occurring in the district at the time of this study. At that time, at least, all principals, and the DILNS participants, in particular, were expected to be change agents not maintainers of the status quo.

A link between the district and the school. The relationship between district expectations and the district's theory of action with respect to reform, on the one hand, and a second component of Gabriel's belief system, on the other, is a bit more ambiguous and problematic. This second component involved the belief that the principal was, in effect, the link between the school site and the mandates emanating from the district office. As Gabriel stated:

An effective leader must also be the link between the school and central office. They must be able to communicate and carry out the desires of the district and give accurate feedback to the district about the school. The principal must communicate to the staff the expectations of the superintendent and the board of education as it relates to student instruction.

Now, it is reasonable to assume that most principals and principals-in-training would express somewhat similar sentiments since the principal role is, indeed, a middle manager role. What makes Gabriel's discussion of being a link stand out was that he expressed a very one-sided view of the middle manager role. He never discussed relating staff concerns back to the district or even the desire to hear staff members' concerns, for 
example. In fact, his statement about the principal giving "accurate feedback to the district about the school" was made in the context of letting the district know "what teachers were or were not performing" and "figuring out a way [with district officials] to get rid of deadwood." In addition, he never even alluded to the need for a principal to find a way to balance implementing district mandates with staff requests and concerns. While he did mention the need to give teachers the ability to "have some input," he went on to state that this should be done because it "makes them at least feel better."

The relationship between this second component of Gabriel's thinking and the district's thinking was classified as ambiguous and problematic at the outset of this section. That is because much of the district's rhetoric was about leaders being reflective practitioners, problem solvers, and vision creators (either with or without collaboration with staff members). On the other hand, there was also a strong emphasis from the district on implementing district mandates as specified and, at least in the early years of the reform, a de-emphasis on staff input. Even in the reform movement's later years, efforts to give teachers and principals input could have been interpreted as being done primarily because opportunities for input "makes them at least feel better." So, at least in terms of this second component of Gabriel's belief system, there may not have been as sharp a contrast between what the district wanted done and what Gabriel believed should be done as on the other points. Indeed, this whole discussion could be seen as highlighting some rather glaring inconsistencies in the district's theory of action.

Communicating and engaging with staff only indirectly. The third key leadership dimension articulated by Gabriel was the belief that the way to engage with staff was 
through small, intimate meetings rather than in large group settings. Gabriel, in fact, compared being a principal to being "an effective politician":

An effective politician and an effective school leader use one on one conversations, small little backdoor visits, individual things. I'm not sure that you can get up in front of a large group and make the decisions or have the same effect as you can on a small individual basis. And I think there are certain things you need. You need patience. You need the ability to see the big picture. There are lots of things that you need.

Gabriel's belief on how to engage with staff were once again in sharp contrast to those of the Vision Setters and the Collaborators. Members of both these groups believed in engaging directly with staff as a whole school community as well as working with staff individually to improve practice. District thinking also endorsed a range of interaction strategies and working in a range of forums, both large and small.

An elitist view of public education. A fourth and final component of Gabriel's belief system about the principalship and education generally also contrasted with district thinking in an era when no child is to be left behind. This fourth component is captured in the following quotation taken from the initial interview with Gabriel:

I consider myself pretty liberal. The general tone in education is we can and will save all kids at one time. But I think if we allowed kids choices and where that choice comes in, at what age and with parents and all, I don't know. It's not you getting rid of a kid because they're a behavior problem necessarily but if this kid is a slug who doesn't want to be there and you know, is showing passive aggressiveness or no achievement ... then let's find something that they are 
successful at and something that they are good at and help them do that and if they want to come back and get a formal education and get biology and chemistry and those sorts of things, then great. If not, oh well.

Participants' Leadership Philosophies at the End of a Year Of Training

During their first year of training in the DILNS programs, participants were employed as fulltime interns, working alongside a master principal to experience the job of the principal firsthand. In addition, the DILNS participants took coursework at the university that enabled them to earn their preliminary administrative credential, which was required in the state of California to work as a principal or vice principal. A good portion of this coursework, however, was delivered in innovative ways and involved completing projects related to their internship assignments and engaging in reflective seminars about their internship experiences. At the end of the year of training, each participant was once again interviewed to assess what change, if any, occurred in their leadership beliefs, and what program factors, if any, impacted their beliefs.

A number of findings from this second round of interviewing were worth noting. First, the Collaborators, and the individual originally characterized as the Keeper, for the most part, articulated sets of beliefs during the second round of interviews that were very consistent with their initial beliefs. With the other group, there were major differences: Three of the six Vision Setters articulated sets of beliefs that were quite different from the beliefs they had articulated as they began their preparation program.

To unpack the participants' changes in beliefs this section proceeds in the following way: participants will continue to be discussed under the group in which they originally were placed (Collaborators, Vision Setters and the Keeper). This will make it 
possible to compare and contrast the original beliefs participants espoused during the first round of interviewing with what they articulated during the second round of data collection.

The Collaborators

As noted above, for the most part, the Collaborators continued to emphasize the same three leadership dimensions they had previously articulated at the start of their program: developing a shared vision for the school; creating a professional learning community; and supporting and working alongside staff to improve practice.

Furthermore, what they said about each of these dimensions was, in most cases, only slightly different from what they said as they began the preparation program. Details about the normally subtle shifts in thinking are discussed briefly below.

Developing a shared vision. With only one exception, the Collaborators continued to articulate views regarding the development of the vision that were in harmony with what was previously espoused. As Table 4.10 illustrates, five of the Collaborators continued to articulate beliefs that emphasized collaborating with staff to develop the vision. For example, as she had done at the outset of the program, Kate stressed the need to "work with staff to be successful" including having teachers "help make the vision for the school." Anne, as before, discussed working with "staff as partners" to create the vision, while Olivia once again emphasized the importance of the principal being "able to set goals with staff and develop a vision with them." As was the case in the first round of interviews, Kate's, Anne's or Olivia's comments could easily have been spoken by Mia or Nidia as well. 


\section{Table 4.10: Collaborators' Beliefs on Developing a Shared Vision}

Beliefs upon entering the DILNS

\begin{tabular}{|c|c|c|}
\hline Kate & $\begin{array}{l}\text { It is important to share control of } \\
\text { the school and decision making. If } \\
\text { people buy into something, you go } \\
\text { a lot further. That's what's so } \\
\text { important at the school site, that } \\
\text { it's a collaborative community } \\
\text { effort because if you get all the } \\
\text { teachers to buy into a ... vision a } \\
\text { school will move a lot faster. }\end{array}$ & $\begin{array}{l}\text { I believe I need to work with staff to be } \\
\text { successful. That means from the start they } \\
\text { need to be empowered to be good teachers } \\
\text { and leaders, they need to help make the } \\
\text { vision for the school so that they are invested } \\
\text { in the school. Otherwise, resistance builds. } \\
\text { I've seen it before. I don't want that. I want } \\
\text { them engaged and I guarantee things will } \\
\text { improve if they are part of creating things. }\end{array}$ \\
\hline Nidia & $\begin{array}{l}\text { To be effective the principal needs } \\
\text { to be able to bring the school } \\
\text { community together to share the } \\
\text { responsibility for decisions, to } \\
\text { work together to develop the } \\
\text { school's vision and goals. }\end{array}$ & $\begin{array}{l}\text { I think I said this last time but now I really } \\
\text { believe that the principal needs to be a bridge } \\
\text { builder and help everyone get their views on } \\
\text { the table so that vision can be built for the } \\
\text { school. If teachers are allowed to be part of } \\
\text { these decisions they will be better teachers } \\
\text { and want to be on campus rather than leave } \\
\text { right when the contract says it is ok. }\end{array}$ \\
\hline Danna & $\begin{array}{l}\text { A successful vision inherently } \\
\text { requires that all stakeholders } \\
\text { promote it or it will not be } \\
\text { achieved. These stakeholders will } \\
\text { not cultivate the vision unless they } \\
\text { help construct it. }\end{array}$ & $\begin{array}{l}\text { It [the vision] takes time and must be done } \\
\text { with staff as partners. If I decide the vision } \\
\text { for the school without them there will be no } \\
\text { buy in. }\end{array}$ \\
\hline Mia & $\begin{array}{l}\text { A vision should not just belong to } \\
\text { the principal. }\end{array}$ & $\begin{array}{l}\text { I can't just say here's our vision. That won't } \\
\text { work because it shouldn't be only mine. }\end{array}$ \\
\hline Olivia & $\begin{array}{l}\text { The principal needs to be able to } \\
\text { work with staff and collaborate } \\
\text { with them on developing the } \\
\text { school's vision. }\end{array}$ & $\begin{array}{l}\text { I keep thinking how am I going to make a } \\
\text { better school and set goals every week and } \\
\text { for the year. I think a great leader can do that } \\
\text { and being a leader is, you know, being able to } \\
\text { set goals with staff and develop a vision with } \\
\text { them to make the needed changes at a school. }\end{array}$ \\
\hline Robert & $\begin{array}{l}\text { The fact is that you [as a } \\
\text { principal] are there truly with a } \\
\text { vision of how kids learn and that } \\
\text { you are able to get people around } \\
\text { the table to help create the vision } \\
\text { and have them become invested } \\
\text { and part of deciding the vision. }\end{array}$ & $\begin{array}{l}\text { I [as principal] need to set the vision for the } \\
\text { school. }\end{array}$ \\
\hline
\end{tabular}

What did appear to change, however, was what Robert said about creating a school's vision. Previously he had discussed the importance of the principal first having a vision for the school but, in time, engaging with staff to develop a shared vision. 
Although it was noted in the above analysis that Robert might have viewed this later engagement as little more than procedural display (i.e., as little more than a public relations activity), it was also noted that Robert had been emphatic about the principal not being "the one saying, 'I think we need to do this [determining the vision for the school]," but rather that the principal should very quickly be a facilitator of conversations so “that it's not just sort of here I am, I am changing everything, but, rather, let's look at this group."

After a year in the program, however, Robert believed the principal "need[s] to set the vision for the school." At this point, there was no longer any talk of "getting people around the table"; rather, Robert, at this point, stated without equivocation or qualification that an "effective leader" is a "strong leader" who unilaterally decides the school's vision. Ultimately, whether this seemingly "new" thinking represents a significant shift in Robert's beliefs about how a school's vision gets constructed (and who does the construction), or whether Robert's beliefs about this first dimension were really more like the Vision Setters' thinking on this point all along is still somewhat elusive.

Developing a professional learning community. After a year in the program, all the Collaborators, including Robert, continued to emphasize the importance of teachers, staff and principals collaborating together to improve instructional practice. The terms learning community or community of learners were, in fact, used once again by four individuals. Again, as can be seen in Table 4.11, the other two participants who did not use either the term learning community or the term community of learners did articulate 
beliefs that endorsed the learning community/community of learners concept even though

the specific terminology was not used.

\section{Table 4.11: Collaborators' Beliefs on Developing a Professional Learning Community}

Beliefs upon entering the DILNS

Beliefs after a year in the DILNS

\begin{tabular}{|c|c|c|}
\hline Kate & $\begin{array}{l}\text { A school needs to function like a family so } \\
\text { that all teachers are supporting each other } \\
\text { [and] that all teachers are there for the } \\
\text { children [and] that a teacher doesn't belong } \\
\text { just in the front row of that classroom and } \\
\text { that their only concerns are those kids in } \\
\text { that class. They have to expand their } \\
\text { concerns about the whole school, about } \\
\text { their grade level, from their classroom to } \\
\text { grade level to the whole site. }\end{array}$ & $\begin{array}{l}\text { The very best means the very best teachers. We cannot } \\
\text { have teachers here that are just here to collect a } \\
\text { paycheck. The only way we can do that is with hard } \\
\text { work and true focus and honest conversations about the } \\
\text { work that's happening and sharing work and working } \\
\text { together and turning things around and basically building } \\
\text { a learning community. }\end{array}$ \\
\hline Nidia & $\begin{array}{l}\text { Effective administrators must foster a } \\
\text { supportive environment so that teachers are } \\
\text { willing to take risks to improve their } \\
\text { practice. Building a community of learners } \\
\text { is the responsibility of the principal, the } \\
\text { leader of the school. }\end{array}$ & $\begin{array}{l}\text { Well teachers should be modeling what they want the } \\
\text { students to do. Students should have the opportunity to } \\
\text { solve the problem either through talking or some kind of } \\
\text { interactive time to solve whatever it is they are supposed } \\
\text { to be doing. I think that they should be coming out with a } \\
\text { new learning, that they should have learned something, } \\
\text { not something that they already know. The same needs } \\
\text { to happen for staff during professional development. I } \\
\text { mean we all need to come out with new learnings and } \\
\text { work together to improve and be a community of } \\
\text { learners. }\end{array}$ \\
\hline Danna & $\begin{array}{l}\text { Collaboration needs to occur so that } \\
\text { teachers are encouraged to work together } \\
\text { at and across grade levels to identify } \\
\text { strengths and weaknesses in instruction. }\end{array}$ & $\begin{array}{l}\text { We need to come together and collaborate as a staff } \\
\text { and figure out how we can work through things } \\
\text { together to improve instruction. }\end{array}$ \\
\hline Mia & $\begin{array}{l}\text { In order to develop a true community of } \\
\text { learners, teachers must have opportunities } \\
\text { to plan together, reflect together, read } \\
\text { professional materials, discuss them and } \\
\text { then apply their learning. This constitutes } \\
\text { a very powerful way to not only respect } \\
\text { teacher differences, but build leaders } \\
\text { within a site to support student } \\
\text { achievement. As a leader I hope to make } \\
\text { sure that teachers have the time to help } \\
\text { one another develop professionally and to } \\
\text { be part of that development. }\end{array}$ & $\begin{array}{l}\text { This work [of leading a school] can't be done by } \\
\text { administrators alone and it has to be done by teachers } \\
\text { who take leadership roles who truly want to be } \\
\text { teachers, who want to be in their classrooms and want } \\
\text { to lead this work alongside their peers. I believe my } \\
\text { role as an administrator is to provide them the time, } \\
\text { the place, the structure and the materials to do } \\
\text { that...So a learning community is a place where that } \\
\text { sort of thinking and practice is not only welcomed, it's } \\
\text { expected and the community fosters that thought, that } \\
\text { way of thinking, that way of supporting one another to } \\
\text { get there. }\end{array}$ \\
\hline
\end{tabular}


Table 4.11 Continued

\begin{tabular}{|c|c|c|}
\hline Robert & $\begin{array}{l}\text { Well to me a learning community is a } \\
\text { group of people getting together with the } \\
\text { goal in mind of supporting each other. } \\
\text { That it's not going to be one that just sort } \\
\text { of is didactic, but the fact is that dynamic } \\
\text { conversation takes place. } \\
\text { It is your job as an effective school leader } \\
\text { to create a dynamic learning community } \\
\text { where staff have many opportunities to } \\
\text { learn together ... and to create an } \\
\text { atmosphere where risk taking is } \\
\text { encouraged and teachers feel supported. }\end{array}$ & $\begin{array}{l}\text { I want every parent, every child, every teacher, [and] } \\
\text { every employee to know the fact is we're becoming a } \\
\text { learning community... I think that it's a group of } \\
\text { people getting together to learn new things, to try } \\
\text { things and being excited about our learning together. } \\
\text { That we can bounce and we can learn from each } \\
\text { other that parents are in school part of this learning } \\
\text { community and so that they feel welcomed into it, } \\
\text { that they bring their strengths into it. The kids, I } \\
\text { want them to see that they are very integral part. } \\
\text { Two words I keep telling the staff and the kids are } \\
\text { "respect" and "responsibility. }\end{array}$ \\
\hline Olivia & $\begin{array}{l}\text { I think a leader needs to create a } \\
\text { community of learners where teachers can } \\
\text { share their thoughts and strategies in a safe } \\
\text { way and as a result others can benefit. It is } \\
\text { not just me determining what to learn. }\end{array}$ & $\begin{array}{l}\text { You've got teacher leaders and you have to bring } \\
\text { them up too because I think a really good leader } \\
\text { builds on the strengths of their staff and then finds } \\
\text { the areas that teachers need help with or staff } \\
\text { members need help with and works with them or } \\
\text { engages with staff to have them work with other staff } \\
\text { and support one another. It is not only the principal } \\
\text { but everyone making sure instruction is improving. }\end{array}$ \\
\hline
\end{tabular}

What did change during the second round of interviews, however, was the number of participants who believed the principal should take an activist approach in developing and shaping the learning community within a school. During the initial set of interviews, Robert and Nidia were the only two Collaborators who articulated an activist approach to developing the learning community. Other Collaborators were either silent on the matter or described a more informal and indirect role for the principal. They talked, for example, about the principal encouraging staff to work together or providing opportunities for them to work. With the exception of Mia, who continued to emphasize the more informal role the principal can play in creating a learning community by asserting the principal's role as providing "the time, the place, the structure, and the materials" for staff to work together, the Collaborators all now, articulated a more activist and engaged approach for the principal's involvement in the learning community. 
Kate, for example, discussed how "we" need to develop a "true focus" by "working together and turning things around" In her previous interview, Kate always referred to "they" or the teachers when discussing the concept of the learning community. She did not appear to believe that the principal played an active role in the learning community. While subtle, this shift in terminology and her subsequent thoughts suggest that she now views the principal as needing to be more engaged and active in developing and fostering the work of the learning community. Olivia discussed a myriad of ways the principal should be involved in the school's learning community. According to her:

A good leader builds on the strengths of their staff and then finds the areas that teachers need help with or staff members need help with and works with them or engages with staff to have them work with other staff and support one another. It is not only the principal but everyone making sure instruction is improving. Nidia intimated that staff might need to set goals because they needed to come out with "new learnings" as a member of a "community of learners" and Danna discussed how "we need to come together and collaborate as a staff." Similarly, Robert stated that he "wants every parent, every child, every teacher, [and] every employee to know the fact is, "We're becoming a learning community."

Supporting and working with school staff. All six Collaborators also continued to believe that the principal should collaborate with teachers and work alongside them in their classrooms to provide support. This conclusion is supported by the before and after quotes included in Table 4.12 . 
Table 4.12: Collaborators' Beliefs on Supporting and Working Alongside Staff

Beliefs upon entering the DILNS

\begin{tabular}{|c|c|c|}
\hline Kate & $\begin{array}{l}\text { A great leader is one that will never ask their } \\
\text { workers to do something that they wouldn't do } \\
\text { or don't do. The principal's value and mission } \\
\text { is student achievement--that means that } \\
\text { person has to be in the classroom and it's also } \\
\text { a person that is assisting and encouraging new } \\
\text { approaches to education because you want to } \\
\text { make everyone feel like they've got } \\
\text { something to offer and learn no matter how } \\
\text { long they've been in the field. Value the } \\
\text { teachers, promote their growth, honor those } \\
\text { old approaches while encouraging new } \\
\text { approaches and promote collaboration. }\end{array}$ & $\begin{array}{l}\text { You [i.e. the principal] apply different } \\
\text { supports for different needs and realizing } \\
\text { that that's really what you really have to do } \\
\text { for adult learners. You can't treat all adult } \\
\text { learners as the same. So you plan different } \\
\text { levels of support. You need to work with } \\
\text { them... They need to know that they could } \\
\text { talk about what they are struggling with and } \\
\text { feel safe about that. }\end{array}$ \\
\hline Nidia & $\begin{array}{l}\text { Learning is lifelong. Without ongoing } \\
\text { learning, principals would be on automatic } \\
\text { pilot. School leaders and teachers alike need } \\
\text { to be learners. An excellent leader needs to } \\
\text { be willing to model ongoing professional } \\
\text { development. }\end{array}$ & $\begin{array}{l}\text { An effective leader will collaborate with } \\
\text { teachers and work with them in a supportive } \\
\text { way. }\end{array}$ \\
\hline Danna & $\begin{array}{l}\text { I lead by example and I think I lead by if I ask } \\
\text { teachers to do something then I need to also } \\
\text { show them that I'm willing to take it on. If } \\
\text { there is an area someone needs to work on, I } \\
\text { would be happy to work on it with them so } \\
\text { that they know that I will learn alongside } \\
\text { them. You can have all the knowledge in the } \\
\text { world but if you can't give it to other people, } \\
\text { what good is it. }\end{array}$ & $\begin{array}{l}\text { I want to show that I learn alongside } \\
\text { teachers. Whatever we start on I am going to } \\
\text { take on as well. .. There's a lot of different } \\
\text { ways I can support. I can have my peer } \\
\text { coach model high quality instruction in a } \\
\text { certain area. They can see other teachers } \\
\text { who I think are teacher leaders in that area. I } \\
\text { can model myself in an area and one of the } \\
\text { other things that's really important to me and } \\
\text { other teachers on the site is that everybody } \\
\text { learns together. }\end{array}$ \\
\hline
\end{tabular}


Table 4.12 Continued

\begin{tabular}{|c|c|c|}
\hline Mia & $\begin{array}{l}\text { An effective school leader must know that good } \\
\text { teachers want good leaders. They [teachers] want } \\
\text { to know that the person responsible for their school } \\
\text { understands what they do on a day to day basis. } \\
\text { They want to rely upon that person to support them } \\
\text { in their efforts to educate and challenge students. } \\
\text { They want to know that they will be recognized for } \\
\text { their knowledge, their willingness to continue } \\
\text { learning and their determination to work for the } \\
\text { common good of their school communities. } \\
\text { I believe all people learn by example. It seems only } \\
\text { logical to extend and express what I value about } \\
\text { teaching and learning, by showing and doing as } \\
\text { well as expressing so that others in the school } \\
\text { community may begin to understand it and work } \\
\text { with me to help the school. If I provide a consistent } \\
\text { model, the teachers will be encouraged to provide } \\
\text { the same for their students. }\end{array}$ & $\begin{array}{l}\text { My vision is clearly attached to the fact } \\
\text { that I think teachers will grow when } \\
\text { someone gives them time and space and } \\
\text { opportunities to learn. I'll model a } \\
\text { lesson for them or team it if they want } \\
\text { to. I'll get them help from a peer coach } \\
\text { or pair them up with a teacher. }\end{array}$ \\
\hline Robert & $\begin{array}{l}\text { I don't want to go and ask them [teachers] to do } \\
\text { something without giving them really a lot of } \\
\text { support. I don't want them to go in [the classroom] } \\
\text { and feel I'm going to make a fool of myself so I'll } \\
\text { make sure that I go in there and spend a couple of } \\
\text { hours a day supporting teachers. }\end{array}$ & $\begin{array}{l}\text { So my role is the more supportive the } \\
\text { teachers feel, the more supportive they } \\
\text { are going to put on and pass that onto } \\
\text { their kids and that level of learning is } \\
\text { the ultimate goal... So my role of } \\
\text { leadership is to really create that } \\
\text { atmosphere of support to do it. I cannot } \\
\text { ask teachers to do something if I can't } \\
\text { give them the support for that. It's } \\
\text { unfair to teachers or anybody else to be } \\
\text { asked to do something and then say } \\
\text { "well you're on your own." So my real } \\
\text { strong belief is I have to create an } \\
\text { atmosphere where people want to be } \\
\text { here and they feel supported, that they } \\
\text { will be willing to take that next step. }\end{array}$ \\
\hline Olivia & $\begin{array}{l}\text { As a principal you have an opportunity to help } \\
\text { teacher's grow, nudging them, giving them more of } \\
\text { a push because it is all about kids. The principal } \\
\text { can try to make changes, maybe one on one, } \\
\text { whatever the teacher needs. An excellent leader } \\
\text { needs to be willing to model ongoing professional } \\
\text { development so they're [principals] not just on the } \\
\text { outside organizing the school but they know what's } \\
\text { going on in the classroom because that's what this } \\
\text { is all about and I think in the past, principals from } \\
\text { the past managed the schools from the outside. }\end{array}$ & $\begin{array}{l}\text { A leader is a person who can come into } \\
\text { a school and really see the staff, where } \\
\text { they are and make plans for their future, } \\
\text { guide the staff to become better } \\
\text { teachers and do that by listening and } \\
\text { hearing them and respecting and } \\
\text { supporting them. So, hearing out what } \\
\text { they believe and need, being able to } \\
\text { balance their beliefs with my beliefs } \\
\text { and making sure that it's all about the } \\
\text { children and helping the teachers } \\
\text { improve too. }\end{array}$ \\
\hline
\end{tabular}


While all six of the Collaborators continued to emphasize the importance of the principal supporting and working with teachers to improve their practice, only one individual, Olivia, overtly discussed the importance of helping teachers improve by "listening and hearing them and respecting and supporting them." This contrasts with the beginning of the year interviews in which three individuals (Kate, Mia and Robert) articulated the belief that the principal needed to "value" or "recognize" the knowledge and expertise of staff. It is not clear whether these omissions represent merely an oversight or whether they speak to a subtle but important shift in thinking as a result of the Collaborators being socialized into the principal role in a district that, for the most part, approached educational reform in a relatively top-down manner.

\section{The Vision Setters}

As was stated at the beginning of this section, three of the six Vision Setters articulated sets of beliefs after a year in the program that were quite different from what they had espoused in their initial interview as they entered the DILNS program. Similar to the Collaborators, these three individuals now believed that the principal should not be the lone voice in setting the vision for the school, but rather needed to engage staff in developing a shared school vision. Furthermore, they articulated the belief that the principal needed to focus on building relationships and working with and alongside staff to improve teachers' instructional knowledge and skills, an emphasis that was not included in their comments during the initial interview. The other three members of the Vision Setters continued to emphasize a hierarchical and bureaucratic view of the principal's role and once again emphasized the belief that the principal sets the vision for the school and that the principal needed to be the modeler of effective behavior. 
Developing the vision for the school. The second round of data collection revealed an interesting dichotomy of beliefs within the members of the once relatively homogeneous Vision Setters group. As Table 4.13 points out, half of the participants (Emma, Joy, and Louise) continued to express the belief that the principal needed to independently develop the vision for the school without engaging staff in the process, while the other half (Liam, Sierra and Elena) now articulated a set of beliefs that were drastically different from what they had originally expressed. Liam, for example, who discussed in his original interview the importance of the principal "putting [his] vision out" and then trying to "get everyone to buy into what [the principal] sees as the direction for the school," expressed a radically changed perspective during the second round of data collection. His second interview, in fact, revealed that he now believed it was important to "get buy in" from staff up front by engaging and collaborating with staff to develop a "shared vision" rather than having the principal first craft the vision and then strategize to find a way to get staff to accept what the principal had preordained. As the quote below suggests, Liam's view of developing the vision was now fundamentally different from the hierarchical thinking recorded in the first interview (and summarized in the exemplary quote in Table 4.13). Now he said the following:

They [teachers] can expect that I'm going to develop a shared vision with them, that it's not just going to be "this is what we're doing," but it's going to be kind of a discussion ... I really do believe that sharing some of that leadership and sharing the vision, that it does get people to have greater buy in and you can actually improve your work by doing that. 
Table 4.13: Vision Setters' Beliefs on Developing the School's Vision

Beliefs upon entering the DILNS

Beliefs after a year in the DILNS

\begin{tabular}{|c|c|c|}
\hline Liam & $\begin{array}{l}\text { What you are really trying to do is put } \\
\text { your vision out or the vision you have } \\
\text { for the school for improving student } \\
\text { achievement, putting your vision out } \\
\text { and you stand as the benchmark and } \\
\text { get everyone to buy into what you see } \\
\text { as the direction for the school. } \\
\text { The teachers need to carry it [the } \\
\text { vision] out and it is my job to get } \\
\text { them to do it. }\end{array}$ & $\begin{array}{l}\text { They can expect that I'm going to } \\
\text { develop a shared vision with them, that } \\
\text { it's not just going to be "this is what } \\
\text { we're doing," but it's going to be kind } \\
\text { of a discussion ... I really do believe } \\
\text { that sharing some of that leadership } \\
\text { and sharing the vision, that it does get } \\
\text { people to have greater buy in and you } \\
\text { can actually improve your work by } \\
\text { doing that. }\end{array}$ \\
\hline Sierra & $\begin{array}{l}\text { The leader clearly sets the tone for the } \\
\text { school. He or she must look toward } \\
\text { the horizon and create a vision of } \\
\text { where the school is going. }\end{array}$ & $\begin{array}{l}\text { It's not about me or them [teachers] but } \\
\text { that it's about how can we learn } \\
\text { together and answer questions together } \\
\text { and how can we help the kids together, } \\
\text { and how we as a staff envision this } \\
\text { school being. And that's it's not about } \\
\text { directives. Because teachers also need } \\
\text { to be the decision-makers. }\end{array}$ \\
\hline Emma & $\begin{array}{l}\text { Ultimately, it comes down to you [as } \\
\text { the principal] making the tough } \\
\text { decision and deciding the direction of } \\
\text { the school. You must possess a } \\
\text { vision and mission about what you } \\
\text { want to accomplish. It is through } \\
\text { your vision and mission statement } \\
\text { that a leader is able to attract others to } \\
\text { help attain the ideas and goals found } \\
\text { in the mission. }\end{array}$ & $\begin{array}{l}\text { I like to be in control. I need to be the } \\
\text { one that really determines the path the } \\
\text { school needs to take. }\end{array}$ \\
\hline Elena & $\begin{array}{l}\text { An effective leader must be a change } \\
\text { agent and have the knowledge, vision } \\
\text { and courage to get a commitment } \\
\text { from others who may not like one's } \\
\text { ideas. I think you have to have a good } \\
\text { vision and that vision is based on } \\
\text { what you see the kids need to learn. } \\
\text { It's looking at your teachers. It's } \\
\text { being able to look at all of those } \\
\text { things and know where you need to } \\
\text { go ... So you need to have a strong } \\
\text { vision for the school. }\end{array}$ & $\begin{array}{l}\text { People will be more apt to carry out a } \\
\text { school vision if they take part in the } \\
\text { process of creating it. }\end{array}$ \\
\hline
\end{tabular}


Table 4.13 Continued

\begin{tabular}{|l|l|l|}
\hline Joy & $\begin{array}{l}\text { The school vision serves as the } \\
\text { foundation for all decisions. I do } \\
\text { believe that one of the main } \\
\text { responsibilities [of the principal] is ... } \\
\text { to set the tone at the school site. }\end{array}$ & $\begin{array}{l}\text { I think if I start to let anybody else's } \\
\text { political agenda or political input or } \\
\text { stuff start to affect the responsibility } \\
\text { that I have to kids, I'll be an ineffective } \\
\text { leader... You have to- you create the } \\
\text { vision... I need to create the focus for } \\
\text { how we're going to raise student } \\
\text { achievement }\end{array}$ \\
\hline Louise & $\begin{array}{l}\text { They [teachers] are what make what I } \\
\text { as a principal] see and believe work } \\
\text { so I need them to buy into things. } \\
\text { They may not always see the way it's } \\
\text { going to be but at least they need to } \\
\text { really understand my vision and then } \\
\text { they can carry it out. }\end{array}$ & $\begin{array}{l}\text { I need to have a vision for the school } \\
\text { when I walk in the door that first day. }\end{array}$ \\
\hline
\end{tabular}

Elena, who also discussed in the beginning of the program the need for the principal "to have a strong vision for the school," stated during her second interview that "people [teachers] will be more apt to carry out a school vision if they take part in the process of creating it." Sierra also now discussed the importance of having teachers be "decision makers" and the principal not giving "directives," especially in the area of the vision.

These comments could be interpreted in at least two ways. On the one hand, the comments seem to suggest that Liam, Sierra and Elena fundamentally reconceptualized their view of the principal role, especially as it relates to developing the vision, as a result of participating in the program. According to this interpretation, they no longer saw the principal as a lone ranger setting the vision for the school; now the principal was a collaborator who works with and alongside staff to craft a shared school vision.

There is at least one other possible interpretation that could be given to this apparent shift in perspective; that is, these Vision Setters were simply mouthing what they construed to be the program's party line. In other words, even though their 
fundamental beliefs had not really changed, they may have felt obligated to articulate the idea of jointly constructing a school's vision with the school's staff because that was what was emphasized in the program.

Liam's, Sierra's and Elena's other comments, including those across the other subcategories, however, suggest that the first interpretation is probably the more correct one and that these three individuals did, indeed, reconceptualize the principal's role. If they were "faking it" in the second interview, in other words, they were amazingly consistent. The following comments by Liam, for example, suggest that he had, indeed, rethought the role of the principal and now believed his original thinking about vision construction was ineffective:

Yeah, I think that particularly in coming into a new school as a new leader, it would be very - it would be easy to come in very heavy-handed and say, "This is what we're doing. This is who I am." But that's not going to be the most effective way to get people to respond.

Sierra and Elena displayed a similar consistency during their second interviews, even as they articulated a set of beliefs with respect to the vision construction that contrasted dramatically with what each had said during the first interview.

Modeling instruction. One of the key dimensions articulated by each of the Vision Setters during the first round of interviews was the belief that the principal needed to set the direction for effective instructional practice by not only being highly engaged in classrooms but also by modeling for teachers what the teachers should be doing and setting the example that staff would need to follow. During the second round of interviews, Emma, Joy and Louise once again continued to express this hierarchical view 
of the principal and articulated a set of beliefs consistent with what they had previously

stated during their first round of data collection. This conclusion is supported by the

before and after quotes in Table 4.14 .

Table 4.14: Vision Setters' Beliefs on Modeling Instruction

Beliefs upon entering the DILNS

Beliefs after a year in the DILNS

\begin{tabular}{|c|c|c|}
\hline Liam & $\begin{array}{l}\text { My theory of leadership I would say is that } \\
\text { you are the leader that can support your } \\
\text { staff to articulate your vision. You are sort } \\
\text { of like on an island. I mean you have to be } \\
\text { the modeler and change agent. You can also } \\
\text { provide the resources and the materials and } \\
\text { technology and funds, all of those things } \\
\text { that focus on improving instruction but you } \\
\text { are the one that needs to push the envelope } \\
\text { and model what are good teaching strategies } \\
\text { for staff. }\end{array}$ & $\begin{array}{l}\text { But a school leader and I think it goes for any } \\
\text { type of leader, a school leader in particular has to } \\
\text { be able to build communities, has to get people } \\
\text { working together, has to get people a sense that } \\
\text { their feedback, their concerns, their issues have a } \\
\text { place, has to be responsive to needs. }\end{array}$ \\
\hline Sierra & $\begin{array}{l}\text { You know, you're it [as principal]. You've } \\
\text { got to model and you've got to get out there } \\
\text { in the classrooms and make sure it's } \\
\text { happening and not just sit in your office and } \\
\text { worry about the budget because it is the } \\
\text { principal that brings about change. }\end{array}$ & $\begin{array}{l}\text { I would say that it's about working together as a } \\
\text { team. It's definitely teamwork to meet } \\
\text { individual student needs not cookie cutter needs } \\
\text { but to really get in there, get dirty, get to know } \\
\text { the kids on all levels, both administrators, peer } \\
\text { coaches, teachers, assistants, and make informed } \\
\text { decisions. It's about everyone has the right to } \\
\text { succeed and we need to support them to achieve } \\
\text { that right not to make excuses. It's not about } \\
\text { what I can't do as a learner or as a teacher, it's } \\
\text { about what I can do and to build on those } \\
\text { strengths and support those strengths to cover } \\
\text { and meet the needs of those still not there. }\end{array}$ \\
\hline Emma & $\begin{array}{l}\text { There are two different streams of thought } \\
\text { going into the school- } \\
\text { There are the teachers and then there is the } \\
\text { administration. And there seems to be like } \\
\text { this river running between them and we } \\
\text { don't have the same idea... The principal } \\
\text { has to shape the instruction in the classroom } \\
\text { and make sure the teachers are teaching } \\
\text { effectively and the principal is the expert } \\
\text { and needs to be in the classroom modeling } \\
\text { for staff. }\end{array}$ & $\begin{array}{l}\text { The challenge is how do you keep that fire } \\
\text { burning [for teachers] that you can't sit back and } \\
\text { not keep improving instruction each year and it's } \\
\text { just not okay to sit back. A lot of teachers are just } \\
\text { sitting back and they're not really pushing those } \\
\text { kids, the expectation isn't there, the rigor is not } \\
\text { there, that's the hard part. That's the part that } \\
\text { you've got to- and so the challenge is how to } \\
\text { present the new learning and the new push to } \\
\text { keep the fire burning and... and I need to find a } \\
\text { way to keep their fires burning. }\end{array}$ \\
\hline
\end{tabular}


Table 4.14 Continued

\begin{tabular}{|c|c|c|}
\hline Elena & $\begin{array}{l}\text { I think the principal needs to be a role model for } \\
\text { his or her staff. In order to motivate and push } \\
\text { students and staff forward, an effective leader } \\
\text { needs to lead staff development and model his or } \\
\text { her learning. A leader must show others, through } \\
\text { his or her own actions, how to be reflective and } \\
\text { insightful about instruction because teachers, at } \\
\text { least many that I have been around, will not } \\
\text { change otherwise. }\end{array}$ & $\begin{array}{l}\text { Relationships are important. It doesn't } \\
\text { matter how much I know unless I show how } \\
\text { much I care. I need to be a role model and } \\
\text { walk the talk. I need to utilize the expertise } \\
\text { of a diverse staff to look at situations } \\
\text { through a variety of lenses and provide } \\
\text { opportunities for the entire staff to get to } \\
\text { know each other better and help the entire } \\
\text { staff to see that they are both the recipient } \\
\text { and imparter of valuable knowledge }\end{array}$ \\
\hline Joy & $\begin{array}{l}\text { Leadership is best given by example. The } \\
\text { principal is the epicenter. An effective } \\
\text { administrator will show what she values through } \\
\text { example and action. } \\
\text { Principals must get out and model what they } \\
\text { want their teachers to do otherwise it is not going } \\
\text { to happen and teachers will continue to stay at } \\
\text { their level. Sometimes a principal has to mandate } \\
\text { things. }\end{array}$ & $\begin{array}{l}\text { Yeah, I think that it's so critical how I am } \\
\text { on campus at all points in the day to set an } \\
\text { example that I am a learner and that I'm } \\
\text { happy to be here and I want to be here and } \\
\text { I'm here because I love the children and } \\
\text { I'm here because I care about learning ... } \\
\text { because I don't think teachers necessarily } \\
\text { believe that. If I exemplify that because } \\
\text { that's what I believe, then hopefully, others } \\
\text { will pick up on that and any apathy or } \\
\text { disgruntleness or whatever comes into play } \\
\text { or personal life, whatever, when we get on } \\
\text { to the site everyday, that we can do the best } \\
\text { we can for the kids....so, again I need to be } \\
\text { the leader because otherwise I fear that if } \\
\text { not, we will be at the same place at the end } \\
\text { of the year as now and instruction will not } \\
\text { have improved. }\end{array}$ \\
\hline Lo & $\begin{array}{l}\text { The school is a machine with no one part } \\
\text { succeeding without the other. The machine will } \\
\text { work when there is understanding and } \\
\text { professionalism ... no one piece is untouchable } \\
\text { and the principal is at the top of the machine. }\end{array}$ & $\begin{array}{l}\text { It's tough love kind of thing. Doing what } \\
\text { needs to be done in a fair, open-minded } \\
\text { way but that's how I've always been. I've } \\
\text { just changed it from teaching to } \\
\text { administrator. }\end{array}$ \\
\hline
\end{tabular}

The before and after quotes for the other three individuals who were initially classified as Vision Setters, i.e., Elena, Sierra, and Liam, however, evidence that there thinking on this issue had shifted, just as it had shifted on the vision setting issue. Once again, in other words, they expressed a set of beliefs that was very different from what they originally espoused about the principal's role. In the second round of interviews, in fact, each expressed a set of beliefs that highlighted the importance and the 
need for the principal and his or her staff to work "together as a team" to improve instructional practice. There was also now a specific emphasis, in each of these three former Vision Setter's comments, of the importance of the principal building and maintaining relationships with his or her staff. Elena, for instance, linked relationship building to the concept of distributed expertise:

It doesn't matter how much I know unless I show how much I care. I need to be a role model and walk the talk. I need to utilize the expertise of a diverse staff to look at situations through a variety of lenses and provide opportunities for the entire staff to get to know each other better and help the entire staff to see that they are both the recipient and imparter of valuable knowledge.

Sierra, who originally viewed the principal as the sole individual who brings about change, also expressed in her second interview the importance of working together with all staff to ensure that everyone on campus, from teachers to students to administrators succeed.

I would say that it's [her leadership philosophy] about working together as a team. It's definitely teamwork to meet individual student needs not cookie cutter needs but to really get in there, get dirty, get to know the kids on all levels, both administrators, peer coaches, teachers, assistants and make informed decisions. It's about everyone has the right to succeed and we need to support them to achieve that right not to make excuses. It's not about what I can't do as a learner or as a teacher, it's about what I can do and to build on those strengths and support those strengths to cover and meet the needs of the students who are still not there. 
And Liam, too, emphasized the importance of the leader being a bridge to get people to work together. As he stated:

A school leader and I think it goes for any type of leader, a school leader in particular has to be able to build communities, has to get people working together, has to get people a sense that their feedback, their concerns, their issues have a place, has to be responsive to needs.

The beliefs Elena, Sierra, and Liam expressed above are similar to the concept of a learning community or community of learners to which the Collaborators were committed. These beliefs, coupled with the beliefs they each articulated around the need for the principal to engage with staff in the vision creating process, suggest that the changes in their beliefs are more than superficial but actually represent significant shifts in their conception of the role of the principal.

\section{The Keeper}

What emerged from the first round of data collection in relation to Gabriel was a picture of the principal that was quite different from that of the Collaborators and the Vision Setters. The principal, according to Gabriel, was to be a keeper of the status quo whose purpose was to be that of a traditional middle manager responsible for linking district mandates and what actually happened in the school. Gabriel also had a very elitist view of public education, and he understood that his elitist thinking was in conflict with the district's theory of action and the philosophy of the DILNS program.

The second round interview revealed that Gabriel's beliefs remained rather consistent with what he had previously articulate although he did mention that the principal needed to unilaterally set the vision for the school and attempt to get "buy in" 
from staff. He did not elaborate on whether the vision would be one he crafted or one that would simply be a local version of the district's mandates. No accurate interpretation could therefore be made as to the meaning of his statement but it was worth noting that this was the first time that he discussed paying any attention to the staff's wishes or getting "buy in" from staff.

\section{Summary}

This chapter described the beliefs participants had at the beginning of the DILNS program and compared these initial beliefs to the beliefs participants articulated at the end of the first year of the program. Three categories emerged from the initial round of interviewing: the Collaborators-who believed the role of the principal was to share decision making, build a collaborative community of learners and to work with and provide support to school staff; 2) the Vision Setters-who believed that it was the principal's responsibility to set the direction and tone for the school by developing the school's vision and strategically engaging staff to carry out the mission; and, lastly, 3) the Keeper - the person who believed that the principal is not a change agent, but rather a keeper of the status quo whose goal is to be a link between the district, the district's mandates and the school.

During the second round of interviews, the Collaborators' beliefs were generally consistent with the beliefs they had originally articulated. One member, however, did experience a partial shift in thinking and now espoused the belief that the principal needed to set the vision for the school himself. Earlier, he appeared to have endorsed at least a modest amount of collaboration in the vision setting process. 
The most dramatic changes in thinking, however, occurred with the Vision Setter group. By the end of their first year in the program, three of the individuals who were originally classified as Vision Setters (and will subsequently be called Reformed Vision Setters) articulated beliefs that sounded more like the thinking of Collaborators than the thinking of the original Vision Setter group. The belief systems of the other three members of the Vision Setters remained consistent with what they had previously espoused. The Keeper also remained rather consistent in what he espoused to believe but, as was mentioned before, he dropped out of the program after the first year and was never placed in an administrative position. 


\section{CHAPTER V \\ FINDINGS, PART II: COMPARING DILNS PARTICIPANTS' BELIEFS WITH THEIR ACTIONS}

Chapter IV, the first Findings chapter, documented that at least certain program participants shifted their beliefs, presumably as a result of participating in the DILNS program. Of course, ultimately, what really matters is whether espoused beliefs are manifested in actions. Consequently, the purpose of this chapter is to compare and contrast the espoused theories of leadership each participant held at the end of their first year of training in the DILNS program with their actions as school leaders.

\section{Programmatic Context}

At the end of the first year of training, after each participant earned his or her preliminary administrative credential, it was expected that participants would be placed in administrative positions, either as principals or as vice principals. Eleven of the thirteen members did, in fact, become administrators. The two other participants, Elena, a Vision Setter, and Gabriel, the Keeper, did not become principals or vice principals. Gabriel dropped out of the program at the end of the first year, and Elena became a middle school literacy administrator. Table 5.1 below provides a breakdown of the administrative positions the participants were placed in after their first year of training. Table 5.1 also subdivides the original Vision Setter group into two categories: the Unchanged Vision Setters and the Reformed Vision Setters. The latter group, of course, includes those vision setters who changed their belief system in fundamental ways, ways that aligned more closely with the thinking of the Collaborator group than with those individuals classified as Vision Setters at the outset of the program (and, of course, the unchanged Vision Setters at the end of the first year). 
Table 5.1: Placement of Participants after One Year of Training

\begin{tabular}{|c|c|l|}
\hline Group & $\#$ & \multicolumn{1}{|c|}{ Position after one year in DILNS } \\
\hline Collaborators & 6 & $\begin{array}{l}\text { 4 elementary principals } \\
\text { 2 elementary vice principals }\end{array}$ \\
\hline $\begin{array}{c}\text { Unchanged } \\
\text { Vision Setters }\end{array}$ & 3 & 3 elementary vice principals \\
\hline $\begin{array}{c}\text { Reformed } \\
\text { Vision Setters }\end{array}$ & 3 & $\begin{array}{l}\text { 2 elementary principals } \\
\text { middle school literacy administrator }\end{array}$ \\
\hline The Keeper & 1 & Dropped out of the program \\
\hline
\end{tabular}

The discussion below will be organized around the categories used in Table 5.1.

The beliefs articulated by participants within each group at the end of the first year in the program will be compared to observations of their on-the-job action during Year 2.

Observations were conducted at various points during Year 2 while each participant was in his or her new role. A third round of interviews was also conducted during Year 2, and these interview data were used to triangulate the observation data. Triangulation also occurred through the analysis of key documents that shed light on what administrative strategies each participant employed in their role as the school leader. (For a more detailed discussion of these methodological points, see Chapter 3).

Before proceeding, it is necessary to mention one more procedural point: Because of the contrasting and often unequal functions inherent in the role of the principal and vice principal, it is important to understand the significant factor that context, in particular, played in the ability for each participant to act on his or her beliefs. In general, the five DILNS participants who became vice principals were relegated to directing and managing the operational functions of the school, were not closely involved in supporting and impacting instruction and were often constrained or prevented from implementing strategies of their own because of how the principal structured their role. So, while these five individuals developed and articulated a set of beliefs and a 
philosophy of leadership that they hoped to act upon, they did not all have the ability to enact their philosophical beliefs. Consequently, the results are inconclusive for each of these participants, and they are not discussed in great detail in the discussion that follows. One other participant, Elena, who was a Vision Setter did not become a principal or vice principal but as was mentioned before became a literacy administrator at a middle school. While her position conveyed no formal administrative authority, she was actually given a lot of leeway by the principal to independently implement strategies to impact instruction, and therefore she was included in this round of analysis.

Collaborators Become School Leaders

As Table 5.2 illustrates, of the six individuals who were categorized as Collaborators, four of them became elementary school principals and two became vice principals, one at an elementary school and the other at a middle school.

Table 5.2: Leadership Positions of Collaborators after the First Year

\begin{tabular}{|c|c|}
\hline Collaborator & Placement \\
\hline Kate & Elementary Principal \\
\hline Nidia & Middle School Vice Principal \\
\hline Danna & Elementary Principal \\
\hline Mia & Elementary Principal \\
\hline Robert & Elementary Principal \\
\hline Olivia & Elementary Vice Principal \\
\hline
\end{tabular}

In general, the Collaborators that became principals continued to articulate a set of leadership beliefs that were consistent with what they had previously articulated. The results about whether their actions mirrored the beliefs they espoused, however, were mixed. For the four Collaborators that became principals, three appeared to implement administrative strategies that were relatively consistent with the beliefs they espoused, 
while one Collaborator appeared to implement strategies that appeared to be inconsistent with what she previously identified as her leadership beliefs.

The results for the two Collaborators who became vice principals were also mixed. One participant, Nidia, was constrained by the role the principal crafted for her, and, therefore, was unable to impact the school in a manner that she intended. The other was also constrained but was able to restructure her role to a very small degree to be present for very short periods of time in classrooms to work with teachers, a key element in the Collaborator belief system.

Actions Consistent with Beliefs

Danna, Robert and Mia, whose views stayed relatively constant throughout the year, continued to articulate throughout their first year as principals the importance of collaboration, especially in relation to developing a vision and working with and alongside staff to support their needs and professional growth. Their actions on the job also appeared to support what they had espoused both during Year 1 and Year 2.

Danna, for instance, who at the end of her first year of training in the DILNS expressed the belief that the principal along with teachers "need to come together and collaborate as a staff and figure out how we can work through things together to improve instruction," emphasized a similar point during the third and final interview which took place towards the end of her first year as principal. She also continued, as was stated in the earlier analysis of the Collaborators' beliefs, to not be afraid to display vulnerability or the fact that she may not have all the answers or have mastered all instructional techniques. The following quote helps illuminate this point: 
I expect the staff to publicly challenge each other and me. And I don't mean in a nasty way, but in terms of methodology and practice. If I say well, "This is the way I think a child would learn this particular issue best and you don't agree with me and you have different reasoning, I want to hear your reasoning." Because together, whatever that reasoning comes out to be in the end, it's going to be stronger.

Danna also developed and implemented three specific strategies to support staff. First, she worked closely with teachers in their classrooms to help them diagnose strengths and weaknesses. She described this role as being "an extra set of eyes to give supportive feedback." Second, she modeled lessons for teachers in their classrooms. Third, she paired teachers up with one another in order to "provide support to the teacher in need" and also as a way "to build the leadership capacity of other teachers." Danna described spending roughly $60 \%$ of her time on campus working "directly with teachers to improve their work." Her monthly schedule which listed which classes she would visit during the week supported the $60 \%$ figure she described. In addition, she restructured her day so that during lunch and recess she was available for "check ins" with teachers.

Danna also made time over the weekend to talk to those teachers who "had family responsibilities and kids and couldn't stay past the contracted time of the day." She also called two staff meetings in the beginning of the year with the specific purpose of "providing a forum for everyone to weigh in on the vision." Subsequent meetings were also held with a smaller subgroup of school leaders to craft the vision "based on what everyone said." Based on the actions described above and others that were witnessed while onsite, it is reasonable to assume that Danna's actions corresponded to the beliefs 
she espoused and that she did, in fact, act in ways that signaled that she placed a high priority on supporting teachers in a variety of ways, all of which appeared to be collaborative.

Mia, like Danna, also expected her staff to challenge her thoughts in an effort to make sure "things were right." During a visit to her site, she stated the following:

I usually start by saying, "Here's what we [the leadership team] are thinking about doing." They know they can say, "Have you thought about this? What about that?" They know that. I've told them I expect them to. Just because I think this way doesn't mean it's going to stop there.

Her desire to have staff push back was based on her belief that the principal is "not the expert on all things, especially determining what is the best professional development." So, as the principal of a high needs elementary school, Mia instituted a series of strategies throughout the year to ensure that each teacher had "the best support possible." As she stated, 'I'll model a lesson for them or team it if they want to. I'll get them help from a peer coach or pair them up with a teacher." On at least two visits to her site I was able to sit in on a meeting with her and her peer coach and watch her strategize and suggest which teachers the peer coach might work with. Her strategizing and suggestions seemed quite consistent with the Collaborator belief system she continued to espouse.

Mia was also very present on campus. She was always walking through classrooms and interacting with students and staff. She continually carved out time in the school day for staff to work together. In fact, she created a schedule that allowed three teachers from similar grades to pair up and work together on common skills. She indicated that she did this, in part, to ensure that poorly skilled teachers have access to 
support from other teachers and, in part, to build the leadership capacity of staff. As she stated, "I told them all that we can't do this work by ourselves....So our focus this year was to build leadership skills in at least one person in every grade level."

Mia also asked her teachers to develop individual "professional development plans" early in the year in the hopes of focusing teachers' attention on improving skills. In addition to working with teachers and providing time for them to meet, she made money available for staff to attend professional development seminars; she stated, "I never said no to a single request for money this year if it was about growing professionally or improving instruction." When talking about the vision for the school, she discussed the importance of "going slow to go fast." She stated: "We take our time to set the vision because we have to be on the same page." In fact, she waited approximately 5 weeks into the year "until staff got to know... [her] a bit" before calling a meeting to discuss the vision. Everyone was asked to either share out loud what they envisioned for the school or to write it anonymously on paper. A teacher was placed in charge of collecting the paper and summarizing the day's information so that the collaborative vision setting activity would be on the "up and up" and be a fair process.

Robert's actions also seemed to be consistent with his previously held beliefs regarding supporting teachers. In his second round interview, he stated that his role as a leader "is to really create that atmosphere of support. I cannot ask teachers to do something if I can't give them the support for that." He went on to also state, "It's unfair to teachers or anybody else to be asked to do something and then say,'Well you're on your own." He made himself available to teachers throughout the year to model lessons and actually took great pride in the fact "that most [teachers] have taken me up on the 
offer." During one of my visits to his campus late in the school year, Robert continued to articulate the importance of supporting staff. As he stated, "My role is the more supportive I make the teachers feel, the more supportive they are going to act and pass that onto their kids and that level of learning is the ultimate goal." To that end, he has worked hard to support teachers. He has developed a structure where he and each of the members of his leadership team (the vice principal, peer coach, and literacy administrator) supports a group of six teachers. After six weeks, a different member of the team works with the group. The goal is to make sure that each group has the opportunity to have support from different individuals in part because "one member of the team may resonate better with someone while another may not."

In addition to providing for support from revolving leadership team members, Robert also convened a leadership team meeting that focused on literacy every Tuesday morning so that he could get together with his leadership team and find out "what's happening in the classroom? What do we see? Where do we go next?" This is done not to evaluate but to ensure that "the support is on target." Robert, in fact, explicitly discussed the importance of separating the evaluative part of the job from the supportive part:

My job is about supporting them [teachers] because they are the ones doing the real work. I don't want them to think every time I come in their room I'm going to evaluate them. At some point I will have to but I'm a teacher first and foremost and want to make sure that they feel supported. 
Robert also tried to build relationships and a strong rapport with his teachers by planning social events and making sure that he "was always available" because, in his words, "a team that plays together and stays together can work together."

As was noted earlier, Robert's thinking did deviate from the thinking of other Collaborators when it came to the issue of who should define the school's vision. While other Collaborators emphasized that the vision should be constructed with staff, Robert, at least by the end of the first year, indicated that vision construction was something the principal needs to do alone. On this one point, Robert's belief system was more closely aligned with the beliefs of the Vision Setters than with the other members of the Collaborator group. While Robert's beliefs about vision setting may have been inconsistent with typical Collaborator thinking, they were, as the following Year 2 quote from Robert demonstrates, consistent with his on-the-job actions:

When it came time to discussing [the vision], I had my little speech defining my vision and I think that it went over well. I mean, I told them that we had two challenges and each challenge that we had to deal with and what my plans and my visions were for dealing with the challenges.

\section{Actions Not Consistent with Beliefs}

Kate, who became principal of a troubled school that had low test scores, high poverty and had recently had a major turnover in staff, also devised a series of strategies to engage and help teachers improve their instruction. She, like Mia, provided time out of the classroom each week for teachers to work in triads on specific needs they were having. The triads, which consisted of one strong teacher, one weak teacher and, where possible, one "middle of the road" teacher, however, were very carefully "monitored" by 
one of the leadership team members (i.e., either Kate, herself, the vice principal or the peer coach).

Kate also developed a system for diagnosing what teachers needed through conducting walkthroughs of classrooms to assess and monitor instructional needs and by engaging with teachers one-on-one. During one of my visits to her school late in the year, she discussed these strategies and continued to espouse a rhetoric that certainly seemed consistent with Collaborator thinking. She stated, for example:

You [i.e. the principal] apply different supports for different needs and realizing that that's really what you really have to do for adult learners. You can't treat all adult learners as the same. So you plan different levels of support. You need to work with them.... They need to know that they could talk about what they are struggling with and feel safe about that .

Yet, her actions and some of her other comments seemed to suggest that there was at least some inconsistency or disconnect to what she had previously espoused. While the leadership team was designed to support the work of the triads, and this was explicitly stated to the staff at a meeting I observed, she also later stated that the leadership team's priority was about "documenting" and "keeping a log of how they supported that person so there is evidence" to support a dismissal of the teacher. This goal is obviously different from the goal of building a "safe" environment for teachers and members of the leadership team to openly discuss issues of concern.

Kate also now believed that she needed to model effective instruction for many of the teachers because, as she said to me on the way to a classroom visit one afternoon, "I am just sure that they don't have the skills necessary to teach these kids." Kate added 
that she based this belief in part on the fact that "the last principal cleaned house here for a reason" and went on to state, "I may need to finish the job!"

In order to "finish the job," Kate kept notes on each of her classroom visits. She made it clear that these notes were not kept in order to better support the teacher and check back on their progress. Rather, she articulated her goal in the following way: "to make sure I have all this in writing in case [I needed to write them up]. That's my job."

On the one hand, her strategy of "cleaning house" may be indicative of the poor quality of teaching that existed at the site and the real need that existed to bring about major change. Another plausible rationale for this strategy was that because DILNS participants were expected to be change agents, she felt the need to finish a change effort that was in process when she entered the school, i.e., the "cleaning up" effort to rid the school of incompetent teachers. This is not a far-fetched interpretation given that Kate had had a very close relationship last year with the previous principal of the school and, consequently, may have been privy to information about the school and its staff. While there is no way of knowing which of these-or a number of other possible interpretations-is correct, it is clear, that many of Kate's actions were inconsistent with her espoused belief that the principal needed to work "with" staff and create a "safe" environment for them to grow. At a minimum, her on-the-job behavior does not comfortably align with her earlier beliefs in which she stated "we are all in this together." Whether this is because her earlier beliefs were largely empty rhetoric or because contextual factors can dramatically change beliefs and minimize the impact of training programs remains an open question. 
Role Interference in Translating Beliefs to On-the-Job Actions

Nidia and Olivia, both of whom became vice principals, also behaved on-the-job in ways that often seemed inconsistent with the beliefs they had espoused, but, as was noted above, this inconsistency seems more associated with the vice principal role they played rather than with other factors. Both of these individuals, in fact, discussed feeling constrained by their role and disappointed because they were unable to implement their philosophy of leadership. During one of my site visits to her school, after almost eight months on the job, Nidia confessed that she hadn't been much of an instructional leader. In fact, she felt rather alienated at her school since she was not directly involved in working in classrooms with teachers. She described her experience the following way: As a vice-principal, I haven't done a lot of the getting in the classroom and really doing what I feel my philosophy is in education and being directly involved in the learning of the students and the teachers. So I feel like everything I have been trained to do, studied to do, I'm not using that part of my education and I really miss that. I really miss being in the classroom, working intensely with the teachers to improve their practice, to improve student achievement. I don't feel like I'm doing a lot of that.

Her work focused primarily on dealing with student discipline and other operational issues such as scheduling and bus duty. Nidia mentioned that on several occasions she discussed with her principal the desire to be more involved in the classroom working with teachers but was told that she "wasn't doing enough discipline and that [she] was hiding in the classroom." Needless to say, because of role constraints, it was impossible to assess whether or not Nidia's actions coincided with her beliefs. 
Olivia also discussed feeling bogged down by the operational responsibilities designated to her. As she stated:

I'm doing most of the operational things and that would mean all the scheduling, all the organization of the triads and the partners that we have, the collaboration, and their schedules with the music and prep so that they can meet, so the teachers can meet - handling all the other extra things like we're going to have a bus day here. We've had the police department with their safety program and I've had to organize that. Discipline of course. The testing, ordering the testing. I mean, I could go through this long list of little things of stuff ... and doing scheduling which is a massive undertaking. I can't deal with it any more.

Olivia did, however, manage to get into classrooms "each day," although it was often for "a very short period of time." While it was almost impossible to get a real sense of whether she was "walking the talk" and whether her actions were consistent with her beliefs, there is evidence that she specifically tried to manipulate the system in ways to ensure she could spend time in the classrooms. For example, she came in early or stayed late to take care of some of her operational responsibilities so that she would free up time that she could spend in classrooms. As she stated:

I want to change that [not being in classrooms]. I am trying really hard to make sure that I change that so that I'm making sure the operational pieces don't get in the way. So, I'm making a real effort to put that on another part of the day, like today, I was trying to handle all the ADRP before school ... I spent most of the morning trying to get that taken care of so that I could get out to the classrooms. 


\section{Vision Setters Become School Leaders}

As Table 5.3 points out, two of the Vision Setters became elementary principals, three became elementary vice principals and one participant became a middle school literacy administrator. The two principals, Liam and Sierra, and the literacy administrator, Elena, were the three individuals whose beliefs changed and therefore they are categorized as the Reformed Vision Setters in this section. The three other individuals, Joy and Louise, all of whom became vice principals, did not have any noticeable change in their beliefs and therefore will be called the Unchanged Vision Setters in this section.

Table 5.3: Leadership Positions of Vision Setters During the Second Year

\begin{tabular}{|c|c|}
\hline \multicolumn{2}{|c|}{ Reformed Vision Setters } \\
\hline Liam & Elementary Principal \\
\hline Sierra & Elementary Principal \\
\hline Elena & Middle School Literacy Administrator \\
\hline \multicolumn{2}{|c|}{ Unchanged Vision Setters } \\
\hline Emma & Elementary Vice Principal \\
\hline Joy & Elementary Vice Principal \\
\hline Louise & Elementary Vice Principal \\
\hline
\end{tabular}

\section{Reformed Vision Setters}

Connecting beliefs to action. To a large extent, Sierra, Liam and Elena are the central characters in the beliefs and actions storyline being recounted here because these three individuals were the three members of the initial Vision Setters group who appeared to have changed their beliefs after a year in the DILNS program. They started the year as Vision Setters and ended the year talking more like Collaborators.

Sierra and Liam both became principals; Elena became a literacy administrator, albeit a literacy administrator with considerable power to define how she played that role. 
Interestingly, all three of these Reformed Vision Setters appeared to implement strategies that were aligned with their newly developed belief system. This suggests that the changes documented in the first part of this chapter were not merely cosmetic.

For example, Sierra, who became a principal of a school with a large special needs population, began the year by immediately setting up formal and informal gatherings at the school—e.g., social get togethers, staff lunches, make and take workshops-in the hope of building a cohesive (i.e. a "collaborative") team. These strategies and the thinking behind them were certainly consistent with what Sierra had expressed in her second interview. During that interview she emphasized the importance of "working together as a team." She also made it clear that she wanted "to work with staff."

Because of budget cuts, Sierra lost her vice principal a couple of months into the school year. As a result, she indicated that she got "overwhelmed by the operational aspects of the job"; she also indicated, however, that she worked hard to "not let them [i.e. the operational aspects of the job] interfere" with her time in the classroom. According to Sierra, she spent a minimum of three hours a day in the classroom with teachers. On two separate visits to her school, in fact, I observed her debriefing with teachers about the time she spent in their classrooms observing instruction, modeling or teaming a lesson. Each meeting ended with her saying, "Let me know if there is anything you need or a resource I can get you."

Sierra also assigned her peer coach at the beginning of the year to be a "floater"; that is, she wanted her peer coach, who was also new to the site to spend time "floating" from class to class so that she could quickly build the sort of rapport with the staff that 
would enable her to work closely with teachers. The strategy appeared to be successful. On a visit I made to Sierra's school in the middle of the school year, the peer coach explained to me that she "couldn't believe how much the teachers wanted her support and wanted to work together." Sierra also explained that the work staff members were engaging in was determined by the teachers themselves and not by her or the peer coach. She stated, "The peer coach is working with grade levels also and, as they work as a team, as a grade level, then they have their own skills they have all agreed upon that they want to work on and she guides them through that."

Sierra also provided a variety of other options for staff to collaborate and work together in an effort to improve their skills. For instance, she modeled lessons, paid for teachers to go to conferences and "released" them from their classrooms so that they could observe other teachers, both inside and outside of the school.

Sierra also discussed how she worked with the "entire staff" to "help develop the vision." She held staff meetings where the only agenda item was a discussion about the vision and then followed up with all of the grade level leaders to "hash out the final vision." During a visit I made to her school toward the end of the school year, she continued to discuss the importance of collaborating with staff on the "vision we created" as well as the importance of staff using "self discovery" as a means to guide their professional development. Based on the observations conducted and the discussions and interviews with Sierra, it is reasonable to conclude that the revised belief system articulated at the end of her first year in the DILNS program was very much aligned with her actions during her first year as a school principal. 
Liam's story has a similar bottomline. Liam became principal of a small elementary school and, like Sierra, began the year by immediately trying to engage staff in decision making. During his first staff meeting, for example, in an attempt "to break the ice," he listed the "top twenty things" he expected of staff and the "top twenty things" they could expect of him. During a Year 2 interview, Liam summed up the key message he wanted to get across in the meeting the following way:

I asked the teachers to collaborate with each other, that they participate, that they also have a role in sharing their knowledge and asking for help and not just waiting to get support based on what somebody else is observing but to be reflective and be able to ask for the things that they feel that they need. Liam also told staff they could expect that he would be a "collaborator" and that he would be willing to "work in their classrooms with them because [the principal and teachers] are a team." Each day, in fact, he scheduled time to be in classrooms. On two occasions in which I visited his school, he modeled lessons in a teacher's classroom. Since there was no vice principal or peer coach, he also "relied on teachers" a lot. He identified one key "teacher leader" from each grade level to help plan professional development. He wrote a weekly newsletter to the staff to "keep them informed" and "to let them know [he] want[ed] to communicate with them." During one interview he expressed the hope that all of his work was leading to the development of a "learning community."

Liam indicated that it was hard to get the vision development process started. "Here I am as the new guy on campus," he stated during one interview, "and they have all been here a long time, some have been here a very long time. So, it wasn't easy 
getting them to talk about where the school needs to go." But he went on to say that he was able to use the awful notoriety the school got last year as a result of one teacher's impropriety as leverage "to get everyone to think about a new beginning." On several occasions he met with the whole staff so that everyone could "think aloud" about the vision for the school. On one of my visits to the school, he pointed to a large pile of papers on his desk and pointed out that the pile was an attempt by the grade level leaders and himself to consolidate everyone's ideas about the school's vision into a "couple of pages" that could be given back to the teachers for review. This goal, like most everything else Liam was observed saying and doing during Year 2, was consistent with the new-found beliefs Liam had articulated at the end of the first year in the program.

Elena, the third original Vision Setter to undergo a conversion to a more Collaborator-like belief system, was in a somewhat different position than either Sierra or Liam. During the second year in the program, she did not become a principal; rather she became a literacy administrator. This position has virtually no formal authority attached to it. Nevertheless, Elena was granted a fair amount of liberty by the principal to implement strategies she believed would be effective and have an impact on the staff, and, like the two other Reformed Vision Setters, the strategies she implemented were quite consistent with the beliefs she articulated at the end of her first year in the DILNS program.

During her second interview, conducted at the end of Elena's first year in the program, for example, she had emphasized that "relationships are important" and expressed the belief that "it doesn't matter how much I know unless I show how much I care." One of the first things she did when arriving on site was request that her office be 
"in the main building and not in the office." Her rationale: She wanted "to be close to the teachers so they can find me easily" and so "I don't forget what is important." She spent most days in the classroom working with teachers, modeling lessons and helping teachers develop "units of study." She was able to convince the principal to supply substitute teachers for each team of grade level teachers so that they could focus on planning together. During one of the visits I made to her site, she had carved out an entire day for the sixth grade team "to focus on integrating literacy and social studies." She brainstormed with teachers, acted as a scribe to capture their thoughts, role played how the lesson might actually play out in the classroom and, perhaps more importantly, got agreement from all the teachers for her to come into their classrooms and videotape their lesson so that they could use the tapes as a "learning tool" later. During a follow up visit I made to her site, the principal commented to me that Louise "does more to change things and move instruction around here than I do."

While her main focus was improving literacy learning in the school, she continually strove to make sure that the process was "collaborative" and not "forced." She explained her thinking this way: "Some teachers absolutely must improve. They must get better. But I can't force them to improve. It doesn't work that way. But I sure can help them to." She also made sure that she brought back to the principal the "concerns" teachers expressed. She was aware that her position provided her flexibility and autonomy and that she was able to "walk between the world of teachers and the world of administration." What is important here is that she did walk very much like the Collaborator she had become by the end of Year 1 of the program rather than the Vision Setter she was at the program's start. As she stated, "I am very lucky to have this 
position, and I want to make sure that I am successful. That means helping teachers help students and helping the principal as well."

\section{Unchanged Vision Setters}

Constrained by the role and unable to implement administrative strategies.

Emma, Joy and Louise, all of who became vice principals, were the three Vision Setters whose beliefs remained constant over the year and did not change. These individuals were not more successful in overcoming the constraints of the vice principal role than were their Collaborator counterparts. Each of these Vision Setters, in fact, also complained about feeling "constrained" or "out of the mix" because their responsibilities were so heavily focused on operational aspects of the job. Emma, for instance, complained: "I'm out of the classroom. So, I'm not in the classroom doing, you know, watching teachers teach, watching students learn, going in and working with students." She went on to describe her belief that she should be an instructional leader and work with teachers. As she stated:

I should be [an instructional leader] and I think that part of [the problem] is that

I'm not in the classroom. So, I go for long spurts of time where I'm not even in a classroom during literacy, or during math that I feel my observational skills are fuzzy and going backwards.

Feeling frustrated with her role, Emma worked with the principal to try to reshape her job responsibilities so that she could focus on instruction. As she stated, "We had a heart to heart" talk and "came to an agreement" that I was "actually needed to help teachers, especially the K-1 teachers, because that's my expertise." In the latter part of the year, but only for a very short period of time, she did, in fact, work specifically with 
eight teachers in kindergarten and first grade. She analyzed student work and "told" the teachers what they needed to focus on. She stated, that she "would meet [with teachers] mostly before school, but sometimes after the bell." So, the data on Emma are inclusive as to whether Emma's actions coincided with her beliefs. It does at least appear from her comments that she acted consistent with her prior beliefs, but again, because for most of the year she was relegated to dealing with operational functions there was little opportunity to observe her in action with teachers.

Joy and Louise were also bogged down by the operational responsibilities they had. As Joy stated:

I am the lead operational person and also part of the leadership team. So we have the principal, the vice principal, two staff developers and a math resource teacher, and we meet regularly to basically plan what we are going to do for the school. But the main thing that I actually am doing is discipline.

During a visit to her campus, she expressed that she "was just at the first baby step of what I am capable of doing." Even so, she became resigned to the fact that she would not be able to impact instruction directly "like I had been trained in [the DILNS]" but was determined to make sure that her role as the "disciplinarian" did have an impact on the school.

I knew it [operational aspects] would be part of it. Because the discipline I see it as counseling which I love to do with kids. I love to try to help them. It can be real frustrating. I might have ten kids coming in at once over a fight or something and everything gets pushed aside and I'm dealing with that and if we are suspending them, it takes the whole afternoon between the parent phone calls, 
counseling the kids, the whole deal, to do it appropriately. It's a big time consumer of time, but I strongly believe it, if I can take the time to do that, that over the long term, that's going to have a huge affect on that school. That's where my piece comes in.

It was difficult to gauge how Joy's actions compared to her beliefs given that she did not have much of a chance to put her imprint on the school.

Louise's experience as a vice principal was perhaps the most difficult of all the DILNS members. She seemed even more frustrated than the other two by the fact that she had to deal with all of the "discipline and crap" and was "not an instructional leader." She was unable to have much of an impact on the staff in part because the principal "basically told [Louise] what [her] job was." She also felt caught in the crossfire between the principal and the teachers. She stated, "There is such tension between the teachers and [the principal] and I feel caught in the middle" As a result, Louise discussed the fact that she was "considering going back to the classroom."

\section{Summary}

This chapter compared the espoused beliefs participants' articulated at the end of the first year of the program with their on-the-job actions once they assumed administrative positions during the second year of the program. After the first year of the program, eleven of the twelve DILNS participants who remained in the program moved into formal principal or vice-principal positions; the twelfth remaining cohort member became a literacy administrator at a middle school. Of the eleven members who assumed formal administrative roles, six became principals and five became vice principals. All but one of the six cohort members who became principals acted in ways that were 
consistent with their espoused beliefs after participating in the program for one year. This group included the three Reformed Vision Setters who had radically altered their beliefs, presumably as a result of participating in the program. The one person who behaved in an inconsistent manner was one of the original Collaborators who had been assigned to a highly troubled school where a purge of the teaching staff had begun prior to this individual assuming the principalship.

All five of the vice principals in the study discussed feeling constrained both by their role and the operational duties for which they were responsible for, and thus were inhibited to a large degree from implementing the leadership strategies they had hoped to put into pratice. Therefore, whether or not their theories in action aligned with their theories in use could not be assessed. 


\section{CHAPTER VI \\ FINDINGS, PART III: PROGRAMMATIC INFLUENCES}

The purpose of this chapter is to identify what DILNS participants said about the impact of the DILNS program. The primary focus is on programmatic features that appear to have influenced participants' beliefs. More general comments about programmatic impact also are reported.

As was noted in earlier chapters, participants were interviewed when they entered the DILNS program and, then again, at the end of the first year of training. In both interviews, they were asked to discuss their leadership philosophies and how they viewed the role of the school leader. Their responses to these requests were discussed in Chapter four.

In their second interview, they also were asked to discuss what components of the DILNS program, if any, they felt influenced or impacted their beliefs and ways of thinking. Three program features emerged from the analysis of data generated by this particular line of questioning: a) working as a full time intern and having an opportunity to experience an administrator role firsthand; b) engaging in discussions with other members of their cohort for a sustained period of time in which they felt their beliefs and skills were constantly being challenged; and c) engaging in coursework that was problem based and thus gave participants a chance to "try out" the real work of being a school leader in a relatively low-stakes environment.

To unpack these findings, this chapter proceeds in the following way: The first section focuses on identifying the program features participants identified as being influential on their thinking. In this section, participants will continue to be referred to and listed under their original categories (Collaborators, Vision Setters and the Keeper) in 
order to facilitate making comparisons to the data that were discussed in the prior chapters. It is important to note, however, that especially for the three Vision Setters, Liam, Sierra and Elena, the label, Vision Setter, is no longer appropriate. As was illustrated in the previous chapter, the beliefs of these three individuals had changed radically by the end of the first year in the program, and these changed beliefs-rather than the three individuals' original conception of the principal role-was what was on display when they were observed and interviewed during Year 2. Indeed, by the end of Year 1 and during Year 2, their espoused beliefs and their beliefs-in-use were more aligned with the beliefs of the members of the Collaborator group than with the original Vision Setters.

Program Features that Influenced the DILNS Members Program features that influenced the Collaborators

Table 6.1 highlights those program features that each of the Collaborators stated as being influential in their thinking. Of course, since no member of the original Collaborator group changed her or his essential beliefs about the principalship and the principal role, the identified program features either reinforced the beliefs the Collaborators had articulated at the outset of the program or influenced less overarching and, at times, more technical beliefs. Indeed, some of the "beliefs" that participants talked about when asked to discuss the impact of programmatic features might be better characterized as skills.

As Table 6.1 illustrates, five Collaborators indicated that they were influenced by the internship experience. In addition, the cohort experience and the problem based learning activities were each discussed by half of the participants who were originally 
classified as Collaborators. What participants actually said about each of these features is discussed below.

Table 6.1: Program Features that Influenced the Collaborators

\begin{tabular}{|l|c|c|c|}
\cline { 2 - 4 } \multicolumn{1}{c|}{} & Internship Experience & Cohort Experience & $\begin{array}{c}\text { Problem-based } \\
\text { Coursework and } \\
\text { Simulations }\end{array}$ \\
\hline Kate & $\mathrm{X}$ & $\mathrm{X}$ & \\
\hline Nidia & $\mathrm{X}$ & $\mathrm{X}$ & $\mathrm{X}$ \\
\hline Danna & & $\mathrm{X}$ & $\mathrm{X}$ \\
\hline Mia & $\mathrm{X}$ & & $\mathrm{X}$ \\
\hline Robert & $\mathrm{X}$ & & \\
\hline Olivia & $\mathrm{X}$ & & \\
\hline
\end{tabular}

The impact of the internship experience on the Collaborators. During their first year in the program, DILNS members had an opportunity to work as an intern under the guidance of a supervising principal who served as a mentor. As Table 6.2 indicates, all but one of the Collaborators viewed the internship as a powerful opportunity to work closely with an experienced principal and try out the role of the principal, including taking on leadership responsibilities in a safe and relatively risk free environment. Robert, for example, discussed the importance of having the internship serve as a "testing ground." He stated that the first year of the DILNS program was about "sort of think[ing] about it [being a principal]" and the internship provided the additional opportunity to actually "try it out." He also stated:

The year was good because ...I think for a lot of it, it was nice, the blending [of theory and practice]. I mean, one of the big things is being able to be on a school site and, after the rough first couple of weeks, that I really was allowed to take on a leadership role and I was able to do like the staff development which I felt real 
comfortable with but [my supervising principal] allowed me to change and try things. So that really helped that, you know, I presented it to her and sometimes it was really good. Well I got to try things out. So that's nice to have that testing ground.

Others such as Kate, Nidia and Olivia also discussed the importance of having actual responsibilities on site to try things out. Kate for example, expressed the importance of working in a safe environment and having a "case load where I did almost everything that the principal did." Kate also had the opportunity to take on responsibilities that she previously "had never had to do before" as a teacher while Nidia described the internship as "intense [and] eye-opening" because it gave her "the sense of the responsibilities that the principal has and what her or his job really entails."

While Olivia also mentioned the significance of "having opportunities to lead," she also discussed the internship as a chance to be "reflective." As a result of being "able to reflect freely last year as an intern" and having a responsive mentor, Olivia felt she was better prepared to be a principal than she would have been without the internship. As she stated:

I think going into a classroom now, I'm much keener at looking for "what does this teacher need and how as an administrator I can help her get there?" So that part, I think I'm seeing it better and I'm getting a better feel for what I need to talk to teachers about. 
Table 6.2: The Impact of the Internship Experience on the Five Collaborators Who Indicated this Programmatic Feature as Influential

\begin{tabular}{|c|c|}
\hline & Internship Experience \\
\hline Kate & $\begin{array}{l}\text { I actually had a case load [during my internship] where I did almost everything that [the } \\
\text { principal] did. So, supporting teachers, I went out and worked with the community, lead } \\
\text { some principal-parent coffees, did some staff development .... Doing the write-ups } \\
\text { which I had never had to do before of teachers, you know, what you see in the } \\
\text { instructional support. It was very time consuming. Working with the community, doing } \\
\text { the letter writing, doing the communication writing. So I took on, as the year went on, I } \\
\text { took on more and more and more of what she did. So as I came in in the beginning, I } \\
\text { did a lot of shadowing but later more and more of responsibilities of her work came on } \\
\text { to my shoulders even though it was her signature as a practice aspect of it... It was } \\
\text { amazing and I learned so much from it. }\end{array}$ \\
\hline Nidia & $\begin{array}{l}\text { Well, initially, I shadowed the principal. So when she did observations, I did } \\
\text { observations with her. When she did department meetings, I went to the department } \\
\text { meetings with her. I'd say that would be the first couple of months. Mid-year, she lost } \\
\text { her staff developer so I did the staff development with her. I think we tried to cover } \\
\text { everything but there's so much to cover .... [It was] intense, eye-opening. When you } \\
\text { see, you get the sense of the responsibilities that the principal has and what her or his } \\
\text { job really entails. }\end{array}$ \\
\hline Mia & $\begin{array}{l}\text { I wanted to be with somebody [during my internship] to see who they were and how } \\
\text { that influenced their leadership. Do you really have to be a different person? The } \\
\text { answer is absolutely not. But somehow I needed some permission over the last year to } \\
\text { become more comfortable with that idea to be comfortable with myself. It sounds really } \\
\text { odd saying it now but it's true and somehow along this year, I worked that out ... I } \\
\text { desperately needed somebody to spend time with to be able to ask really hard questions. } \\
\text { So it sounds weird but [my supervising principal] is very different from me. [I learned] } \\
\text { you don't have to be like another person to learn from them but I was able to watch her } \\
\text { all year and she has a family and I got to see her style and I got to wonder because I } \\
\text { used to get into her head, I got to wonder a lot about is the person that I talk and hear } \\
\text { think out loud really that person that I see doing this work over here with these teachers. } \\
\text { Risk free - solidify her beliefs - mentor to reflect with }\end{array}$ \\
\hline Robert & $\begin{array}{l}\text { The first year, last year, was one of these things that was sort of think about it [being a } \\
\text { principal], sort of, you know, organize it and then actually try it out. So I had that year } \\
\text { of chance to then say "okay, now if I am my own principal, would I do this?" Rather } \\
\text { than "well I think about this a year ago and now let's try it." So the year was good } \\
\text { because ....I think for a lot of it, it was nice, the blending. I mean, one of the big things } \\
\text { is being able to be on a school site and after the rough first couple of weeks that I really } \\
\text { was allowed to take on a leadership role and I was able to do like the staff development } \\
\text { which I felt real comfortable with but [my supervising principal] allowed me to change } \\
\text { and try things. So that really helped that, you know, I presented it to her and sometimes } \\
\text { it was really good. Well I got to try things out. So it's nice to have that testing ground. }\end{array}$ \\
\hline Olivia & $\begin{array}{l}\text { The program prepared me to be an instructional leader. I was able to reflect freely last } \\
\text { year as an intern .... But I think going into a classroom now, I'm much keener at } \\
\text { looking "what does this teacher need and how as an administrator I can help her get } \\
\text { there?" So that part, I think I'm seeing it better and I'm getting a better feel for what I } \\
\text { need to talk to teachers about ... [My supervisory principal on my internship] would } \\
\text { answer my questions. She was there for me. She gave me opportunities to lead. } \\
\text {...Yeah. I would not want to get this degree [administrative credential] and then just } \\
\text { walk in [as a new principal] without that [internship] experience component. }\end{array}$ \\
\hline
\end{tabular}


Mia's description of the internship experience was somewhat different from the descriptions of the other participants who cited the internship as being influential. Mia's description emphasized the importance of the relationship between her and her principal mentor. She said, "I wanted to be with somebody [during my internship] to see who they were and how that influenced their leadership. [I wanted to know] do you really have to be a different person [than yourself to be a principal]?" Because she was able to work closely with her mentor during the internship, she came to the realization that you "absolutely [did] not" have to change who you were to be a principal. Through the internship she also solidified her personal beliefs and built self confidence:

Somehow I needed some permission over the last year to become more comfortable with that idea [that I could be a principal and] to be comfortable with myself. It sounds really odd saying it now, but it's true, and somehow, along this year, I worked that out ... I desperately needed somebody to spend time with to be able to ask really hard questions. So it sounds weird but [my supervising principal] is very different from me. [I learned] you don't have to be like another person to learn from them, but I was able to watch her all year and she has a family and I got to see her style and I got to wonder because I used to get into her head, I got to wonder a lot about is the person that I talk and hear think out loud really that person that I see doing this work over here with these teachers.

Danna was the only Collaborator not to identify the internship as being an important influence. She was more neutral than negative about the experience. She 
simply indicated that the experience had not impacted her beliefs and had not had much of an impact in other areas either.

The impact of the cohort experience on the Collaborators. Kate, Nidia and Danna each mentioned the value of working with their cohort members who were going through similar experiences. In particular, each mentioned the importance of using the other cohort members for "support." Kate, for instance, mentioned that because the other members were also "in the same boat," it was "sort of like hav[ing] this support system that you know you can always go and talk to."

Table 6.3: The Impact of the Cohort Experience on the Three Collaborators Who Indicated this Programmatic Feature as Influential

\begin{tabular}{|l|l|}
\cline { 2 - 3 } & \multicolumn{1}{|c|}{ Cohort Experience } \\
\hline Nidia & $\begin{array}{l}\text { The networking and support were very strong. Oh actually being able to know you are } \\
\text { going to go through a block with a team of other interns that are going to be principals } \\
\text { too, because then you sort of like have this support system that you know you can } \\
\text { always go and talk to. You know, sort of like you are in the same boat so you know you } \\
\text { can talk to each other. }\end{array}$ \\
$\begin{array}{l}\text { I think we all felt a strong bond to each other the whole way through because of our } \\
\text { common goals and where we come from. But I felt like and I had several conversations } \\
\text { about it, that just coming out of the classroom, I put a lot of stress on myself to be at the } \\
\text { same learning point as other people that had been doing staff development and doing } \\
\text { administrative type, had administrative type responsibilities. Some people, I think, } \\
\text { actually started the program or administrative credential and had dropped out of it. So I } \\
\text { always felt like I was like trying to catch up. But I realized that, well it's not so } \\
\text { important to catch up because I'll probably never catch up to some but it was important } \\
\text { that I was able to do what I could do and look at that realistically for me and use them } \\
\text { for support. And they did support and help me. }\end{array}$ \\
\hline
\end{tabular}


Table 6.3 continued

\begin{tabular}{|l|l}
\hline Danna & Being able to work with other people that were in the same situation was helpful
\end{tabular} because you could work through your level of inexperience together. I think if I had to put an overall umbrella on my learnings it would be that I feel extremely supported in all areas. If I had a question about any piece of this work, any piece of leadership work, I have all kinds of different resources. Mostly people that I can go to if I'm struggling with something that I need to really work on or something, I know who I can go to and I feel like I would not be imposing on them to ask and that's really the biggest piece because if you know you're doing this and you're not standing out there all by yourself and people want you to be successful, they want you do well, that makes me feel better. That makes me want to take more risks so then they'll come up to you and say, "well here's something to try to deal with that" and to know that there's that support really makes all the difference....So, I think that we can continue to use each other for support because I think because we're going through similar situations, we can call each other with questions that we might not call somebody else on. We might be uncomfortable calling somebody with more experience but you can afford to say, "you know, I just really don't get this budget. thing," and they're going to probably be in a similar state so they're not as likely to make judgments about that. They're more likely to say, "well here's what I did. This is how I dealt with it." They might be dealing also with this actual similar situation at their school.

As Table 6.3 illustrates, Nidia and Danna also described the value of "support" the cohort provided. In addition, as the material on the Table indicates, they also described how the support helped them overcome or at least deal with the insecurity they each felt about their "inexperience." And Nidia, Danna and Kate all mentioned the value of continuing the professional relationship that developed between them and their cohort members. Danna, whose words could easily have been spoken by any of the others, summed up why maintaining relationships with the cohort members was important:

I think that we can continue to use each other for support because I think because we're going through similar situations, we can call each other with questions that we might not call somebody else on. We might be uncomfortable calling somebody with more experience but you can afford to say [to the other cohort members], "You know, I just really don't get this budget. 
The impact of problem-based learning on the Collaborators: Throughout their

year in the DILNS, each participant was engaged in problem-based learning (PBL) and other related forms of experiential learning, including simulations of realistic school experiences. These activities were designed to give participants an opportunity to grapple with real problems that occur daily in most schools.

Table 6.4: The Impact of the Problem-based Simulations on the Three Collaborators Who Indicated this Programmatic Feature as Influential

\begin{tabular}{|c|c|}
\hline & Problem-based Coursework and Simulations \\
\hline Danna & $\begin{array}{l}\text { The very first class that we took, that problem-based learning class Was very, very } \\
\text { helpful. Because they were actual problems that could be encountered at a school site } \\
\text { and then we as a group worked through that and it wasn't something that you had to } \\
\text { work through on your own which is what I have to do now. It was nice to have other } \\
\text { people in your group and the instructors to provide all the different resources. Then we } \\
\text { could pull from that and fix them up with some kind of solution to that problem and it } \\
\text { made me understand that it is doable, that when you come across a problem that you } \\
\text { think is amazingly difficult to handle that there are ways to handle it and being able to } \\
\text { do that at elementary, and middle and high school. }\end{array}$ \\
\hline Robert & $\begin{array}{l}\text { But it was interesting. The case studies at the beginning, the first case studies were very } \\
\text { interesting aimed together and gathering ideas for the small group and so I liked that, } \\
\text { that type of thing. What was always the idea was would I be able to implement this in } \\
\text { the school? So that was my particular group's thing is we didn't want to say "oh yes, } \\
\text { let's pretend we have lots of money. Let's pretend that we all of these different things." } \\
\text { So our group was looking at it realistically. "Could we actually take this and then } \\
\text { implement it in our own school?" So that was one of our criteria. So it was nice being } \\
\text { able to do that. Well it even helped last year because some of the stuff that I did, I then } \\
\text { was able to take out in my school that I interned with. So the principal there allowed me } \\
\text { to start that type of conversation or we tried it out. So that was nice. The fact that I did } \\
\text { it here, I did it in my class, and then we, you know, talked with [my supervisory } \\
\text { principal on my internship]. So I think that was the type of thing of leadership that made } \\
\text { me think about how I wanted to be a leader }\end{array}$ \\
\hline Olivia & $\begin{array}{l}\text { Yeah, that was stressful [the simulations] but it is so much like the day we're having. } \\
\text { That's so real. Now I think back and I think of how real that is because that's what } \\
\text { happens everyday. So even though that was scary and a lot of it's like, "wow," it's what } \\
\text { we do everyday. That's another thing. I think I learned to voice my opinion } \\
\text {...Explaining what elementary is like, how you would write a professional development } \\
\text { plan, working with people who don't have an understanding of writing professional } \\
\text { development then having them help me with the safety because we come from high- we } \\
\text { did a high school. Having people give me input of what high school is like I think was } \\
\text { really powerful because I think as a leader you have to know what's going on at all } \\
\text { levels. That part was really good. }\end{array}$ \\
\hline
\end{tabular}


Danna, Robert and Olivia each described the significance of exploring real world problems in the classroom prior to actually having to deal with them on a site. They also believed that the knowledge and skills they were learning would easily transfer to school contexts and help them be successful on the job. Danna described the value of the problem-based learning and the connection between them and how she would take up the role of the principal this way: "The very first class that we took, that problem-based learning class was very, very helpful because they were actual problems that could be encountered at a school site." She went to describe the confidence she developed from the experience:

It made me understand that it [the job of the principal] is doable, that when you come across a problem that you think is amazingly difficult to handle that there are ways to handle it and being able to do that at elementary, and middle and high school."

Olivia described the PBL experiences as "powerful" and through them "learned to voice [her] opinion, while Robert indicated that he was able to carry over what he learned in the PBLs to his work as an intern:

Well it [the simulations] even helped last year because some of the stuff that I did [in the PBL], I then was able to take [and actually see how it worked] in my school that I interned with. So the principal there allowed me to start that type of conversation [about what I was learning] or we tried it out. So that was nice. The fact that I did it here [in the internship], I did it in my class, and then we, you know, talked with [my supervisory principal on my internship]. So I think that 
was the type of thing of leadership that made me think about how I wanted to be a leader.

Program features that influenced the Vision Setters.

As Table 6.5 indicates, only two individuals who were originally classified as Vision Setters identified the internship experience as being influential, while only one original Vision Setter cited the cohort experience as being influential. Thus, for this group, the problem-based learning strategy was most frequently cited as being influential. Four members of the original Vision Setters group, in fact, identified problem-based learning as having had a significant impact on their thinking; three of these individuals were from the subgroup that had changed their basic beliefs about the principalship. Because this study was focused on shifts in beliefs and whether (and, if so, how) a principal training program can influence such a shift, this section begins by examining what the Reformed Vision Setter group, in particular, said about problem-based learning and its impact.

Table 6.5: Program Factors that Influenced the Vision Setters

\begin{tabular}{|l|c|c|c|}
\cline { 2 - 4 } \multicolumn{1}{c|}{} & Internship Experience & Cohort Experience & $\begin{array}{c}\text { Problem-based } \\
\text { Coursework and } \\
\text { Simulations }\end{array}$ \\
\hline Liam & $\mathrm{X}$ & & $\mathrm{X}$ \\
\hline Sierra & & & $\mathrm{X}$ \\
\hline Emma & $\mathrm{X}$ & & $\mathrm{X}$ \\
\hline Elena & & & $\mathrm{X}$ \\
\hline Joy & & $\mathrm{X}$ & \\
\hline Louise & & & \\
\hline
\end{tabular}

The impact of the problem-based learning coursework and simulations on the

Vision Setters. Liam, Sierra and Elena, the three Vision Setters who had a drastically 
different set of the beliefs at the end of their first year in the DILNS, were also three of the four Vision Setters who identified the problem-based coursework (PBL) as having been influential in their leadership beliefs. While it is not possible to make a causal link between the Vision Setters change in beliefs and the PBL, it seems reasonable to consider the possibility that the PBLs impacted the thinking of the Visions Setters. One Reformed Vision Setter, in fact, explicitly mentioned the PBL experiences while discussing her changed beliefs:

I think that, philosophically, it [the PBLs] helped me try to establish the importance of knowing, as a leader, what your beliefs are and how important that is to figure that out. Things like how to come up with a shared vision in a group. So I'm thinking of the classes where we did that. Probably where we had to do those case studies - not case studies but the problem-based learning where you had to discuss what you might do in that case.

Table 6.6: The Impact of the PBL Experience on the Four Vision Setters Who Indicated this Programmatic Feature as Influential

\begin{tabular}{|l|l|}
\cline { 2 - 3 } \multicolumn{1}{c|}{} & \multicolumn{1}{|c|}{ Problem-based Learning Coursework and Simulations } \\
\hline Sierra & $\begin{array}{l}\text { We got a lot better skills at observing in classrooms and being able to synthesize } \\
\text { our observations to come up with how we would meet and present with a teacher } \\
\text { so this role playing conversations that we would have with teachers based on } \\
\text { observations. Having a critical eye for student engagement, room environment, } \\
\text { teacher practice, being able to really quickly assess that, that was definitely a very } \\
\text { powerful experience for me. }\end{array}$ \\
$\begin{array}{l}\text { I think the most practical and the most applicable [part of the program] was the } \\
\text { [School Management] class. Working through the communication to parents } \\
\text { through a vision was powerful... But looking at the professional study for the } \\
\text { year. It was just the most applicable. It was the most actual real-life. The in- } \\
\text { basket for instance was incredibly applicable. }\end{array}$ \\
\hline $\begin{array}{l}\text { Elena think that, philosophically, it [the PBL case studies and case studies] helped me } \\
\text { try to establish the importance of knowing, as a leader, what your beliefs are and } \\
\text { how important that is to figure that out. Things like how to come up with a } \\
\text { shared vision in a group. So I'm thinking of the classes where we did that. } \\
\text { Probably where we had to do those case studies; not case studies but the problem- } \\
\text { based learning where you had to discuss what you might do in that case. }\end{array}$ \\
\hline
\end{tabular}


Table 6.6 Continued

\begin{tabular}{|l|l|}
\hline Joy & $\begin{array}{l}\text { The work groups of five that we worked with on the PBL's that was one of the } \\
\text { most critical pieces. You had the hypothetical schools. You would come up with } \\
\text { a plan on how to make that school work. And we had to do more than one, we } \\
\text { had to do another PBL too. So all of us sitting around with my group of five } \\
\text { people and hashing out how we would take a school from a vision to a real high } \\
\text { student achievement included ideas like this. The first step was you have to create } \\
\text { and establish probably the working relationship. Again, these are the procedures } \\
\text { we went through in the ELDA program. All of these things that in our discussion } \\
\text { and in our analysis of how you move people and how you move groups and work } \\
\text { with adults that these are all of the things that we concluded. Not just once, not } \\
\text { just twice, but in three PBL's. As we worked as interns at our sites, we saw this } \\
\text { play out. }\end{array}$ \\
\hline
\end{tabular}

Interestingly, as Elena elaborated these ideas, her emphasis was less on the substance of the PBL and more on the PBL process. The PBL process normally entails groups of approximately five cohort members working together to respond to a hypothetical issue or problem (e.g. the need to create a vision, write a mission statement, develop a school discipline and safety plan, create a staff development plan) that has arisen in a particular (but virtual) elementary, middle, or secondary school. Elena emphasized that, by working with her peers on an array of PBL tasks, she had come to understand the importance of listening to multiple stakeholders and gathering multiple viewpoints.

As noted, two other Reformed Vision Setters also indicated that the PBL experiences had been influential. It is more difficult to connect the dots between these experiences and their reformulated belief systems, however, since they tended to emphasize skill learning when they discussed the impact of the PBLs. Sierra, for instance, discussed the impact of the PBL activity that focused on developing a vision for a school. She described this particular PBL as being the "most applicable" and "the most actual real-life" experience of the program. She did not, however, link this experience to the 
change in her beliefs, as Elena had done. Similarly, Liam, the third original Vision Setter whose beliefs changed from what they were at the beginning of the program, described the PBLs as being "powerful," but he, too, did not specifically link the PBL work to belief change. Instead, he discussed how the "role playing conversations" helped him develop "better skills at observing in classrooms and being able to synthesize observations."

As Table 6.6 also illustrates, Joy, a fourth member of the Vision Setter group whose beliefs did not appear to change, also discussed the "critical" nature of the PBL. According to her, the group members learned "in our discussion and in our analysis of [the PBL] how you move people and how you move groups and work with adults." Since she remained an Unchanged Vision Setter to the end, it seems as if the the lesson she learned from the PBL experience about how to move people may have been radically different from the lessons learned by the three other members of the Vision Setter group who now espoused and enacted a more collaborative approach.

The impact of the internship experience on the Vision Setters. As Table 6.7 demonstrates, only two people, Liam and Emma, mentioned the internship as being significant. They, however, had quite different perceptions of the experience, and these different perceptions almost certainly mean that the experiences were influential for each in different ways. Liam, for example, emphasized the value of the internship, much as members of the original Collaborator group had done. He stated, "[The internship] definitely helped me to get a better understanding of the principal's role, so that was something that was a benefit for me." He also described the benefit of being able to lead some activities on campus "like coaching and observing in classrooms and leading some 
parent things and writing monthly parent newsletters." Even though he was given the ability to do things "independently," his supervising principal made sure that he focused on learning new skills and knowledge. He described this independence/support binary in the following way: "So there was a time where my supervisor suggested that though I have these skills we'll pull back a little bit because there was still a lot for me to learn directly from her."

Table 6.7: The Impact of the Internship Experience on the Two Vision Setters Who Indicated this Programmatic Feature as Influential

\begin{tabular}{|l|l|}
\hline Liam & $\begin{array}{l}\text { So that [the internship] definitely helped me to get a better understanding of the } \\
\text { principal's role so that was something that was a benefit for me. When I was } \\
\text { there in the beginning I shadowed but what happened was, at the very beginning, } \\
\text { you know, when we were calibrating our observations, she noticed that I had a } \\
\text { real strong critical eye and the ability to communicate and kind of a grasp of that } \\
\text { so real quickly, she was relinquishing and delegating and I was doing more things } \\
\text { independently. Like coaching and observing in classrooms and leading some } \\
\text { parent things and writing monthly parent newsletters. It happened really quickly } \\
\text { and it was something that happened in my student teaching that they recognized } \\
\text { skills and strengths and they said, "go for it." So there was a time where my } \\
\text { supervisor suggested that though I have these skills we'll pull back a little bit } \\
\text { because there was still a lot for me to learn directly from her. }\end{array}$ \\
\hline Emma think she [supervising principal] wanted me to get a real clear overview of the \\
school. Did I accomplish all those? I don't think so. I think some of the stuff \\
was very one-sided. I think she wanted me to be able to confer and instruct \\
teachers and yet she would set it up so that they thought I was practicing. \\
$\begin{array}{l}\text { As opposed to we're having a conference and actually being responsible for that } \\
\text { conference. Yeah, it was interesting. She would like me to hold a difficult } \\
\text { conversation from something I saw in an observation with a teacher and yet, most } \\
\text { of the time, when the teacher would come in, she would set it up saying, "well } \\
\text { Cheryl's going to practice this. It's part of her learning. She needs to be able to } \\
\text { have the conversations with you but this is practice." ...I found it a little bit } \\
\text { demoralizing that the conversation would be "Cheryl needs to practice this." But } \\
\text { I really didn't have an official role there as an intern. I really wasn't it. That was } \\
\text { my impression that I was just somebody who was there to learn and I would be } \\
\text { gone. }\end{array}$ \\
\hline
\end{tabular}

Emma, on the other hand, had a much different, and, in fact, a decidedly negative perception of her internship. She indicated that she did not have the opportunity to take 
on any leadership responsibilities "independently," as did Liam, and, moreover, she felt rather demeaned by the internship experience. While Emma stated that she believed her supervising principal wanted her "to get a real clear overview of the school," she also indicated that she was never able to get this overview because everything "was very onesided." She explained:

I think she [the supervising principal] wanted me to be able to confer and instruct teachers, and, yet, she would set it up so that they thought I was practicing as opposed to we're having a conference and actually being responsible for that conference. Yeah, it was interesting. She would like me to hold a difficult conversation from something I saw in an observation with a teacher and yet, most of the time, when the teacher would come in, she would set it up saying, "well Emma's going to practice this. It's part of her learning. She needs to be able to have the conversations with you but this is practice.

Emma went on to describe that she "found it a little bit demoralizing" to be treated in such a way.

What is interesting about how Emma described how she was treated during her internship experience is that she used rather similar language in describing how she envisioned the role of the principal. In her initial interview, for example, she indicated "that there are two different streams of thought going into the school-there are the teachers and then there is the administration" and the teachers get treated rather differently than the administrators. In her second interview, and after having the "demoralizing" internship, she continued to state the fact that she "likes to be in control" and noted that, as principal, she will "be the one who determines the path for the school." 
One would suspect that, given her internship experience, that she might have been more inclined to become more inclusive or collaborative. That obviously was not the case. Indeed, if anything, the "demoralizing" experience seems to have reinforced her desire to have power.

The impact of the cohort experience on the Vision Setters. Louise was the only Vision Setter to discuss the impact of the cohort on her experience in the DILNS, and, as with Emma and the internship, the impact here was described in negative terms. As the quote below illustrates, Louise, in fact, described the cohort experience as being very harmful because of competitiveness and a lack of camaraderie among cohort members: It was dog eat dog and a lot of us pumped ourselves up when we were with the other ELDA members and not let anybody know that a) we were having problems or b) that we weren't doing something right or c) there were issues because you wanted to look strong. When there are only twelve other people, you wanted to look strong and be the best of the best. So you rarely even talked about those things. You got stifled but you wondered if everybody else was playing the same game. You don't want to show any weaknesses in that kind of group because they're going to go after your jugular. Not everybody would and there was a lot of support with that group. But, like I said, you just don't want to show your weaknesses because a lot of people in that group would have exploited them. Louise's depiction was radically different from how the Collaborators discussed the experience. Yet, her description of the cohort experience coincides with how she discussed the role of the principal. She had a very rigid view of the principal and believed it was not necessary for the principal to engage or solicit the views of others. Rather it 
was only important for others to understand the principal's beliefs and the vision he or she sets. As she stated:

They [teachers] are what make what I [as a principal] see and believe work so I need them to buy into things. They may not always see the way it's going to be but at least they need to really understand my vision and then they can carry it out.

\section{Program Features that Influenced the Keeper}

Gabriel described having a rather negative experience in the program. As was stated in Chapter 3, he dropped out of the program after the first year. Some of his comments about the program provide insight into what might have also contributed to his decision to leave. He believed that having an internship along with other courses was a "huge amount to ask of people" and was causing him, as well as others, to get sick. He stated, "Because it was so intense ... [people's] personal lives were getting shortchanged and I know talking to many of them [other cohort members] it was difficult to balance spouses and kids and other things going on." As a result of the internship and the other work in the DILNS program being "so intense" he described that he was "able to almost disassociate [himself] at one point from everything." 


\section{CHAPTER VII \\ SUMMARY, DISCUSSION, IMPLICATIONS}

This chapter briefly reviews the purpose of the study, the methods that were used and the major findings. The focus then shifts to the implications this study has for the educational leadership field. The chapter concludes with a set of recommendations for practice and further research.

\section{Brief Review of the Problem and Methods of Study}

As was discussed in Chapter 1, principal preparation programs continue to be heavily criticized for their inability to prepare individuals who are not only qualified but prepared and able to be effective school leaders. This criticism, coupled with an increasing shortage of individuals willing to take on the principal's role in era of accountability in which "no child is to be left behind," places stress on the individuals and institutions responsible for training aspiring principals. Adding complexity to the mix is the fact that, as the literature suggests, we have, at best, a limited understanding of how to help aspiring principals develop and put into play new sets of skills and beliefs that will help them be successful in the role. There is also little research that focuses on how aspiring principals develop new sets of beliefs that are congruent with the role of the principal as an instructional leader, or on how principal preparation programs impact participants' beliefs.

Thus, the overarching purpose of this qualitative study was to deepen understanding and knowledge of the linkage between principal preparation and changes in beliefs. More specifically, the study focused on one principal preparation program which has been given the pseudonym, Developing Instructional Leaders for New Schools (DILNS). This study sought to understand how beliefs shifted during the course of the 
program and what participants said about program features that influenced these shifts. The study also examined the congruity—or, in some cases, the incongruity-between participants' espoused beliefs and their theories-in-use

The research for this study involved a series of interviews with all 13 members of the DILNS. Formal interviews were conducted with each individual as they began their training in the program, at the end of their first year of training and at the end of their second year in the program while they were in their new role as a school leader. These interviews sought to understand what were the participants' beliefs regarding leadership, whether any changes occurred in their beliefs, and, if beliefs had shifted, the nature of the shift. The study also asked students to identify program features that they considered influential in shaping their beliefs about how they played the principal role. In addition, participant observations as well as a careful analysis of participant and program documents were utilized to triangulate the interview data and to determine whether there was congruence between espoused beliefs and on-the-job actions.

The interviews were all coded using Atlas.ti, a qualitative research software program. Initial coding categories were adapted from the research questions that were articulated in the proposal and were grounded in the education leadership, principal preparation and educational reform literature. Conceptual memos were written to record the salient themes that emerged as well as to record hypotheses that were to be examined during the ongoing analysis process. A role ordered matrix was then used to organize the data in terms of the research questions and categorize the themes and identify the relationship between participants and what they espoused. By looking across matrices, it was also possible to examine relationships between participants' espoused beliefs over 
time and also to examine the relationship between each participant's espoused beliefs and his or her actions.

\section{Discussion of Findings}

This section briefly summarizes the research findings. The section is organized around the four research questions that were discussed in Chapter 1.

Research Question \#1

What are the aspiring principals' beliefs and conceptions regarding school leadership as they enter the Developing Instructional Leaders for New Schools program?

As was discussed in Chapter 4, three classifications of participants - the Collaborators, the Vision Setters and the Keeper-emerged from the data analysis based on participants' initial beliefs about the principal role. Interestingly, all of the participants with the exception of Gabriel, who was the one member in the Keeper group, viewed the principal as a change agent, though those classified as Collaborators and those who were characterized as Vision Setters at the start of the study perceived the change agent role differently. The Collaborators identified three leadership dimensions as key to being a successful leader. They were: collaborating with staff to develop a shared vision for the school; creating a professional learning community within the school; and supporting and working alongside staff to improve practice.

The Collaborators believed that change comes about at a school not by imposing mandates but by engaging with staff, developing relationships and building a culture of inclusiveness. In fact, the word collaboration was used rather pervasively by the Collaborators. In the following quote, Kate, one of the six cohort members who made up 
the Collaborator group, summed up how central collaboration was to each of the group member's philosophy of leadership:

It is important to share control of the school and decision making. If people buy into something, you go a lot further. That's what's so important at the school site, that it's a collaborative community effort because you get all the teachers to buy into a certain type of learning, a certain format or learning or certain discipline plan or vision and a school will move a lot faster. Just like in the classroom, you have the students develop classroom rules and you get all the kids to buy into the rules. The kids are feeling like they are developing and improving the class and are part of the class, then they are going to buy in.

An analysis of the Vision Setters' initial interview data also led to the identification of three leadership dimensions associated with being an effective principal. They were: setting the vision and direction for the school; strategically using communications to convince the school staff to embrace the school vision that had been developed by the principal; and setting the example by modeling best practices for staff.

The Vision Setters, in short, had a very different perspective about how the principal could bring about change from that of the Collaborators. They had a rather traditional and bureaucratic perspective of the principal role. That is, the principal's responsibility, according to the Vision Setters, was first and foremost to set the agenda for the school. Sierra, a Vision Setter, described it this way: "The leader clearly sets the tone for the school. He or she must look toward the horizon and create a vision of where the school is going." Just as frequently as the Collaborators used the term collaboration, 
the Vision Setters used the term buy-in. Elena, one of the members of the Vision Setters group, emphasized the importance of using communication to get buy-in:

An effective leader must communicate effectively and include all stakeholders students, parents, teachers and others - so that everyone will be reminded of what the school's vision and mission for achievement are. Teachers especially need to be reminded and the more they hear the message the more they might buy in. Not surprisingly, given their principal-centric view of change, the Vision Setters also believed the principal needed to be the resident expert on instructional issues. From the Vision Setters' perspective, the principal did not look to collaborate with staff or attempt to learn from them. Rather, the principal was the person who understood what teachers should do in the classroom and modeled effective practices for members of the teaching staff.

Finally, at the start of the study (and the start of the program), there was an outlier member in the DILNS program whose perspective on leadership was vastly different from the other participants and thus deserved his own group. This individual was characterized as the Keeper. There was a stark difference between his views and the beliefs expressed by all the other DILNS members (and also district officials, for that matter). As his designated name implies, the Keeper viewed the principal not as a change agent but as a keeper of the status quo. This was a rather unexpected finding given that the DILNS program was designed to develop leaders who were change agents. Consistent with his views on the principal's role in the change process were two other beliefs: the principal serves as a link between the district and its mandates and the school and the 
school staff's practices and the principal communicates and engages with staff only indirectly. The Keeper also held a rather elitist view of public education.

Research Question \#2

How did the aspiring principals' beliefs and conceptions regarding school leadership change, if at all, over the two year period of this study?

\section{The Collaborators}

Five of the six members of the Collaborators continued to articulate beliefs that emphasized the importance of collaborating with staff to develop the vision. Robert, one of the Collaborators, however, did appear to have a shift in his beliefs about the vision development process. To be sure, during his initial interview, Robert did seem to be of two minds about the role the principal should play in vision development. He did, however, indicate in his initial interview that he believed the principal needs to be "able to get people around the table to help create the vision and have them become invested and part of deciding the vision." During the second interview conducted at the end of the first year of the program, however, Robert said that the principal "need[s] to set the vision for the school." He no longer discussed or even alluded to involving the staff in the vision development process. On the two other dimensions of the Collaborator belief system, Robert's thinking during the second interview was consistent with he had articulated during the initial interview.

Indeed, all of the Collaborators continued to believe that it was important to develop a learning community at the school site and four of the six Collaborators used either the term learning community or the term community of learners, as three of the four had also done during their initial interviews. Even so, a rather subtle but important change did occur in four of the participants. In the first interview, only two of the 
participants discussed actively engaging in developing the learning community or setting the agenda for the work to be undertaken in the community, while four of the Collaborators prescribed a less activist role for the principal, one that involved "providing opportunities" or creating the "time and space" for teachers to meet. During the second round of interviews, however, four Collaborators-two more than beforedescribed need for the principals to be highly proactive in developing their schools' learning communities.

Lastly, while all six of the Collaborators continued to emphasize the importance of the principal supporting and working with teachers to improve their practice, there was also a subtle change that was worth noting. In their initial interview at the beginning of the year, three of the Collaborators specifically mentioned the need for the principal to "value" or "recognize" the knowledge and expertise of staff. However, during the second interview, only one individual overtly discussed the importance of helping teachers improve by "listening and hearing them and respecting and supporting them."

\section{The Vision Setters}

After a year of training, half of the six Vision Setters continued to express the belief that the principal needed to independently develop the vision for the school without engaging staff in the process. The other three individuals who originally were placed in the Vision Setter group, however, now articulated a set of beliefs that focused the principal on collaborating with staff to develop the vision. This shift in thinking is illustrated by the following excerpt from Liam's second interview:

They [teachers] can expect that I'm going to develop a shared vision with them, that it's not just going to be "this is what we're doing," but it's going to be kind of 
a discussion ... I really do believe that sharing some of that leadership and sharing the vision, that it does get people to have greater buy in and you can actually improve your work by doing that.

The same three Vision Setters who had changed their beliefs regarding the need to collaborate with staff while articulating a school's vision also changed their view of how staff should be supported and engaged. In the second round of interviews, for instance, each expressed a set of beliefs that highlighted the importance and the need for the principal to work "together as a team" with staff to improve instructional practice. Elena's comments illustrate the altered thinking of three of the original Vision Setters. It doesn't matter how much I know unless I show how much I care. I need to be a role model and walk the talk. I need to utilize the expertise of a diverse staff to look at situations through a variety of lenses and provide opportunities for the entire staff to get to know each other better and help the entire staff to see that they are both the recipient and imparter of valuable knowledge.

\section{The Keeper}

Gabriel, the Keeper, dropped out after the first year of the program. Even so, his second interview revealed that there may have been a subtle shift in his beliefs. What emerged from the second round of data collection was a belief that the principal needed to unilaterally set the vision for the school but also attempt to get "buy in" from staff. Previously, he did not talk about the need to develop a vision for the school; rather, the emphasis was on accepting the district's guiding vision and insuring it got implemented. The Keeper's beliefs on other matters remained consistent with the beliefs that he articulated in his initial interview. 
Research Question \#3

To what do the aspiring principals attribute changes in their beliefs to components of the DILNS program?

Three program features emerged from the analysis as having had an impact, in one way or another, on all of the DILNS participants. The three features were: a) working as a full time intern and having an opportunity to experience an administrator role firsthand; b) engaging in discussions with other members of their cohort for a sustained period of time in which they felt their beliefs and skills were constantly being challenged; and c) engaging in coursework that was problem based and thus gave participants a chance to "try out" the real work of being a school leader in a relatively low-stakes environment. Interestingly, the first two features, which have been consistently cited in the literature as features of exemplary principal preparation programs, were not always seen as having had a positive impact. In addition to kudos from some, these program features were also panned by others. Some participants, for example, complained that their carefully selected supervising principals were less than adequate role models and/or provided inadequate learning opportunities during internships. There were also complaints from some about a less-than-functional competitiveness among cohort members.

The most notable findings about program factors impacting beliefs, however, was the finding about the impact of the problem-based simulations (PBL). All three of the members of the original Vision Setters who exhibited a major change in their beliefs during the second interview described the PBLs as an influential feature of the program 
and one changed Vision Setter, Elena, specifically indicated that the PBL experience had made her rethink her leadership philosophy. Elena said:

I think that, philosophically, it [the PBL simulation strategy] helped me try to establish the importance of knowing, as a leader, what your beliefs are and how important that is to figure that out. Things like how to come up with a shared vision in a group. So I'm thinking of the classes where we did that. Probably where we had to do those case studies; not case studies but the problem-based learning where you had to discuss what you might do in that case.

Research Question \#4

To what extent do participants' espoused theories of school leadership coincide with their theories in use once they assume administrative roles?

As noted above, the Keeper, dropped out of the program and therefore was also not included in the final round of data collection and analysis. In addition, the five DILNS participants who became vice principals all discussed, during a third on-the-job interview, feeling "constrained" by the operational responsibilities associated with the vice principal role. Some also mentioned having to work within a philosophical scheme and organizational patterns which had been developed and promoted by their principals and which they personally did not always agree with. For one or both of the above reasons, these five individuals were not able to implement many administrative strategies they had talked about in earlier interviews, and, therefore, it was impossible to assess whether or not their espoused beliefs were consistent with their practice.

Of the remaining seven individuals, six were principals, four of whom were Collaborators and two of whom were Vision Setters, and one was a literacy administrator 
with far more room to maneuver than all of the vice principals reported having. Four of the principals were originally classified as Collaborators; two of the principals and the person in the literacy administrator position were originally classified as Vision Setters but were also the three individuals whose beliefs changed and were reclassified as the

\section{Reformed Vision Setters}

Five of the six principals (three who were Collaborators and two who were the Reformed Vision Setters) as well as the one Reformed Vision Setter who was a literacy administrator all implemented strategies that were aligned with their theories in use. The other principal, who was a Collaborator, did not implement strategies that appeared to be aligned with what she claimed to believe. Kate, the individual who exhibited a discrepancy, indicated in her second interview that she believed teachers "need to know that they could talk about what they are struggling with and feel safe about that." On the job, however, she asked the members of her leadership team to "document" what was going on in the classroom at all times so she could, in her words, "clean house." At a minimum, her actions suggested that she was not building a supportive environment where everyone could feel "safe" and "supported."

\section{Implications of the Findings for Practice}

As noted above, the purpose of this dissertation study was to address a topic that, for the most part, had not been discussed in the empirical literature: the impact preparation programs have on participants' role-related beliefs. This topic was addressed by investigating the impact that one innovative principal preparation program, the Developing Instructional Leaders for New Schools (DILNS) program, had on the belief systems of its aspiring principals. The study also explored (a) how participants' beliefs 
compared and contrasted to their actual practice and (b) which program components participants believed influenced their beliefs and ways of thinking.

In reviewing the results of this study summarized above, three findings seem especially significant for those involved with principal preparation. They are: a) the change that occurred in at least three of the participants' belief systems and the fact that their actions on the job were consistent with their beliefs; b) the impact that problembased learning had on participants' beliefs; and c) participants sometimes conflicting views about the impact of the cohort structure and the full-time internship, two program components that are frequently judged by the field to be best practices. The implications of each of these findings are discussed below.

\section{Impacting Beliefs is a Realistic Goal for Principal Preparation Programs}

As the review of the literature in Chapter 2 pointed out, changing beliefs is difficult. Senge (1990) and Sanders (2000) remind us that our mental models, the representations we have of the world, are deeply embedded in our psyche and often serve as a filter to prevent new information from seeping in. As a consequence, as Rokeach $(1968 ; 1973)$ and others point out, our belief systems are exceedingly resistant to the efforts of others to change them.

The findings in this study, however, suggest that changing beliefs is not a completely unrealistic goal for a principal preparation program to embrace. The DILNS program did, after all, have an impact on participants' beliefs. While the program did not change each member's beliefs, the program appears to have helped three out of thirteen participants' alter their beliefs in a significant way. 
The three individuals whose beliefs changed began the program with a very top down bureaucratic view of the principalship. After a year in the DILNS program, however, their beliefs were fundamentally changed and they now viewed the principal as needing to engage with staff to develop a shared vision for the school. Furthermore, when these individuals assumed leadership positions, they behaved in ways that were quite consistent with their newly developed ways of thinking.

One could argue that the evidence presented here about a preparation program's ability to influence beliefs is not all that compelling. Three out of thirteen, after all, translates to only $23 \%$ of cohort members being affected. Indeed, for every Vision Setter who changed his or her beliefs, there was also a Vision Setter who ended his or her first year in the program with his or her initial Vision Setter belief system intact. Many of these individuals also enacted a Vision Setter view of the principalship on the job. Furthermore, one person who sounded like a Collaborator throughout the program behaved more like a Vision Setter once she actually assumed an administrative role.

On the other hand, it must be remembered that six out of the thirteen participants came into the program espousing beliefs that were consistent with the conception of the principalship that was being emphasized in the program. Hence, belief change was not required. Furthermore, the one person whose beliefs seemed inconsistent with her practice undoubtedly received mixed messages during her internship experience in the program because she was placed in a site that emphasized--possibly for good reason-a top-down leadership strategy.

Possibly even more important is the fact that the literature has consistently documented that beliefs are difficult to change (see, for example, Block \& Hazelip, 1995; 
Sanders, 2000), and Argyris and Schön (1974) have demonstrated the frequent mismatch between people's espoused theories and their theories in use. Thus, the fact that there was a significant shift in beliefs with three individuals--and that this shift also got manifested in their practice-must be considered at least somewhat significant. At the very least, this study suggests that changing beliefs is possible and, consequently, a not totally unrealistic goal for a preparation program to embrace.

Experiment with the Problem Based Learning (PBL) Strategy

Of course, changing beliefs will never be easy, so it is worth considering what this study says about how a program might actually accomplish this difficult task. In this study, the three individuals whose beliefs radically changed over the course of the program all pointed to the problem-based learning $(\mathrm{PBL})$ experiences as having been a significant influence in their training. One of these participants, without being prompted to do so, specifically connected the dots between the PBL activities and changes in her beliefs. Thus, while this study does not and can not claim for certain that the PBL was the cause of the shift in participants' beliefs, there is certainly some evidence-albeit less than definitive evidence - to support the claim that it was a contributing factor.

This grounded hypothesis, of course, is consistent with other literature on the impact of the PBL process. For example, as was noted in the literature review presented in Chapter 2, studies by Coles (1985) and Newble and Clark (1986) suggest that students enrolled in courses that utilize PBL experience a range of benefits. They are more likely than students enrolled in similar courses using more traditional pedagogy to take a "deep" approach to learning. The literature also suggests that individuals who participate in PBL 
are more likely to have better attitudes about their learning and retain more material (de Vries, Schmidt \& de Graaff, 1989).

The research on teacher beliefs also provides additional support for the claim that PBL is more likely than most pedagogical strategies to impact participants' beliefs and ways of thinking. Dwyer, Ringstaff and Sandholz (1991), for example, found that teachers did, in fact, have changes in their beliefs when they were engaged in learning which placed them in the "thick of change, taking risks and facing uncertainty" (p.52). PBL is designed to accomplish this particular purpose, albeit in a virtual environment that, as participants noted, is less threatening than real world situations.

So, while it is not possible to use the data from this study to demonstrate a definitive connection between the changes in beliefs that occurred in the three participants whose beliefs changed and the PBL strategies they engaged in, there is certainly some evidence from this study to suggest a link between their changed thinking and PBL. Furthermore, this evidence is consistent with what other studies have demonstrated about the impact of PBL in particular and experiential learning in general. Hence, it seems justifiable to encourage other people delivering principal preparation programs to consider employing the PBL strategy, albeit experimentally. Reconsider Whether Cohorts and Internships are Unequivocal Indicators of Best Practice

DILNS' participants also indicated that the cohort experience as well the internship experience were influential to their development (although not necessarily in terms of shifting fundamental beliefs). The findings were, in many ways, predictable given that both internships and cohorts are widely endorsed in the best practices 
literature. What was somewhat surprising, however, was that these program components were not always seen as having had a positive impact on the DILNS participants.

The cohort experience, for instance, has been shown to be an advantage in developing the skills and knowledge of those learning a new role (Teitel, 1997; Basom, Yerkes, Norris \& Barnett, 1996; Yerkes, Norris, Basom \& Barnett, 1994). In this study, however, the evidence suggests that simply putting people into a cohort structure does not necessarily mean that a collaborative and supportive learning community will develop or that what develops will result in desired outcomes for the participants. In fact, the competitive nature that existed among cohort members was seen by several individuals as inhibiting their growth and development as principals.

The literature on cohorts suggests one possible source of the problem. Basom, Yerkes, Norris \& Barnett (1996), in their study of cohorts, for instance, have alerted us to the salient role that a group facilitator plays in promoting the interdependence of the members of the cohort. Interdependence, according to Basom et al. (1996) can help create a positive learning environment that encourages members to work together and, thus, provide opportunities for individual and group development, as well as assisting members to achieve their potential and reach their goals.

In the case of the DILNS, there was no mention by any of the participants of a facilitator or instructor who worked with the group and helped them build a sense of interdependence. Instead, some of the participants (and at least one in particular) complained about the negative environment created by the overly competitive nature of the cohort. Barnett and Muse (1993) have pointed out that participants in cohorts who work together closely throughout a program often "question the idea of being 
competitively graded with one another" (p. 409). In fact, it was clear to the DILNS participants that their performance in their classes would, in part, determine if and where they would be placed as principals. This may have contributed to the climate of competitiveness felt by some of them. While competition is somewhat inevitable between cohort members, programs need to recognize the potential harm competition can cause and appropriately deal with problems as they arise. This study suggests that the cohort context can become a highly charged competitive environment in which little sharing and support occurs. Consequently, programs need to pay close attention to how the group initially forms and to ensure that appropriate facilitation of the cohort group occurs throughout the program so that an environment conducive to learning can occur.

This study also raises a similar cautionary note about the use of internships. Several of the DILNS members, for example, discussed the fact that their internship experience did not provide them with the opportunity to engage in leadership activities. In fact, several felt that their internship experience amounted to little more than shadowing the principal and performing operational tasks. This is especially important to note as the current trend in the principal training field is to provide more opportunities for field based work and internships. While the specific structure of internships may vary from program to program (i.e. year long interships, semester interships), they all include one similar variable: the mentoring principal. The quality of the indvidual who serves as the mentor can make the diffference between a successful internship exprience and a lackluster one. The evidence from this study suggests that principal preparation programs need to place a strong focus on ensuring that appropriate individuals are selected and trained as mentors to support individuals in their internship experiences. And, if a 
programmatic goal is changing beliefs, there should be alignment between a mentor principal's beliefs and ways of operating and the beliefs being promoted by the program. Programs also need to monitor interns and their mentors to ensure that the aspiring principals are provided on-going opportunities to engage in realistic activities beyond simply shadowing the principals, in order to be involved in the kind of experiences that will ready them for the principalship.

\section{Implications for Further Research}

This section focuses on research that needs to be done. Four recommendations are presented. They are based, at times, on findings from the study but also on important questions that were beyond the scope of this particular study. The first issue fits under the latter category: Further research is needed to connect the dots between participants' beliefs and student achievement. In other words, research is needed to help understand whether or not a collaborative approach to leadership, which is touted in the professional literature (Bennett, Wise, Woods, \& Harvey, 2003; Elmore, 2000; Spillane, Halverson \&, Diamond, 2001), was emphasized in the DILNS training, and was the predominant approach DILNS members endorsed and enacted, does indeed lead to greater student achievement. Or is it the case that situational factors should be looked at to determine the best approach to improving the academic performance of students?

To state this first question another way, a way that contextualizes the question in the context of this particular study: Was the DILNS member who espoused beliefs consistent with those of the Collaborators yet acted in ways that were more consistent with being a Vision Setter, in fact, acting rationally based on what she found in her particular context or would she have had a more positive impact on student achievement 
if she had remained true to the collaborator goals she espoused? Further research that links leadership style with student achievement could at least suggest whether the discontinuity between words and deeds observed in this study was, in fact, appropriate.

Second, research is needed to look at how factors other than the training that occurs in principal preparation programs support or inhibit individuals' abilities to learn and perform on the job. In this study, for instance, the participants who became vice principals were constrained by their role and the way that role was defined in the district. They were unable to implement instructional strategies and were relegated to performing mostly operational factors. This suggests that there are at least two major pieces to ensuring that individuals are able to be successful on the job as a school leader. The first, and the one this study examined, is determining the most effective way to train aspiring principals to ensure that they develop the beliefs, knowledge and skills necessary to be effective. The other, which is of equal importance, is determining at the district and school level how to remove the barriers that prevent principals and vice principals from being successful. In other words, research is needed to unpack what conditions prevent school leaders from succeeding. The vice principals in this study encountered a culture that they were either unprepared for, not trained to deal with or so constricting that they could not find a strategy to counter it. The success of principal preparation programs have to be understood in the larger context of the district and its policies and practices and the culture for learning that either exists or does not exist in the district.

Of course, if conditions cannot be changed, the thrust, and possibly the timing of preparation programs may have to be altered. It makes little sense to prepare people to be instructional leaders if they are to be placed in the sort of vice principal roles found in 
this particular district. It would make more sense to prepare them to be vice principals and to do instructional leadership training later in their professional lives.

Third, one of the major findings from this study was that problem-based learning was identified as significantly influencing each of the three individuals whose beliefs changed and, was specifically associated with the change in beliefs in one of the individuals. Given that many principal training programs utilize a variety of "innovative" strategies - i.e. experiential learning, internships, case studies, medical model rotations of schools and problem-based learning-further research is warranted to identify which program features work best to train individuals.

While this study suggested that problem-based learning had the greatest impact on participants' ways of thinking, further research is needed to understand what aspects of PBL have the greatest impact on individuals and whether or not PBL should be a predominant component of the training that aspiring principals undertake. Another question that warrants further research is whether PBL was successful in this case in particular because individuals were able, through other components of their training, to then put what they have learned into action and try them out. Clearly, there is not enough evidence from this study to answer these questions or indicate that PBL should be the predominant strategy employed by principal training programs. Nevertheless, future study is needed to document and unpack the impact of PBL, in particular, and to study the effectiveness of other "innovative" program features and any possible interaction effects when multiple innovative strategies are employed.

Finally, as was mentioned in the implications for practice section, several DILNS participants discussed having a visceral reaction to one program component or another. 
Given this finding, it appears justified to consider studying whether certain "types" of people learn better under certain circumstance or situations. Future research should look at student attributes, learning styles, personality types and also the type of situational factors discussed in the previous section as factors in determining what type of training program students should enter and, more generally, whether a diversity of program types should be offered. This type of research may be able to help the field determine the best course of training for individuals, rather than the hodgepodge ones size fits all strategy the field so often employs.

\section{Summary}

Principal preparation programs have long been criticized because of the disconnect that exists between what tends to be taught in these programs and what practitioners need to know and be able to do when they become principals. Yet, despite years of criticism, most principal preparation programs continue to be judged less than successful in producing effective school leaders. In fact, the recently released report by Levine (2005) highlights the "failures" that continue to be perpetuated by these programs. Adding to the heightened cynicism of the field is the fact that there is also little rigorous and systemic research about principal preparation in general, and there is even less work focused on understanding how preparation programs impact the belief systems of aspiring principals.

This study, in a modest way, helps fill the gap that exists in the literature about how programs impact individual's beliefs and what program components had the greatest impact on participants. The study examined how one innovative program resulting from a university/school district collaboration impacted the belief systems of the aspiring 
principals who participated in the program. The study also examined how participants' espoused beliefs aligned with their on-the-job activity and which program components appeared to have the greatest impact on participants whose beliefs were altered in significant ways.

The findings from this study suggest that principal preparation programs can, indeed, impact the belief systems of some students and students' new beliefs do, indeed, get translated into action when they take on administrative roles. The study also suggests that problem-based learning may be an effective tool for impacting beliefs.

In the end, of course, this study raises more questions than it answers. Consequently, the study's primary contribution may be as a model for additional work that needs to be done to understand the impact of principal preparation programs on aspiring school leaders. 


\section{REFERENCES}

Albanese, M. \& Mitchell, S. (1993). Problem based learning: A review of literature on its outcomes and implementation issues. Academic Medicine, 68, 52-80.

Andrews, R. \& Soder, R. (1987). Principal instructional leadership and school achievement. Educational Leadership, 44, 9-11.

Anstrom. T. (1999). The effectiveness of a cohort model for principal preparation programs and leadership practices. Unpublished doctoral dissertation, George Mason University.

Argyris, C. (1976). Increasing leadership effectiveness. Malabar, FL: Robert E. Kreiger Publishing Company, Inc.

Argyris, C. (1980). Inner contradictions of rigorous research. New York: Academic Press.

Argyris, C. (1982). Reasoning, learning and action: Individual and organizational. San Francisco: Jossey Bass.

Argyris, C. (1985). Strategy, change and defensive routines. Boston: Putman.

Argyris, C. (2000). Flawed advice and the management trap: How managers can know when they're getting good advice and when they're not. New York: Oxford University Press.

Argyris, C., Putnam, R., \& Mclain Smith, D. (1985). Action science: Concepts, methods, and skills for research and intervention. Jossey Bass.

Argyris, C. \& Schön, D. (1974). Theory in practice: Increasing professional effectiveness. San Francisco: Jossey-Bass.

Argyris, C. \& Schön, D. (1978). Organizational learning: A theory of action perspective. Reading, Mass: Addison Wesley.

Argyris, C. \& Schön, D. (1996). Organizational learning II: Theory, method and practice. Reading, Mass: Addison Wesley.

Barnett, B. (1995). Developing reflection and expertise: Can mentors make the difference? Journal of Educational Administration, 33(5), 45-59.

Barnett, B., Basom, M., Yerkes, D., \& Norris, C. (2000). Cohorts in educational leadership programs: Benefits, difficulties and potential for developing leaders. Educational Administration Quarterly, 36(2), 255-282. 
Barnett, B. \& Muse, I. (1993). Cohort groups in educational administration: Promises and challenges. Journal of School Leadership, 3, 400-415.

Basom, M., Yerkes, D., Norris, C., \& Barnett, B. (1995). Exploring cohorts: Effects on principal preparation and leadership practice. St, Louis, MO: Danforth Foundation.

Basom, M., Yerkes, D., Norris, C., \& Barnett, B. (1996). Using cohorts as a means for developing transformational leaders, Journal of School Leadership. 6, 99-112.

Bennett, N., Wise, C., Woods, P. \& and Harvey, J. (2003). Distributed leadership. National College for School Leadership.

Bierema, L. (2003). Systems thinking: A new lens for old problems. The Journal of Continuing Education in the Health Professions, 23, 27-33.

Block, J. \& Hazelip, K. (1995). Teachers' beliefs and belief systems. In L.W. Anderson (Ed.), International encyclopedia of teaching and teacher education (2nd Ed.). New York: Pergamon Press.

Bredeson, P. (1993). Letting go of outlived professional identities: A study of role transition and role strain for principals in restructured schools. Educational Administration Quarterly, 29(1), 34-68.

Bridges, E.M., \& Hallinger, P. (1992). Problem-based learning for administrators. [Electronic Version].ERIC: Clearinghouse on Educational Management, University of Oregon.

Bridges, E.M., \& Hallinger, P. (1995). Implementing problem-based learning in leadership development. [Electronic Version]. ERIC: Clearinghouse on Educational Management, University of Oregon.

Bridges, E.M., \& Hallinger, P. (1997). Using PBL to prepare educational leaders. Peabody Journal of Education, 72(2), 131-146.

Brody, H, (1992). Philosophic approaches. In B. Crabtree \& W. Miller, (Eds.), Doing qualitative research (pp. 174-185). Newbury Park, CA: Sage.

Brookfield, S. D. (1986). Understanding and facilitating adult learning. A comprehensive analysis of principles and effective practices. Milton Keynes: Open University Press.

Brookover, W.B. \& Lezotte, L.W. (1977). Changes in school characteristics coincident with changes in student achievement. East Lansing, Michigan State University, College of Urban Development. 
Browne-Ferrigno, T \& Shoho, A. (2002). An exploratory analysis of leadership preparation selection criteria. Paper presented at the UCEA Conference in Pittsburgh, Pennsylvania, November 1, 2002.

Browne-Ferrigno, T \& Shoho, A. (2003). Do admissions processes in administrator preparation programs assure students with potential to become effective principals? Paper presented at the AERA Conference in Chicago, Illinois, April, 2003.

Buffie, E. G. (1989). The principal and leadership: Elementary principal series no. 1. Phi Delta Kappa Educational Foundation.

Cambron-McCabe, N.H. (1999). Confronting fundamental transformation of leadership preparation. In J. Murphy \& P.B. Forsyth (Eds.) Educational administration: $A$ decade of reform (pp. 217-227). Thousand Oaks, CA: Corwin Press, Inc.

Camburn, E., Rowan, B., \& Taylor, J. (2003). Distributed leadership in schools: The case of elementary schools adopting comprehensive school reforms. Educational Evaluation and Policy Analysis, 25(4), 347-373.

Coleman, D., \& Achilles, C. (1987). An agenda for program improvement in educational administration preparation. Planning and Changing, 18, 120-127.

Coleman, J., Campbell, E., Mood, A., Weinfeld, E., Hobson, D., York., R., \& McPartland, J. (1966). Equality of Educational Opportunity. Washington, DC: Government Printing Office.

Coles, R.M. (1985). Differences between conventional and problem-based curricula in their students' approaches to studying. Medical Education, 19(4), 308-309.

Cordeiro, P. \& Sloan, E.S. (1996). Administrative interns as legitimate participants in the community of practice. Journal of School Leadership, 6, 4-29.

Craik, K. (1943). The nature of explanation. Cambridge: Cambridge University Press.

Creasap, S. (2003). The effects if mentoring and sustained reflection on educational leadership practice. Unpublished doctoral dissertation, Ohio State University.

Creighton, T. \& Jones, G. (2001). Selection or self-selection? How rigorous are our selection criteria for education administration preparation programs? Paper presented at the National Council of Professors of Educational Administration in Houston, Texas, August, 2001.

Creighton, T.B. \& Shipman, N.J. (2002). Putting the H.O.T.S. into school leadership preparation. Educational Leadership Review, 3(3), 26-31. 
Crow, G. \& Glascock, C. (1995). Socialization to a new conception of the principalship. Journal of Educational Administration, 33(1), 22-43.

Crow, G. \& Matthews, J. (1998). Finding one's way: How mentoring can lead to dynamic leadership. Thousand Oaks, California: Corwin Press, Inc.

Cunningham, W., \& Cordeiro, P. (2000). Educational administration: A problem based approach. Needham Heights, MA: Allyn \& Bacon

Daloz, L.A. (1999). Mentor: Guiding the journey of adult learners. San Francisco: Jossey Bass.

Dana, N. \& Pitts, J. (1993). The use of metaphor and reflective coaching in the explosion of principal thinking. A case study of principal change. Educational Administration Quarterly, 29, 323-338.

Daresh, J. (1988). Are field based programs the answer to reform of administrator preparation programs.[Electronic Version]. ERIC: Clearinghouse on Educational Management, University of Oregon.

Daresh, J. \& Playko, M. (1990, September). Mentor programs: Focus on the beginning principal. NASSP Bulletin, 74, 73-77.

Darling- Hammond, L., \& McLaughlin, M. (1995). Policies that support professional development in an era of reform. Phi Delta Kappan, 597-604.

Davis, S. Darling-Hammond, L. LaPointe, M. \& Meyerson, D. (2005). Principal preparation and development programs: A review of literature on effective leadership education. Stanford Educational Leadership Institute.

Denzin, N. (1978). The research act: A theoretical introduction to sociological methods. $2 \mathrm{~d}$ ed. Thousand Oaks, CA: Sage.

de Vries, M., Schmidt, H., \& deGraaff, E. (1989). Dutch comparisons: Cognitive and motivational effects of problem-based learning on medical students. In $\mathrm{H}$. Schmidt (Ed.), New Directions for Medical Education, pp.231-238.

Dew, J.R. (1995). Creating team leaders: The challenge of leading ina democratic manner. Journal of Quality and Productivity. Retrieved on line at http://bama.ua.edu/ st497/pdf/creatingteamleaders.pdf.

Donmoyer, R. (1990). Generalizabilty and the single-case study. In E. Eisner \& A. Peshkin (Eds.). Qualitative inquiry in education: The continuing debate, (pp. 175200). New York: Teachers College Press. 
Dwyer, D., Ringstaff, S., \& Sandholtz, J. (1991). Changes in teachers' beliefs and practice in technology rich classrooms. Educational Leadership, 48, 45-52.

Dwyer, D., Ringstaff, S., \& Sandholtz, J. (1992). Teacher beliefs and practices part II: Support for change. The evolution of teachers' instructional beliefs and practices in high-access-to-technology classrooms first-fourth year findings. ACOT report \#9. California: Apple Computer Inc.

Edmonds, R. (1979). Effective Schools for the urban poor. Educational Leadership, $37(1), 16-21$.

Edmondson, A. \& Moingeon, B. (1999). Learning, trust and organizational change. In M. Easterby-Smith, L. Araujo and J. Burgoyne (Eds.) Organizational learning and the learning organization, London: Sage.

Elmore, R. F. (2000). Building a new structure for school leadership. Washington, DC: The Albert Shanker Institute.

Farkas, S., Johnson, J., Duffett, A., Foleno, T., \& Foley, P. (2001). Trying to stay ahead of the game: Superintendents and principals talk about school leadership. Washington, D.C.: Public Agenda.

Fauske, J., \& Johnson Jr., B. (2003). Principals respond to the school environment with fluidity, alignment, vigilance, and fear. In W.Hoy \& C. Miskel (Eds.) Studies in leading and organizing schools. Information Age Publishing.

Finklestein, S. \& Hambrick. D. (1996). Strategic Leadership: Top executives and their effects on organizations. St. Paul, MN: West Publishing Co.

Fullan, M. (1992). Successful school improvement. Buckingham: Open University Press.

Fullan, M. (1993). Change forces: Probing the depths of educational reform. Bristol, PA: Falmer.

Fullan, M. (2001). Leading in a culture of change. New York: Teacher's College Press.

Gastil, J. (1997) A definition and illustration of democratic leadership. In K. Grint (Ed.) Leadership, Oxford: Oxford University Press.

Griffith, J. (1999). The school/leadership climate relation: Identification of school configurations associated with change in principals. Educational Administration Quarterly, 35(2), 267-291.

Grogan, M., \& Roberson, S. (2002). Developing a new generation of leaders by capitalizing on partnerships. International Journal of Educational Management, $16,314-318$. 
Gronn, P. (2000). Distributed properties: A new architecture for leadership. Educational Management and Administration, 28(3), 317-338.

Gronn, P. (2002). Distributed leadership. In K. Leithwood \& P. Hallinger (Eds.), Second international handbook on educational leadership and administration. Dodrecht, The Netherlands: Kluwer Publishers.

Guba, E \& Lincoln, Y. (1989). Fourth generation evaluation. Beverly Hills, CA: Sage

Hale, E \& Moorman H. (2003). Preparing school principals: A national perspective on policy and program innovations. Institute for Educational Leadership Washington, D.C.

Hall, G. \& Hord, S. (2001). Implementing change: Patterns, principles, and potholes. Boston, MA: Allyn and Bacon.

Hallinger, P. (1984). Principal instructional management rating scale. New York: Leading Development Associates.

Hallinger, P \& Heck, R. (1996). Reassessing the principal's role in school effectiveness: A review of empirical research. Educational Administration Quarterly, 32, 5-44.

Hallinger, P \& Heck, R. (1998). Exploring the principals' contribution to school effectiveness: 1980-1985. School Effectiveness and School Improvement, 9(2), 157-191.

Hallinger, P., Leithwood, K., \& Murphy, J. (Eds.). (1993). Cognitive perspectives on educational leadership. New York: Teachers College Press.

Hallinger, P. \& Murphy, J. (1985). Assessing the instructional management behavior of principals. The Elementary School Journal, 86 (2), 217-242.

Hallinger, P. \& McCary, C. (March 1992). Developing the strategic thinking of instructional leaders. Occasional paper no 13. National Center for Educational Leadership.

Hart, A.W. \& Pounder, D.G. (1999). Reinventing preparation programs: A decade of activity. In J. Murphy \& P. Forsyth (Eds.), Educational leadership programs: $A$ decade of reform. Columbus, MO:UCEA.

Hegarty, P. \& Simco, N. (1995). Partnership and progress: Teacher-mentoring in United Kingdom teacher education (primary), Action in Teacher Education, 17(2), pp. 69-75. 
Hess, F. \& Kelly, A. (2005). The accidental principal. Education Next. The Hoover Institute.

Hitt, M. \& Tyler. B. (1991). Strategic decision models: Integration different perspectives. Strategic Management Journal, 12 327-51.

Hubbard, L \& Newman, R. (2002). Principal leadership programs and principal interns: reconciling theories of leadership. Paper presented at the UCEA Conference in Pittsburgh, Pennsylvania, November, 2002.

Institute for Educational Leadership. (2000). Leadership for student learning: Reinventing the principalship. Washington DC.

Jackson, B. \& Kelley, C. (2002, April). Exceptional innovative programs in educational leadership. Educational Administration Quarterly, 38(2), 192-212.

Jean, E. \& Evans, R. (1995). Internship/mentorships for first year principals: Implications for administrative certification and graduate program design. [Electronic Version]. ERIC: Clearinghouse on Educational Management, University of Oregon.

Jones, G \& Creighton, T. (2002). Lessons form the performing arts: Can auditioning improve the selection process in university administration preparation programs in the $21^{\text {st }}$ century? [Electronic Version]. ERIC: Clearinghouse on Educational Management, University of Oregon.

Kagan, D.M. (1992a). Implications of research on teacher beliefs. Educational Psychologist, 27, 65-90.

Kim. D.H. (1993). The link between individual and organizational learning. Sloan Management Review, 35, 37-51.

King, C. (2001). Leading forward, learning backward: An exploratory study of the effects of prior learning experience on urban school leader strategic action. Unpublished doctoral dissertation, University of Michigan State University.

Knowles, M.S. (1980). The modern practice of adult education: From pedagogy to andragogy. ( $2^{\text {nd }}$ edition). New York: Cambridge Books.

Krauss, C. (1996). Administrator preparation programs: Impact on job preparedness and learning. Unpublished doctoral dissertation, University of Connecticut.

Kruegger, J.A. \& Milstein, M. M. (1995). Promoting excellence in educational administration: What really matters? Planning and Changing, 26, 148-167. 
Laplant, J. 1988. An examination of approaches to field based learning in other professions. Paper presented at American Education Research Association.

Lashway, L. 2002. Developing instructional leaders. [Electronic Version]. ERIC: Clearinghouse on Educational Management, University of Oregon.

Leithwood, K. \& Jantzi, D. (1990). Transformational leadership: How principals can help reform cultures, School Effectiveness and School Improvement, 1(4),249-280.

Leithwoood, K., Seashore-Lewis, K., Anderson, S. \& Wahlstrom, K. (2004). Review of research: How leadership influences student learning. University of Minnesota.

Leithwood, K. \& Stager, M. (1989). Expertise in prinicpals' problem solving. Educational Administrator Quarterly, 25(2), 126-161.

Levine, A. (2005). Educating school leaders. The Education Schools Project. Washington, DC.

Lieux, E.M. (1996). A comparative study of learning in lecture versus problem-based format. About Teaching, 50, 25-27.

Lincoln, Y, and Guba, S. (1985). Naturalistic inquiry. Thousand Oaks, CA: Sage Publications.

Lucas, S. (2001). The effect of transformational principal and teacher leadership on school culture. Unpublished doctoral dissertation, University of MissouriColumbia.

Lunenberg, F \& Ornstein, A. (1996). Educational administration: Concepts and practices. $2^{\text {nd }}$ ed. Belmont, CA: Wadsworth Publishing Co.

Major, C., \& Palmer, B. (2001). Assessing the effectiveness of problem-based learning in higher education: Lessons from the literature. Academic Exchange Quarterly, 5 (1).

Martin, W. \& Willower, D. (1981). The managerial behavior of high school principals. Educational Administration Quarterly, 17, 69-90.

McCarthy, M. (1999). The evolution of educational leadership preparation programs. In J. Murphy \& K. Louis (Eds.), Handbook of research on educational administration ( $2^{\text {nd }}$ ed.). (pp119-140). New York: Longman

McKerrow, K. (1998). Administrative interhsips: Quality or quantity? Journal of School Leadership, 8(2), 171-186. 
Merriam, S. \& Caffarella, R. (1991). Learning in adulthood. San Francisco: Jossey Bass.

Miles, M., \& Huberman, M. (1994). Qualitative data analysis. Thousand Oaks, CA: Sage Publications.

Milstein, M. (1992, October). The Danforth Program for the preparation of school principals (DPPSP) six years later: What have we learned. Paper presented at the Danforth Principals Preparation Network and University Council for Educational administration. (ERIC Document Reproduction Service No. ED 355 659).

Milstein, M. (1993). Changing the way we prepare educational leaders: The Danforth experience. Newbury Park, CA: Corwin Press.

Milstein, M., Bobroff, B., \& Restine. L. (1991). Internship programs in educational administration: A guide to preparing educational leaders. New York: Teachers college Press, Columbia University.

Milstein, M. \& Krueger, J. (1997). Improving educational administration preparation programs: What we learned over the past decade. Peabody Journal of Education, 72(2) $100-116$.

Murphy, J. (1980). Getting the facts: A fieldwork guide for evaluators and policy analysts, Glenview, IL: Scott Foresman.

Murphy, J. (1988). The unheroic side of leadership: Notes from the swamp. Phi Delta Kappan, 69, 654-659.

Murphy, J. (1992). The landscape of leadership preparation: Reframing the education of school administrators. Ohio State University: Corwin Press.

Murphy, J. (1999). Changes in preparation programs: Perceptions of department chairs. In J. Murphy \& P.B. Forsyth (Eds.) Educational administration: A decade of reform (pp.170-191). Thousand Oaks, CA: Corwin Press.

Murphy, J. (2001). Reculturing the profession of educational leadership: New blueprints. Paper Commissioned for the first meeting of the National Commission for the advancement of Educational Leadership Preparation.

Murphy, J. \& Hallinger, P. (1992). The principalship in an era of transformation. Journal of Educational Administration, 30 (3), 77-88.

National Association of School Boards of Education (NASBE). (1999). Principals of change: What principals need to lead schools of excellence. Report of the NASBE Study Group on School Leadership. 
National Staff Development Council (2000). Learning to lead, leading to learn. National Staff Defense Council.

Nespor, J. (1987). The role of beliefs in the practice of teaching. Journal of Curriculum Studies, 19, 317-328.

Newble, D.L. \& Clarke, R.M. (1986). The approaches to learning of students in a traditional and in an innovative problem based medical school. Medical Education, 20, pp267-273.

Newman, R., \& Hubbard, L. (2003). The role of principal leadership training in urban school reform. Paper presented at the Hawaii International Conference on Social Sciences. Honolulu, Hawaii, June 14, 2003.

Norris, C. (1992). Developing a vision of the humane school. In Barnett, B. Mcquarrie, F. \& Norris, C. (Eds.) The moral imperatives of leadership: A focus on human decency. Fairfax, VA: National Policy Board for educational Administration, 106128.

Pajares, M.F. (1992). Teacher Beliefs and educational research: Cleaning up a messy construct. Review of Educational Research, 62, 307-332.

Pajares, F. (1993). Preservice teachers' beliefs: A focus for teacher education. Action in Teacher Education, 15, 45-54.

Patton, M. (2002). Qualitative evaluation and research methods. $3^{\text {rd }}$ ed. Thousand Oaks, CA: Sage.

Peel, H., Peel, B., \& Baker, M. (2002). School/university partnerships: A viable model. International Journal of Educational Management, 16(7) 319-325.

Peterson, K. (2001). The professional development of principals: Innovations and opportunities. Paper Commissioned for the first meeting of the National Commission for the advancement of Educational Leadership Preparation.

Playko, M. (1995). Mentoring for educational leaders: A practitioner's perspective. Journal of Educational Administration, 33(5), 84-92.

Playko. M. and Daresh, J. (1992). Field based preparation programs: Reform of administrator training or leadership development? Paper presented at the Annual meeting of UCEA. [Electronic Version]. ERIC: Clearinghouse on Educational Management, University of Oregon. 
Pounder, D., Reitzug, U., \& Young, M. (2002). Preparing school leaders for school improvement, social justice, and community. In J. Murphy (Ed.), The educational leadership challenge: Redefining for the $21^{\text {st }}$ century). One Hundred-First Yearbook of the National Society for the Study of Education. (pp. 261-288). Chicago: University of Chicago Press.

Restin, N. (1997). Learning and development in the context of leadership preparation. Peabody Journal of Education, 72(2), 117-130.

Richardson, V. (1996). The role of attitudes and beliefs in learning to teach. In J. Sikula (Ed.). Handbook of research on teacher education. (pp 102-199). New York: Simon \& Schuster.

Rokeach, M. (1968). Beliefs, attitudes and values. San Francisco: Jossey-Bass.

Rokeach, M. (1973). The nature of human values. New York: Free Press.

Rowan, B. (1990). Commitment and control: Alternative strategies for the organizational design of schools. In C. Cazden (Ed.), Review of research in education. Washington, DC: American Educational Research Association.

Ruff, W. (2002). Constructing the role of instructional leader: The mental models of urban elementary school principals. University of Texas at San Antonio, August, 2002.

Rutter, M., Maughan, B., Mortimore, P., Ouston J. \& Smith, A. (1979). Fifteen thousand hours. Cambridge, MA: Harvard University.

Sanders, L. (2000). Watching the gap: Teacher learning in history social science. Unpublished doctoral dissertation, Harvard University.

Schmidt, H.G., Dauphnee, W.D., \& Patel, V.L. (1987). Comparing the effects of problem based and conventional curricula in an international sample. Journal of Medical Education, 62(4), 305-315.

Scribner, J., \& Donaldson, J. (2001). The dynamics of group learning in a cohort. From non-learning to transformative learning. Educational Administration Quarterly, $37,605-636$.

Senge, P. (1990). The fifth discipline: The art of practice and the learning organization. New York: Doubleday.

Senge, P. (1999). Learning to alter mental models. Society for organizational learning. Retrieved on line, from www.solonline.org $/ \mathrm{res} / \mathrm{kr} / \mathrm{mentalmodel} / \mathrm{html}$. 
Senge, P., Cambron-McCabe, N., Lucas, T., Smith, B., Dutton, J., \& Kleiner, A. (2000). Schools that learn: A fifth discipline fieldbook for educators, parents, and everyone who cares about education. New York: Doubleday Dell.

Sergiovanni, T. J. (1984). Developing a relevant theory of administration. In T. J. Sergiovanni, \& J. E. Corbally (Eds.), Leadership and organizational culture: New perspectives on administrative theory and practice, (pp. 275-291). Urbana, IL: University of Illinois Press.

Sergiovanni, T.J. (1996). Leadership for the schoolhouse. San Francisco: Jossey-Bass.

Smith, R. (2003). Problem based versus lecture based medical education: A meta analysis of cognitive and non cognitive outcomes. Unpublished dissertation, University of Florida.

Smith, S.C., and P.K. Piele. (1997). School leadership: Handbook for excellence.. [Electronic Version].ERIC: Clearinghouse on Educational Management, University of Oregon.

Smith, W. \& Andrews, R. (1989). Instructional leadership: How principals make a difference. Alexandria, VA: Association for Supervision and Curriculum Development.

Smylie, M. A., Conley, S., \& Marks, H. M. (2002). Exploring new approaches to teacher leadership for school improvement. In J. Murphy (Ed.), The educational leadership challenge: Redefining leadership for the $21^{\text {st }}$ century (One hundred and first yearbook of the National Society for the Study of Education, Part I, pp. 162-188). Chicago: University of Chicago Press.

Soder, R. \& Andrews, R. (1985). Equity and excellence: The moral imperatives of compulsory schooling. Curriculum in Context, 6-9.

Somers-Hill, M. (1995). Educational leadership cohort models: Changing the talk to change the walk. Planning and Changing, 26, 179-189.

Southern Regional Education Board (SREB). (2005). The quality offield experiences in educational leadership programs.

Spillane, J., \& Sherer, J. (2004). A distributed perspective on school leadership: Leadership practice as stretched over people and place. Presented at AERA, San Diego, April 2004

Spillane, J., Halverson, R., \& Diamond, J. (1999). Toward a theory of leadership practice: A distributed approach. Institute for Policy Research working paper 
Spillane, J., Halverson, R., \& Diamond, J. (2001). Investigating school leadership practice: A distributed perspective. Educational Researcher. 30

(3), 23-28.

Spillane, J. P., Diamond, J. B., \& Jita, L. (2000, April). Leading classroom instruction. A preliminary explanation of the distribution of leading practice. Paper presented at the annual meeting of the American Educational Research Association, New Orleans.

Spradley, J.P. (1979). The ethnographic interview. New York: Holt, Rinehart, Winston.

Stein, S. \& Gewirtzman, L. (2003). Principal training on the ground: Ensuring highly qualified leadership. Heinemann.

Stein, M., Hubbard, L. \& Mehan, H. (2002). Reform ideas that travel far afield: The two cultures of reform in district \#2 and San Diego. AERA National Conference, New Orleans.

Stronge, J. (1988). A position in transition? Principal, 67(5), 32-33.

Suk Yee Hung, S. (2001). The nature of administrative internships on principal preparation. Unpublished dissertation, Teachers College, Columbia University.

Teitel, L. (1997). Understanding and harnessing the power of the cohort model in preparing educational leaders. Peabody Journal of Education, 72(2), 66-85.

Tirozzi, G. (Feb 2001). The artistry of leadership: The evolving role of the secondary school principal. Phi Delta Kappan, 82(6) 434-439.

Tucker, M. (2003). Out with the Old. Retrieved online from http://www.educationnext.org/20034/20.html.

Vernon, D. \& Blake, R. (1993). Does problem based learning work? A meta analysis of evaluative research. Academic Medicine, 68, 550-563.

Weber, G. (1971). Inner City Children can be taught to read: Four successful schools. Washington, DC: Council for Basic Education.

Weick, K.E. (1983). Managerial thought in the course of action: The executive mind. Srivastava (Ed.). San Francisco: Jossey Bass..

Wendel, F.C. (ed.) (1992). Reform in administrator preparation: Myths, realities and proposals. Tempe, AZ: The University Council for Educational Administration.

Yerkes, D., Norris, C., Basom, M., \& Barnett, B. (1994). Exploring cohorts: Effects on principal preparation and leadership practice. Connections, 2(3), 1, 5-8. 
Young, M., Peterson, G., \& Short, P. (2001). The complexity of substantive reform: $A$ call for interdependence among key stakeholders. Paper Commissioned for the first meeting of the National Commission for the advancement of Educational Leadership Preparation. 
APPENDIX A

DILNS Cohort 3 Protocol I:

Initial interview 
DILNS Cohort 3 Protocol I:

Initial interview

\section{Background}

- Years teaching

- Where did you get your teaching and administrative credential?

- Grade level taught

- Career path (e.g. teacher, staff developer etc.)

- Gender, ethnicity, age

- Before coming to the DILNS program were you teaching in this district or another? Which district?

- How did you learn about the DILNS program?

- What drew you to this principal leadership program?

- Did anyone recommend you to the program?

- Did you consider any other principal leadership programs?

- Why did you decide to participate in this program?

- Why do you think you were chosen for this program?

\section{Philosophy of education and leadership}

- Could you describe your philosophy of education?

- What or who was most instrumental in helping you construct your philosophy of education? (e.g., people, books, classes etc).

- Has your philosophy of education changed over time? Why or why not? How has it changed?

- Could you describe your philosophy of leadership? (e.g., key attributes of a good leader; how do you see yourself as a leader; what leadership qualities do you posses?)

- What do you need help with to become a more effective leader?

- What leadership roles have you experienced?

- Could you name the readings on leadership or other factors that have influenced your leadership philosophy the most?

- Has your philosophy of leadership changed over time? Why or why not? How has it changed?

\section{Peer Interaction in their Cohort}

- I understand that you are in a cohort of 14 others. Could you describe your expectations for working with the cohort?

- Do you have a sense of how you are similar or different from others in your cohort?

- Does this create smaller, informal relationships with certain folks?

- How would you describe the others in terms of philosophy of education/leadership? What does the variation look like? 


\section{Other supports}

- Are there other supports that you expect to receive as you participate in this program? What are they?

- Regarding Current support - what forms of support are provided now that you are an in a full time internship? Are they sufficient? What else could support you as an intern?

\section{Challenges}

- What are the major challenges you foresee with being in this program? (Academic content, time, money, people, conflict in vision/philosophy, etc.?)

\section{Local School District Reform}

- I understand that this collaboration between DILNS and the university is quite unique. What is your understanding about why they formed this collaboration?

- How has the District reform constructed the training that you have received? In what ways?

- How much instruction have you received in the content of the Blueprint? Reading strategies? Content of the Reform? Is it sufficient? Do you need to know more as a principal?

\section{Outcomes}

- What do you still need to learn and how will you learn it?

- Do you expect you will be prepared for a permanent position as an administrator at the end of your DILNS training? Why?

Are there other considerations, recommendations, areas that you would like to comment on to add to my understanding of program or yourself? 


\section{APPENDIX B}

DILNS Cohort 3 Protocol II:

Second Interview 


\section{DILNS Cohort 3 Protocol II: \\ Second Interview}

\section{Administrative background}

- Was the work you undertook in this program related to your current work as a principal?

- Would you identify the skills and knowledge that you wish you had that your coursework did - did not - provide you?

- Frequently educators distinguish between the operational side of an administrator's job and the instructional side of the job. Could you explain what is meant by this? What are operational duties/instructional duties? What was the distribution in course content for each of these categories? Was each given the appropriate weight? Why or why not? (again, get specific examples).

\section{Philosophy of education and leadership}

- Could you describe your philosophy of education? (The intern will probably privilege certain things e.g. social justice, discipline, preparation for higher education, school to career, closing the achievement gap, etc.).

- Has your philosophy of education changed over the course of the program? Why or why not? How has it changed?

- Could you describe your philosophy of leadership? (e.g., key attributes of a good leader; how do you see yourself as a leader; what leadership qualities do you posses?)

- Has your philosophy of leadership changed over the course of the program? Why or why not? How has it changed?

- What do you need help with to become a more effective leader?

\section{Experience in the DILNS program}

\section{Coursework}

- I am interested in learning the ways in which your coursework is related to the work you do as an administrator. Could you describe the applicability of the courses taken through the DILNS to your current work responsibilities and roles? (Here we want very specific examples of the course, who taught it and why or how was the course useful/applicable or not?)

- I understand that the DILNS program focuses on Problem Based Learning (PBL). Could you describe what PBL is? What was your experience with PBL? How was it helpful or not? Were cases relevant or not? How could it have better prepared you as an intern for the role of principal?

- Were there courses that seemed irrelevant to your work? (provide specifics as to which ones and why not relevant)

- Would you identify skills and knowledge that you wish you had that your coursework did not provide you? 
- I understand that there is a collaborative mix between district personnel and USD faculty: Did this combination of faculty enhance understanding of content and practice of leadership? How, in what ways? Why was it a good thing? Or was it?

- Frequently educators distinguish between the operational side of an administrator's job and the instructional side of the job. Could you explain what is meant by this? What are operational duties/instructional duties? What was the distribution in course content for each of these categories? Was each given the appropriate weight? Why or why not? (again, get specific examples)

\section{Mentorship and training with "Emily Aims"}

- Could you describe the professional relationship that you had as an intern with "Emily Aims"? What were her job/roles/ responsibilities for interacting with you? What were your responsibilities?

- How often did you meet?

- How did she evaluate your work/ what criteria were used?

- Has this relationship been helpful? In what ways? Why or why not? Ways to improve?

- Do you share the same philosophy of education/leadership? How is it similar or different?

- How did disagreements get resolved?

- Are you satisfied with the level of responsibility you were given at your site?

- Are you satisfied with the level of support you were given at your site? (probe for details)

Relationship with a Mentor principal (Another support given to interns)

What components of the relationship with your mentor principal have enhanced/detracted from your learning experience?

- What style of leadership did your mentor principal demonstrate and how did that inform your notions of leadership?

- How would you describe your principal's philosophy of education? How did that inform your own notions of education?

- Were there points of disagreement re. leadership style and practice? (specifics)

- How did disagreements get resolved?

\section{Peer Interaction in their Cohort (A possible opportunity for support?)}

- I understand that you are in a cohort of 13 others. Could you describe the cohort experience? Do you study together? Is it a supportive/collegial relationship? You are all vying for positions in the district so does interaction include a competitive component?

- How are you similar or different from others in your cohort?

- Does this create smaller, informal relationships with certain folks?

- How would you describe the others in terms of philosophy of education/leadership? What does the variation look like?

- How do competing ideologies play out in the program? (e.g., interesting debate, conflict, dropout etc.) 


\section{Other supports}

- Are there other supports that you receive as you participate in this program? What are they and how do they help?

- Regarding Current support - what forms of support are provided now that interns are in full-time leadership positions and are they sufficient? What else could support you as an intern?

\section{Challenges}

- What are the major challenges with being in this program? (Academic content, time, money, people, conflict in vision/philosophy, etc.?)

\section{Local School District Reform}

- I understand that this collaboration between the district and USD is quite unique. What is your understanding about why they formed this collaboration?

- How has the school district reform constructed the training that you have received? In what ways?

- Is the training you receive from DILNS consistent with district reform philosophy and practice? If different, how does it differ?

- How much instruction have you received in the content of the Blueprint? Reading strategies? Content of the Reform? Is it sufficient? Do you need to know more as a principal?

\section{Outcomes}

- Could you describe your placement experience at your school?

- How is the experience? Major problems, areas where you need help, areas where you feel most competent? (Again getting at job preparedness)

- Was the placement appropriate?

- Did experience prepare you for the realities of the position? Provide specific examples

- What are your expectations for how this experience as an administrator in the Induction \& Support Program will build on knowledge of leadership, effectiveness, and practice?

- What are your current needs in your administrative position, and how will the DILNS program meet those needs?

- What do you still need to learn and how will you learn it?

- Do you expect you will be prepared for a permanent position as a principal at the end of your DILNS training?

Are there other considerations, recommendations, areas that you would like to comment on to add to our understanding of program and its success or limitations in adequately preparing participants for educational leadership positions? 


\section{Administrative strategies}

- What are the strengths of your faculty?

- How do you go about assessing faculty strengths and weaknesses?

- What action do you take to strengthen weaknesses and maintain those strengths?

- Is it clear throughout the school that there are instructional expectations? How do you communicate those expectations?

- What happens when expectations are not met?

- What do you do as principal that impacts instruction in the classroom most?

- Do you have a leadership team? How are they chosen? What function do they serve?

- How would you describe the parent involvement at your school?

- What do you your teachers need from you?

- What do your teachers need from you?

- What do you do to meet the demands for student achievement?

- What metaphor best describes what you do?

\section{Challenges}

- What are the major challenges with being a principal?

- What are your current needs in your administrative position, and how do you anticipate meeting these needs?

- What do you still need to learn and how will you learn it?

- Are there supports available to you in the district to help with these challenges? If so, what are they?

- If not, how do manage the challenges?

- Are there supports that you wish you had that are not currently being provided? If so, what?

\section{Local School District Reform}

- How has the District school reform constructed the training that you have received? In what ways?

- How much instruction have you received in the content of the Blueprint? Reading strategies? Content of the Reform? Is it sufficient? Do you need to know more as a principal? 
APPENDIX B

Consent Form 


\section{Consent Form}

[The Developing Instructional Leaders for New Schools (DILNS) program], a district collaborative project with a consortium of local universities and other agencies in [southern California], provides the support and professional development for [southern California school district's] emerging leaders. As representatives of the University of San Diego and the [DILNS], we (researchers) are responsible for gathering data to help us examine [DILNS] practice and measures its success in preparing individuals to be effective principals with the necessary leadership skills to drive instructional improvement at the site level.

(DLNS program participants/administrators and instructors involved in this program/intern and principal supervisors/participants in other administrative credential programs) have been selected to participate in interviews. The information shared will be important to the ongoing development of the [DILNS] and to the study of this program. Participants will be asked to respond to a series of questions. (The interview will be tape recorded and later transcribed for further analysis/the class will be videotaped and later and transcribed for further analysis.)

Participation in this study should not involve any added risks or discomforts. There are potential benefits of participating in this research. As a participant $\mathrm{I}$, the undersigned, may benefit in the following ways: I may be provided an opportunity to reflect on my experience in the preparation program for school administration/leadership, and to consider my challenges and accomplishments; I may contribute to a body of knowledge on educational leadership preparation, which may inform my own work within school systems; and I will play an important role in the ongoing development of Developing Instructional Leaders for New Schools, thereby influencing the leadership training of future principals both within the [school district]] and also in other future participant districts.

I understand that my research records will be kept completely confidential. All cassette tapes, transcriptions and interview notes will be kept in a locked cabinet. They will be disposed of once the work with the [DILNS] is complete. My identity will not be disclosed without consent required by law. I further understand that data will be written in such a way that individual differences and interview statements will not disclose my identity. I understand that my participation in this study is completely voluntary and that I may withdraw at any time without jeopardizing my job or status within city schools.

I acknowledge that there is no other agreement, written or verbal, beyond what is expressed in this consent form.

I, the undersigned, understand the above explanations and on that basis, I give consent to my voluntary participation in this research.

Signature of Subject

Date

Location

Signature of Principal Researcher

Date

Signature of Witness 